Olavo da Rosa Belloc

\title{
Um Arcabouço para o Desenvolvimento de Simuladores de Procedimentos em Realidade Virtual
}

Dissertação apresentada à Escola Politécnica da Universidade de São Paulo para obtenção do Título de Mestre em Engenharia Elétrica. 
Olavo da Rosa Belloc

\section{Um Arcabouço para o Desenvolvimento de Simuladores de Procedimentos em Realidade Virtual}

Dissertação apresentada à Escola Politécnica da Universidade de São Paulo para obtenção do Título de Mestre em Engenharia Elétrica.

Área de concentração:

Sistemas Eletrônicos

Orientador:

Prof. Dr. Marcelo Knörich Zuffo 
Dedico este trabalho aos meus pais João Afonso e Waldilea Belloc, e à minha esposa Edilaine. 


\section{Agradecimentos}

Ao Prof. Dr. Marcelo Knörich Zuffo, meu orientador, e coordenador dos Meios Eletrônicos Interativos do Laboratório de Sistemas Integráveis da USP, pelo apoio, incentivo e disponibilização de recursos e tempo para a conclusão desta pesquisa.

À minha família e à minha esposa Edilaine, pelo apoio, companheirismo e compreensão ao longo de todo este trabalho.

Aos colegas de pós-graduação, Rodrigo Ferraz, Fernando Teubl, Fabio Rodrigues, Marcia Kondo e Marcio Cabral, pelos conselhos e pelo incentivo.

À toda a equipe de desenvolvimento do Núcleo de Realidade Virtual do LSI-USP, em especial, Mario Nagamura, Alex Cutovoi, Marcos Nobre, Douglas Fonseca e Luiz Paulucci, pela ajuda no desenvolvimento e pela dedicação exemplar.

À Deus, por me ensinar a persistir e ser paciente. 


\section{Resumo}

Os simuladores de treinamento têm se tornado cada vez mais populares, apresentando aplicações em diversas áreas, como na condução de veículos terrestres, aeronaves, procedimentos médicos, operações militares, entre outras. Estes simuladores podem ser classificados em diferentes grupos, de acordo com a finalidade do seu treinamento.

Os simuladores que envolvem o treinamento de procedimentos têm a finalidade de capacitar o usuário na execução de atividades bem definidas, dando ênfase às ações que o usuário precisa efetuar e às relações de dependência existentes entre estas ações.

As aplicações deste grupo de simuladores são o objeto deste trabalho e podem ser usadas em diversas situações, como na montagem, desmontagem, operação e manutenção de máquinas complexas, na execução de atividades que ofereçam risco ao usuário ou, possam causar dano ao equipamento utilizado.

As vantagens associadas com o treinamento em Realidade Virtual têm aumentado a procura por este tipo de aplicação. Apesar disto, no cenário nacional, poucos trabalhos acadêmicos foram publicados nesta área de pesquisa.

Com a finalidade de auxiliar o desenvolvimento de simuladores de procedimentos, este trabalho apresenta a proposta de um arcabouço de treinamento, que foi elaborado com base nos elementos obtidos na revisão da literatura e na investigação de outras arquiteturas e ferramentas.

A revisão da literatura considerou diversas técnicas usadas na descrição dos cenários de treinamento, entre elas, podemos citar a Máquina de estados, Sistema baseado em regras, STORM, Grafos, Diagrama LORA e rede de Petri.

O arcabouço proposto é composto por uma arquitetura, que define os componentes e os conceitos envolvidos no treinamento de procedimentos, e uma biblioteca de software, planejada com base nesta arquitetura e elaborada com o propósito de facilitar o desenvolvimento de aplicações de treinamento.

As características deste arcabouço foram verificadas e validadas através da implementação de dois casos de uso. O primeiro caso consiste em uma aplicação de simulação de troca de cruzeta em linha viva, onde o usuário realiza um procedimento de risco na manutenção de redes de distribuição, e o segundo caso, envolve a prática da montagem e desmontagem de uma Unidade Geradora Hidrelétrica.

Em ambas as aplicações, o modelo de Máquina de estados foi utilizado de forma simplificada na representação dos objetos interativos, e o modelo de rede de Petri foi usado para representar os procedimentos de treinamento. 


\section{Abstract}

The simulators for training have become increasingly popular, with applications in several areas, such as in land vehicles, aircraft, medical procedures, military operations, among others. These simulators can be classified into different groups according to the purpose of their training.

The simulators that involve the training of procedures are intended to empower the user to perform well defined activities, with an emphasis on the actions that the user needs to perform and on the existing dependencies between these actions.

The applications of this group of simulators are the subject of this work, and can be used in various situations, such as in assembly, disassembly, operation and maintenance of complex machinery, in performing activities that poses any danger to the user, or may cause damage to the equipment.

The advantages associated with virtual reality training have increased the demand for this type of application. Despite this, in Brazil, few papers have been published in this area of research.

In order to assist the development of procedure simulators, this work proposes a framework for virtual training, which was based on evidences obtained in the literature review and while investigating other architectures and tools.

The literature review found several techniques used in the description of the training scenarios, among them, we may mention the state machine, rule-based system, STORM, Graphs, LORA Diagram and Petri net.

The proposed framework consists of an architecture, that defines the components and concepts involved in training procedures, and a software library, which was planned based on this architecture and elaborated with the purpose of facilitating the development of applications for training.

The characteristics of this framework has been verified and validated through the implementation of two use cases. The first case is a application for simulating the exchange of a crosshead, where the user performs a risky procedure in the maintenance of distribution networks, and the second case, which involves assembling and disassembling of a Hydroelectric Generating Unit.

In both applications, the model of simple state machine was used to represent the behavior of interactive objects, and the Petri net model was used to represent the training procedures. 


\title{
Sumário
}

\section{Lista de Figuras}

\author{
Lista de Tabelas
}

\section{Lista de Abreviaturas}

1 Introdução 1

1.1 Relevância das aplicações de treinamento de procedimentos . . . . 3

1.2 Motivação . . . . . . . . . . . . . . . . . . . . 4 4

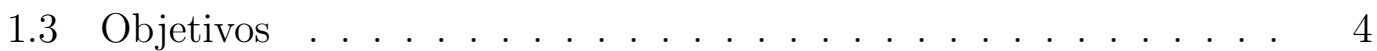

1.4 Metodologia . . . . . . . . . . . . . . . . 5

1.5 Estrutura da dissertação . . . . . . . . . . . . . . . . . . . 6

$\begin{array}{llll}2 & \text { Treinamento de procedimentos em Realidade Virtual } & 7\end{array}$

2.1 Perspectiva Histórica . . . . . . . . . . . . . . . . . . . . . . 7

2.2 Visão geral das arquiteturas . . . . . . . . . . . . . . . . . . 10

2.2.1 Criação do cenário virtual . . . . . . . . . . . . . . . 10

2.2.2 Realização do treinamento . . . . . . . . . . . . . . . . . 12

2.2.3 Informações do cenário de treinamento . . . . . . . . . . . 12

2.3 Técnicas para descrição do cenário de treinamento . . . . . . . . . 15

2.3.1 Modelos geométricos . . . . . . . . . . . . . . 15

2.3.2 Descrição funcional dos objetos . . . . . . . . . . . . 17

2.3.3 Descrição do procedimento . . . . . . . . . . . . . . . . 28

2.3.4 Análise comparativa . . . . . . . . . . . . . 38

2.4 Síntese . . . . . . . . . . . . . . . . . . . . . . . . . 39 
3 Arquitetura do arcabouço $\quad 40$

3.1 Visão geral . . . . . . . . . . . . . . . . . . . . . . . . . 40 40

3.2 Cenário de Treinamento . . . . . . . . . . . . . . . 42

3.2.1 Extensões $($ plug-ins $) \ldots \ldots . \ldots . \ldots . \ldots 43$

3.3 Modelo geométrico . . . . . . . . . . . . . . . . . . . . 43

3.4 Objetos interativos . . . . . . . . . . . . . 45

3.4.1 Classes de Funcionamento . . . . . . . . . . . . . . . . . 46

3.4.2 Ações . . . . . . . . . . . . . . . . . . . . . . 47

3.4.3 Modelo funcional . . . . . . . . . . . . . . . . . . . . 48

3.5 Procedimentos . . . . . . . . . . . . . . . . . . . . 49

3.6 Síntese . . . . . . . . . . . . . . . . . . 51

4 Considerações sobre a implementação $\quad 52$

4.1 Cenário de treinamento . . . . . . . . . . . . . . 53

4.2 Modelo geométrico . . . . . . . . . . . . . . . . 56

4.3 Objetos interativos . . . . . . . . . . . . . . . 57

4.3.1 Propriedades . . . . . . . . . . . . . . . . . 59

4.3 .2 Ações . . . . . . . . . . . . . . . . . . . . 60

4.3 .3 Tarefas ............................. 62

4.4 Procedimentos . . . . . . . . . . . . . . . . . . . . 64

4.4 Redes de Petri . . . . . . . . . . . . . . 65

4.5 Síntese . . . . . . . . . . . . . . . . . . . 66

5 Casos de uso - Aplicações de treinamento no Setor de Energia $\begin{array}{ll}\text { Elétrica } & 68\end{array}$

5.1 Estudo de caso AES Eletropaulo . . . . . . . . . . . . . . . . . . 69

5.1 .1 Redes de distribuição . . . . . . . . . . . . . . . . . . . 69

5.1 .2 Atividade de manutenção . . . . . . . . . . . . . . 71

5.1 .3 Aplicação de treinamento . . . . . . . . . . . . . . 74 
5.1 .4 Realização do treinamento . . . . . . . . . . . . . . . 87

5.2 Estudo de caso Furnas Centrais Elétricas . . . . . . . . . . . . 90

5.2.1 Aplicação de Treinamento . . . . . . . . . . . . . . . . . . 91

5.2.2 Realização do treinamento . . . . . . . . . . . . . . . . . 92

5.3 Avaliação da biblioteca . . . . . . . . . . . . . . . . . . . . . . . . 94

5.3.1 Outras considerações . . . . . . . . . . . . . . . . . . 96

5.4 Síntese . . . . . . . . . . . . . . . . . . . . 97

$\begin{array}{llr}6 & \text { Conclusões } & 98\end{array}$

6.1 Contribuições . . . . . . . . . . . . . . . . . . . . . . . . . 99

6.2 Trabalhos Futuros . . . . . . . . . . . . . . . . 100

$\begin{array}{ll}\text { Referências } & 101\end{array}$

$\begin{array}{ll}\text { Apêndice A - Padrões de redes de Petri } & 106\end{array}$

Apêndice B - Rede de Petri do procedimento de troca de cruzeta 109 


\section{Lista de Figuras}

2.1 Steve descrevendo um equipamento. Extraído de (RICKEL; JOHN-

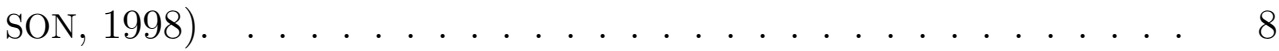

2.2 Camadas de configuração da plataforma VDT. Extraído de (BLÜMEL et al., 2005). . . . . . . . . . . . . . . . . 13

2.3 Visão geral da plataforma GVT. Extraído de (GERBAUD et al., 2008). 14

2.4 Exemplo simplificado de uma rede de sensores-atuadores. . . . . . 19

2.5 Sistema de regras em hierarquia. . . . . . . . . . . . . . . . 21

2.6 Exemplo de uma máquina de estados. Extraído de (DOUGLASS,

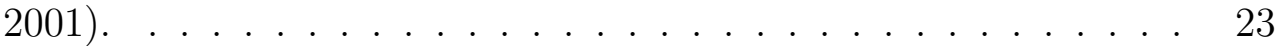

2.7 Máquina de estados para equipamento com bateria. Extraído de (DOUGLASS, 2001).

2.8 Máquina de estados hierárquica e concorrente. Extraído de (CREMER; KEARNEY; PAPELIS, 1995) . . . . . . . . . . . . . . . . 26

2.9 Descrição do objeto STORM. Extraído de (MOLLET; GERBAUD;

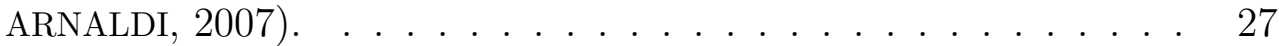

2.10 Exemplo de Objetivos e Restrições. . . . . . . . . . . . . . . . . . 29

2.11 Solução para exemplo de Objetivos e Restrições. . . . . . . . . . . 30

2.12 Representação do procedimento através de grafos. Extraído de (PONDER et al., 2003). . . . . . . . . . . . . . 31

2.13 Dois grupos de ações, mutuamente exclusivos. . . . . . . . . . . . 33

2.14 Conector do diagrama LORA. Extraído de (MOLLET; ARNALDI,

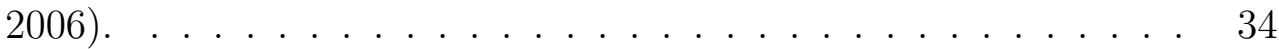

2.15 Diagrama do modelo LORA. Extraído de (MOLLET; ARNALDI, 2006). 34

2.16 Diagrama LORA com percursos alternativos. Extraído de (MOLLET; ARNALDI, 2006) . . . . . . . . . . . . . . . . 35

2.17 Exemplo de Redes de Petri. . . . . . . . . . . . . . . . . . 36 
2.18 Rede de Petri com caminho de retorno. . . . . . . . . . . . . . 37

3.1 Visão geral da arquitetura. . . . . . . . . . . . . . . . . . . . . 41

3.2 Hierarquia da cena. . . . . . . . . . . . . . . . . . . . . . . . 44

3.3 Objeto do procedimento. . . . . . . . . . . . . . . . . . 45

3.4 Classes de funcionamento. . . . . . . . . . . . . . . . . . . . 47

3.5 Máquina de estados de funcionamento. . . . . . . . . . . . . . . . 48

3.6 Rede de Petri com anotações. . . . . . . . . . . . . . . . . 50

4.1 Diagrama de classe do Cenário de treinamento. . . . . . . . . . 53

4.2 Diagrama de classe dos objetos interativos. . . . . . . . . . . 58

4.3 Diagrama de classe das propriedades. . . . . . . . . . . . . . 59

4.4 Diagrama de classe das ações. . . . . . . . . . . . . . . . . . 60

4.5 Principais tarefas do loop da aplicação. . . . . . . . . . . . . . . . 61

4.6 Diagrama do gerenciador de tarefas. . . . . . . . . . . . . . . 62

4.7 Execução de tarefas normais e em thread. . . . . . . . . . . . 63

4.8 Diagrama de classe dos procedimentos. . . . . . . . . . . . . 64

4.9 Diagrama de classes para rede de Petri. . . . . . . . . . . . . . 65

5.1 Poste com cruzeta simples. . . . . . . . . . . . . . . . 71

5.2 Realização da troca de cruzeta em linha viva. Extraído de (ELE-

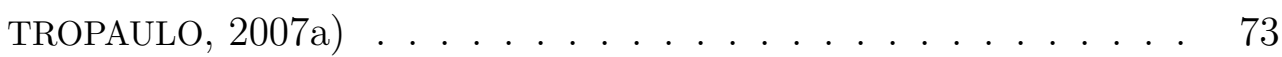

5.3 Identificação das fases da rede secundária e primária. Extraído de (ELETROPAULO, 2007a) . . . . . . . . . . . . 74

5.4 Arquitetura da aplicação de treinamento. . . . . . . . . . . . . 75

5.5 Interface de controle da cesta aérea. . . . . . . . . . . . . . 76

5.6 Modelos geométricos da cruzeta e do conjunto de elevação. . . . . 77

5.7 Diagrama das Classes de Funcionamento para troca de cruzeta. $\quad$. 79

5.8 Trecho inicial do procedimento de troca de cruzeta. . . . . . . . . 84

5.9 Trecho que antecede a substituição da cruzeta. . . . . . . . . . . 86

5.10 Tela de escolha do modo de funcionamento da aplicação. . . . . 88 
5.11 Seleção de objetos na aplicação. . . . . . . . . . . . . . . . . . 89

5.12 Menus principais da aplicação. . . . . . . . . . . . . . . . . 90

5.13 Diagrama das Classes de Funcionamento para a Unidade Geradora. 92

5.14 Trecho inicial do procedimento de desmontagem da Unidade Geradora. . . . . . . . . . . . . . . . . . 93

5.15 Procedimento de desmontagem da UG. . . . . . . . . . . . . 94

5.16 Procedimento de desmontagem do Mancal Guia e Escora do Gerador. 95

A.1 Rede de Petri onde $A$ depende de $B$ ou $C$. . . . . . . . . . . . 106

A.2 Rede de Petri onde $A$ depende de $B$ e $C$. . . . . . . . . . . 107

A.3 Rede de Petri onde $A$ depende de trechos mutuamente exclusivos. 108 


\section{Lista de Tabelas}

2.1 Técnicas para descrição funcional de objetos virtuais. . . . . . . . 38

2.2 Técnicas para descrição do procedimento. . . . . . . . . . . . . 38

4.1 Passos para a construção de um ambiente de treinamento. . . . . 54

4.2 Passos para a condução de um treinamento. . . . . . . . . . . 55

5.1 Extensão da rede de distribuição aérea. Extraído de (ELETROPAULO, 2007a). . . . . . . . . . . . . . 70

5.2 Passos para a troca de cruzeta em linha viva. . . . . . . . . . 72

5.3 Número aproximado de polígonos dos modelos geométricos. . . . . 77 


\section{Lista de Abreviaturas}

AES Applied Energy Services

ANEEL Agência Nacional de Energia Elétrica

CAD Computer-Aided Design

CERV Centro Europeu de Realidade Virtual

GVT Generic Virtual Training

HCSM Hierarchical Concurrent State Machines

HPAC High Pressure Air Compressor

HPTS Hierarchical Parallel Transition System

INRIA Instituto Nacional de Pesquisa em Informática e Automação

ISO International Organization for Standardization

LORA Language for Object-Relation Application

RV Realidade Virtual

SAN Sensor-Actuator Network

SME Subject Matter Expert

STORM Simulation and Training Object-Relation Model

UGH Unidade Geradora Hidrelétrica

UML Unified Modeling Language

VDTC Virtual Development and Training Centre

VDT-Platform Virtual Development and Training Platform

VRML Virtual Reality Modeling Language

XML Extensible Markup Language

X3D Extensible 3D 


\section{Introdução}

O uso das tecnologias de Realidade Virtual (RV) em aplicações de treinamento e capacitação de profissionais para a realização de procedimentos complexos ou de risco, tem se tornado cada vez mais comum e apresentado resultados muito positivos quando comparado com os métodos tradicionais de ensino, como apostilas, manuais, vídeos entre outros (BLÜMEL et al., 2005; LIN et al., 2002).

As tecnologias de software e hardware pesquisadas e desenvolvidas no âmbito de RV contribuem para que os usuários dessas aplicações tenham uma experiência mais amigável e realista ao interagir com os objetos do cenário virtual. A capacidade de reproduzir ambientes virtuais de forma imersiva e interativa reduz as diferenças existentes entre o cenário virtual e a realidade, facilitando a transferência do conhecimento obtido por meio da ferramenta de treinamento para uma situação real (LIN et al., 2002; WEXELBLAT, 1993).

As vantagens apresentadas pelas soluções em RV promoveram o desenvolvimento de simuladores e aplicações de treinamento em diversas áreas, como na condução de veículos terrestres e aeronaves, manutenção e operação de máquinas industriais, realização de procedimentos médicos, operações militares e tratamentos psicológicos. No trabalho desenvolvido por Ponder et al. (2003), este menciona que as aplicações de treinamento pertencem a um ou mais dos seguintes grupos: treinamento de habilidades físicas e motoras (GALLAGHER et al., 2005), treinamento de tomada de decisão (PONDER et al., 2003), e treinamento na execução de procedimentos (WASFY; WASFY; NOOR, 2004).

Os grupos estabelecidos por Ponder classificam as aplicações de simulação de acordo com o propósito do seu treinamento. No entanto, o propósito destas aplicações influencia no estabelecimento dos seus requisitos e as suas principais características.

A maioria das aplicações de treinamento de habilidades físicas e motoras, por exemplo, faz uso de periféricos sofisticados de interação e visualização. Isto porque é extremamente importante que o objeto simulado seja representado da 
forma mais fiel possível, não apenas visualmente, mas funcionalmente, pois são os movimentos do usuário na manipulação deste objeto que estão sendo avaliados e que irão determinar o andamento da simulação. Ainda neste grupo de aplicações, é importante representar com precisão a sensibilidade dos equipamentos ou máquinas que estão sendo simulados, além da variação dos seus parâmetros de funcionamento de acordo com alterações no meio em que estão inseridos. Este compromisso com a precisão da simulação garante que os movimentos treinados pelo usuário poderão ser repetidos com segurança em uma situação real.

Já as aplicações de tomada de decisão envolvem a exposição do usuário a situações que podem comprometer a sua estabilidade emocional ou psicológica. No trabalho de Ponder et al. (2003), os usuários são colocados em uma situação de emergência médica, onde estes precisam tomar decisões rápidas para salvar a vida do paciente. As decisões tomadas pelo usuário são interpretadas por um agente virtual que é responsável por executar as ações necessárias durante a simulação. Neste grupo de aplicações, as habilidades motoras do usuário não são avaliadas. O objetivo deste treinamento é fazer com que o usuário reduza as suas barreiras psicológicas ao enfrentar situações desafiadoras através de um ambiente virtual.

Por último, o grupo de aplicações que contempla o treinamento de procedimentos tem como objetivo fazer com que o usuário entenda quais tarefas ou ações são necessárias para cumprir com um determinado objetivo, dando ênfase nas dependências existentes entre estas ações, e nas consequências decorrentes da execução de cada ação. Neste grupo, a habilidade motora dos usuários não é necessariamente avaliada.

Por exemplo, no trabalho apresentado por Souza et al. (2008), o usuário pode realizar a montagem de uma Unidade Geradora Hidrelétrica (UGH) sem manipular um guindaste ou outros equipamentos auxiliares necessários para esta atividade. O objetivo desta aplicação é apenas demonstrar o processo de montagem de uma UGH, com ênfase na ordem em que as partes precisam ser encaixadas. Desta forma, os equipamentos auxiliares não estão presentes no cenário virtual e o usuário não precisa saber manipulá-los para concluir o procedimento de montagem. Caso contrário, a complexidade para manipular estes equipamentos é tal que exigiria a elaboração de outro simulador apenas para este fim.

Em outro trabalho, desenvolvido por Angelov e Styczynski (2007), o usuário utiliza apenas o mouse para fazer manutenção de um transformador de alta potência. Neste caso, o usuário também não precisa manipular diretamente as ferramentas necessárias ao procedimento. Quando a escolha da ferramenta se 
torna relevante para a atividade em execução, a aplicação de treinamento exige apenas que o usuário indique qual das ferramentas disponíveis é a mais adequada para a tarefa em questão.

Este último grupo de aplicações, cuja ênfase está no treinamento de procedimentos utilizando tecnologias de Realidade Virtual, é o objeto deste trabalho. Este capítulo ainda apresentará a relevância destas aplicações, os objetivos do trabalho e a estrutura deste documento.

\subsection{Relevância das aplicações de treinamento de procedimentos}

As aplicações de treinamento de procedimentos em Realidade Virtual podem ser utilizadas para diversos propósitos, entre eles, o ensino de procedimentos de montagem, desmontagem, operação e manutenção de máquinas complexas, ou a execução de atividades que oferecem risco ao usuário ou ao equipamento.

Nestes casos, a utilização dos recursos de RV permite que o usuário seja capacitado independente da sua localização ou da disponibilidade de equipamento para treinamento. Além disto, o ambiente virtual também permite que o usuário explore as possibilidades existentes sem comprometer a sua segurança ou o funcionamento dos periféricos virtuais.

Embora os acessórios envolvidos na construção de um ambiente virtual imersivo apresentem custos elevados, existem alternativas que viabilizam a elaboração de sistemas mais simples e baratos, porém menos imersivos. As categorias criadas por Cronin (1997) classificam os ambientes de realidade virtual nos seguintes grupos: desktop (SOUZA et al., 2008), semi-imersivo (TEUBL et al., 2009) e completamente imersivo (CRUZ-NEIRA et al., 1992). As soluções em desktop ou semi-imersivo praticamente eliminam a necessidade de utilizar periféricos de custo elevado, o que reduz de forma significativa o custo destas soluções.

Outro fator que contribui para a adoção de treinamentos virtuais é a vasta utilização de modelos CAD na indústria. A disponibilidade destes modelos reduz o trabalho necessário para elaborar os cenários de treinamento, pois grande parte do processo de modelagem já foi realizado, sendo necessário apenas converter o modelo CAD para um formato passível de visualização em tempo-real (OLIVEIRA et al., 2007). 


\subsection{Motivação}

As vantagens do treinamento em ambiente virtual têm aumentado a procura por este tipo de solução. No entanto, para atender as demandas reais de treinamento e capacitação de seus funcionários, as empresas precisam de um conjunto muito amplo de procedimentos representados no ambiente virtual.

O tempo necessário para a elaboração destes procedimentos virtuais e o custo associado com este desenvolvimento são aspectos negativos deste tipo de solução. Segundo Barata et al. (2009), por exemplo, a criação de um cenário para treinar a operação de uma Unidade Geradora Hidrelétrica (UGH) exigiria a reprodução de centenas de procedimentos no ambiente virtual.

No Brasil, existe uma demanda crescente por simuladores de treinamento, porém grande parte das tecnologias de software e hardware são importadas devido ao baixo desenvolvimento nacional deste setor. As poucas publicações acadêmicas nesta área relatam a criação de aplicações específicas para determinados segmentos, não abordando o problema de forma mais ampla.

Desta forma, para viabilizar a criação destas aplicações de forma rápida e fácil, é necessário trabalhar com um mecanismo que permita a construção de componentes reaproveitáveis, evitando o retrabalho e consequentemente, reduzindo o investimento necessário para a elaboração de novos procedimentos virtuais.

Atualmente, o Laboratório de Sistemas Integráveis da Escola Politécnica da USP, onde desenvolvo minhas atividades de pesquisa, participa de projetos em parceria com empresas do setor elétrico, como a AES Eletropaulo (Applied Energy Services Eletropaulo) e Furnas Centrais Elétricas, para propor soluções que aprimorem o treinamento e o processo de capacitação dos seus funcionários, através da elaboração de procedimentos virtuais de manutenção e operação de maquinário.

A principal motivação deste trabalho é, portanto, contribuir com a pesquisa e com o desenvolvimento de uma ferramenta de software que auxilie a elaboração de aplicações de treinamento de procedimentos, reduzindo o investimento necessário para a implantação destas solução, e promovendo o uso das tecnologias de Realidade Virtual no cenário nacional.

\subsection{Objetivos}

O principal objetivo deste trabalho é propor um arcabouço para auxiliar o desenvolvimento de aplicações para o treinamento de procedimentos, concentrando-se 
no uso de tecnologias de RV semi-imersiva e visando a reutilização de componentes para facilitar a criação de novas atividades de treinamento.

Para alcançar o objetivo principal deste trabalho, foi necessário alcançar objetivos específicos, mencionados a seguir:

- Investigar os arcabouços e as ferramentas existentes, através de uma revisão da literatura;

- Propor uma arquitetura, contendo soluções conceituais para os principais módulos de uma aplicação de treinamento de procedimentos;

- Planejar e desenvolver uma biblioteca de software para auxiliar a criação destas aplicações de treinamento;

- Verificar e analisar o funcionamento da biblioteca através da elaboração de casos de uso, visando atender as demandas de treinamento virtual das empresas AES Eletropaulo e Furnas Centrais Elétricas;

\subsection{Metodologia}

Para alcançar os objetivos específicos deste trabalho, as seguintes atividades foram executadas:

- Pesquisa de arquiteturas e técnicas utilizadas para criar ambientes virtuais de treinamento de procedimentos;

- Análise e seleção das melhores técnicas e arquiteturas estudadas;

- Elaboração de uma arquitetura flexível, para facilitar e reduzir o custo do desenvolvimento de novos cenários de treinamento;

- Projeto e desenvolvimento de uma biblioteca de software, seguindo as recomendações da arquitetura proposta;

- Aplicação da biblioteca no desenvolvimento de aplicações de treinamento de procedimentos, visando a sua utilização em casos práticos, que foram estabelecidos em parceria com as empresas AES Eletropaulo e Furnas Centrais Elétricas;

- Avaliação dos resultados obtidos nos casos de uso; 


\subsection{Estrutura da dissertação}

O capítulo 2 apresenta uma revisão da literatura, através da investigação de ferramentas, arquiteturas e técnicas utilizadas para a criação de simuladores de procedimentos em Realidade Virtual. Este capítulo estabelece a fundamentação teórica para a proposta de um arcabouço de treinamento.

A proposta da arquitetura deste arcabouço é apresentada no capítulo 3. Esta arquitetura identifica os principais elementos de um simulador de procedimentos, e estabelece conceitos que irão facilitar a criação de cenários de treinamento, através de mecanismos para representar os seus objetos interativos e os seus procedimentos.

O capítulo 4 apresenta as considerações sobre a implementação da biblioteca de software deste arcabouço. O projeto desta biblioteca é apresentado através de diagramas UML (Unified Modeling Language), e foi elaborado conforme os elementos apresentados na arquitetura.

Para verificar e validar as características da arquitetura e os recursos disponíveis na biblioteca de treinamento, o capítulo 5 apresenta o desenvolvimento e os resultados obtidos na elaboração de dois casos de uso deste arcabouço. Estes casos de uso foram realizados em parceria com as empresas AES Eletropaulo e Furnas Centrais Elétricas, visando atender as demandas de treinamento destas empresas.

O capítulo 6 apresenta as conclusões finais desta dissertação, mencionando as contribuições realizadas e as considerações a serem feitas em trabalhos futuros. 


\section{Treinamento de procedimentos em Realidade Virtual}

Este capítulo apresenta uma revisão da literatura sobre as aplicações, as arquiteturas e as técnicas utilizadas no treinamento de procedimentos em Realidade Virtual. Esta revisão estabelece a fundamentação teórica para o restante do trabalho, e foi realizada principalmente com o auxílio de publicações acadêmicas e manuais de produtos comerciais.

O capítulo inicia com uma breve perspectiva histórica, e em seguida apresenta as principais ferramentas e arquiteturas utilizadas no treinamento de procedimentos, enfatizando as técnicas e os modelos aplicados para equacionar este tipo de problema. No final do capítulo, uma seção resume as vantagens e desvantagens das abordagens discutidas.

\subsection{Perspectiva Histórica}

Algumas aplicações desenvolvidas com ênfase no treinamento de procedimentos ganharam notoriedade no início da década de 90 ao utilizar de forma mais efetiva as tecnologias de Realidade Virtual. Entre os trabalhos publicados nesta década, Jeff Rickel se destacou no meio acadêmico com a apresentação do personagem Steve (JOHNSON; RICKEL, 1997; RICKEL; JOHNSON, 1998). Steve é um personagem virtual animado capaz de executar e demonstrar procedimentos complexos em um ambiente virtual.

Nos primeiros trabalhos, Steve era usado para ensinar estudantes a operar um Compressor de Ar de Alta Pressão (High Pressure Air Compressor (HPAC)) a bordo de navios da marinha americana. Como observado na figura 2.1, Steve possuía apenas a parte superior do tronco, era capaz de se deslocar pelo ambiente virtual e executar gestos simples, como apontar para os objetos presentes no cenário. 
A continuação desta pesquisa permitiu que Steve fosse aprimorado em diversos aspectos, como na capacidade de reconhecer comandos através da linguagem natural, realizar expressões faciais e executar gestos mais suaves e naturais (RICKEL et al., 2002). Estas melhorias permitiram com que Steve fosse utilizado para desenvolver outro tipo de simulador, com o objetivo de treinar os marinheiros americanos a lidar com situações de conflito cultural (HILL et al., 2003), criando cenários em que estes militares são obrigados a tomar decisões sob estresse intenso.

O trabalho apresentado por Lin, Hon e SU (1996), desenvolvido na mesma época que Steve, permitia que os seus usuários manipulassem uma máquina fresadora de três eixos, utilizada na usinagem de pequenas peças. Os usuários desta aplicação podiam, através da representação virtual desta máquina, praticar diversos procedimentos de usinagem.

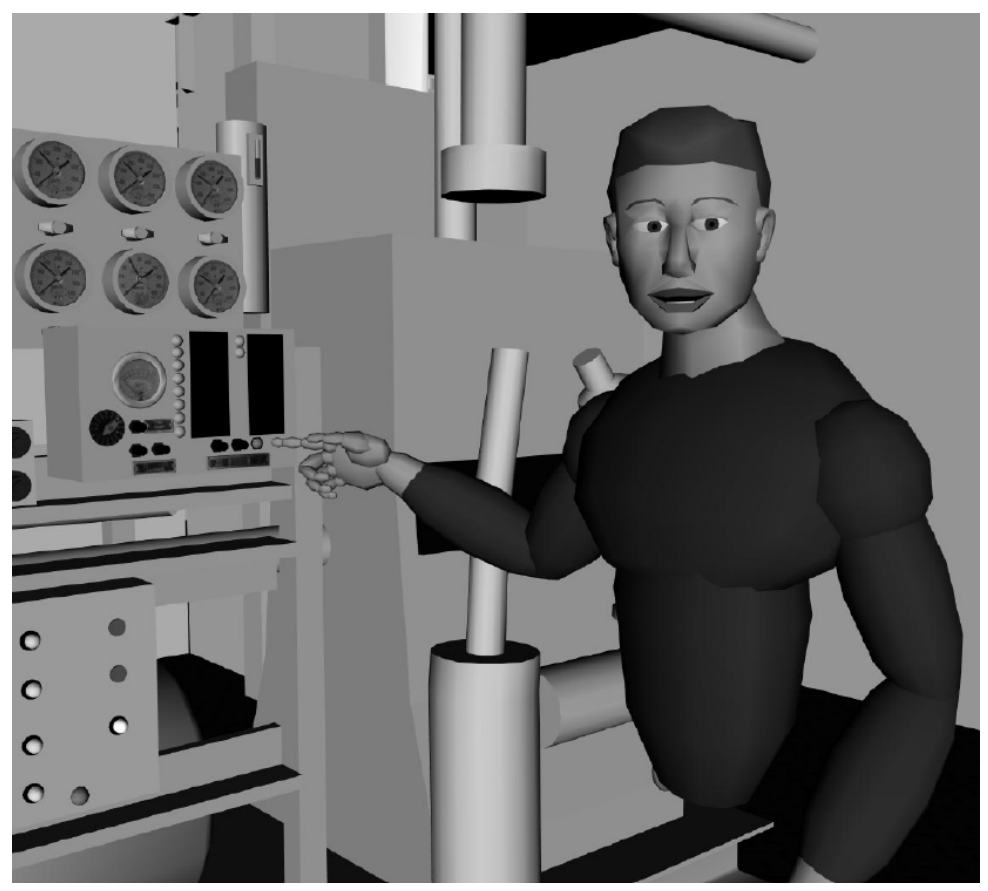

Figura 2.1: Steve descrevendo um equipamento. Extraído de (RICKEL; JOHNSON, 1998).

Os estudantes que utilizaram a aplicação de Lin foram posteriormente avaliados e tiveram seus resultados comparados com outros dois grupos. Um destes grupos havia sido treinado através de manuais tradicionais e o outro com o auxílio de um instrutor. Os estudantes que utilizaram a aplicação de RV tiveram resultados compatíveis com aqueles que foram lecionados por um instrutor. Estes dois últimos grupos, por sua vez, tiveram desempenho muito superior aos alunos que usaram manuais tradicionais. 
Outro trabalho, apresentado ainda na década de 90 por Loftin e Kenney (1995), relata o uso das tecnologias de RV pela Agência Espacial Americana (NASA), no treinamento da equipe de manutenção do telescópio espacial Hubble. Este projeto foi o primeiro a utilizar estas tecnologias no treinamento de pessoal para uma missão espacial. O treinamento consistia na prática de seis procedimentos, todos para serem executados do lado de fora da nave espacial.

A publicação de trabalhos acadêmicos relatando o sucesso do treinamento virtual em segmentos específicos da indústria aumentou a demanda por este tipo de aplicação. Institutos de pesquisa e laboratórios, reconhecidos pelas suas aplicações em RV, elaboraram mecanismos para facilitar a criação de aplicações para treinamento, reduzindo os custos de desenvolvimento e o tempo necessário para a implantação destas soluções.

Desta forma, no início da década de 2000, institutos de pesquisa como o Fraunhofer IFF da Alemanha e o INRIA da França, iniciaram o desenvolvimento de ferramentas de treinamento que ganharam destaque no meio acadêmico: a plataforma VDT (Virtual Development and Training Platform) (BLÜMEL et al., 2005) e o projeto GVT(Generic Virtual Training) (GERBAUD et al., 2008), respectivamente.

Neste período, o instituto de pesquisa alemão Fraunhofer IFF criou o Centro de Desenvolvimento e Treinamento Virtual (Virtual Development and Training Centre (VDTC)). Este centro de pesquisa se especializou no desenvolvimento de aplicações de treinamento, cuja principal ferramenta desenvolvida foi a plataforma VDT (VDT-Platform).

Apesar das publicações acadêmicas não apresentarem detalhes sobre a arquitetura desta plataforma, a mesma é utilizada no desenvolvimento de diversos tipos de aplicações, como na manutenção de transformadores (ARENDARSKI; TERMATH; MECKING, 2008), na operação de fornalhas industriais (SCHENK et al., 2003) e em procedimentos de manutenção de aeronaves (BLÜMEL et al., 2003).

Já o projeto GVT foi desenvolvido através de uma parceria entre três instituições francesas: o Instituto Nacional de Pesquisa em Informática e Automação (INRIA), o Centro Europeu de Realidade Virtual (CERV) e o grupo privado Nexter ${ }^{1}$ (antigas indústrias Giat).

Esta parceria foi estimulada pelo grupo Nexter, fabricante de equipamentos militares, que precisava de uma ferramenta para capacitar os operadores de seus

\footnotetext{
${ }^{1}$ Página web do grupo Nexter: http://www.nexter-group.fr/. Acessado em Agosto/2010.
} 
equipamentos, sem expor estes operadores ao perigo de um treinamento real. Segundo Gerbaud et al. (2008), o projeto GVT possui mais de 50 atividades elaboradas, provendo treinamento para um amplo conjunto de equipamentos.

Apesar de projetos distintos, as arquiteturas destas plataformas contêm muitas características em comum. A próxima seção deste documento apresenta uma visão geral sobre estas arquiteturas e os conceitos fundamentais de sua organização.

\section{$2.2 \quad$ Visão geral das arquiteturas}

As arquiteturas de software desenvolvidas por estes institutos foram planejadas para facilitar a elaboração de cenários virtuais e reduzir o retrabalho no desenvolvimento de novos procedimentos de treinamento.

Para obter estas características, essas arquiteturas separaram a descrição das atividades de treinamento, da ferramenta utilizada pelo usuário. Neste caso, as informações das atividades de treinamento são armazenadas em uma estrutura de dados que é interpretada pela aplicação em tempo de execução. Quando necessário, as atividades podem ser revisadas sem a necessidade de alterar ou refazer a ferramenta de RV utilizada pelo usuário.

Desta forma, o treinamento nestas arquiteturas é implantado em duas etapas principais: a criação de um cenário virtual e a realização efetiva do treinamento. Estas duas etapas estão conectadas através da estrutura de dados que contém as informações do ambiente virtual.

As seções seguintes apresentam mais detalhes sobre a criação do ambiente, a execução do treinamento e estrutura de dados do cenário virtual.

\subsubsection{Criação do cenário virtual}

Um cenário virtual de treinamento é composto por três grupos principais de informação (BLÜMEL et al., 2004):

- Um conjunto de geometrias, materiais e animações, que descreve as características visuais do ambiente virtual;

- As definições de funcionamento dos objetos presentes no ambiente virtual. Estas definições contêm o conjunto de regras que determinam as características funcionais destes objetos virtuais; 
- A descrição das atividades de treinamento. Estas atividades contêm todas as ações que o usuário precisa executar no ambiente virtual para atingir os objetivos do treinamento, além de mensagens de erro, sugestões e outras informações.

Para criar um cenário completo, contendo todos estes três grupos de informação, diversas ferramentas podem ser utilizadas. No caso do primeiro grupo, que contém dados geométricos da cena, aplicações tradicionais como o 3D Studio Max da Autodesk ${ }^{2}$ ou o Blender ${ }^{3}$, são muito utilizadas.

Caso os modelos de algumas máquinas ou peças do treinamento já tenham sido elaborados, por exemplo, para referência de usinagem. Estes modelos, normalmente disponíveis em CAD (Computer-Aided Design), precisam ser apenas convertidos ou adaptados para a visualização em tempo-real. No trabalho apresentado por Oliveira et al. (2007), os modelos geométricos foram convertidos do formato STEP (STandard for the Exchange of Product model data), que contém a descrição dos objetos através de superfícies paramétricas, para o formato VRML (Virtual Reality Modeling language), que contém os modelos no formato geométrico.

Para elaborar o conteúdo dos outros dois grupos de informação, que contêm as regras de funcionamento dos objetos virtuais e as atividades de treinamento do usuário, outras ferramentas são utilizadas. Estas ferramentas são normalmente desenvolvidas pelos próprios laboratórios ou institutos de pesquisa, e não são disponibilizadas publicamente. No entanto, dependendo da complexidade da estrutura de dados escolhida pela arquitetura de treinamento, estas informações podem até ser inseridas manualmente pelo usuário.

Ainda no trabalho de Oliveira et al. (2007), as regras de funcionamento dos objetos e a descrição dos procedimentos de treinamento foram realizadas utilizando a ferramenta comercial Eon Studio, da empresa Eon Reality ${ }^{4}$. Neste caso, como o formato adotado por esta ferramenta é proprietário, apenas a aplicação de treinamento da própria empresa pode ser utilizada para realizar o treinamento.

Todas as informações produzidas nesta etapa de criação e composição do cenário de treinamento são armazenadas na estrutura de dados do ambiente virtual.

\footnotetext{
${ }^{2}$ Página web da Autodesk: http://www.autodesk.com.br/. Acessado em Agosto/2010.

${ }^{3}$ Página do Blender: http://www.blender.org/. Acessado em Agosto/2010.

${ }^{4}$ Página web da Eon Reality: http://www.eonreality.com/. Acessado em Agosto/2010.
} 


\subsubsection{Realização do treinamento}

O treinamento é realizado através de um sistema de execução que interpreta as informações presentes na estrutura de dados do ambiente virtual e cria um cenário de treinamento em RV para que o usuário possa acompanhar e praticar as atividades de forma adequada.

Entre os recursos disponíveis em um determinado sistema de execução, podemos mencionar a renderização da cena 3D, a manipulação e a interação com os objetos virtuais, e os mecanismos para utilizar os acessórios de Realidade Virtual, como luvas, óculos, rastreadores de posição, entre outros.

Conforme apresentado por Blümel et al. (2005), um sistema de execução pode conter diversos modos de funcionamento, entre eles: $\mathrm{O}$ modo de Apresentação (Presentation Mode) e o modo de Treinamento (Training Mode).

O modo de Apresentação é normalmente utilizado para demonstrar um determinado procedimento ao usuário. Neste modo, todas as atividades são executadas automaticamente pela ferramenta, permitindo que o usuário interfira apenas se desejar.

O modo de Treinamento é utilizado para avaliar os conhecimentos do usuário. Neste modo, o usuário deve executar todas as atividades previstas no procedimento sem o auxílio da ferramenta. Normalmente, os erros cometidos neste modo são colocados em um relatório, para registrar os resultados obtidos na avaliação.

\subsubsection{Informações do cenário de treinamento}

As informações do cenário de treinamento contêm, entre outras coisas, as geometrias e os materiais dos objetos, as regras de funcionamento das peças e máquinas virtuais, a definição das atividades de treinamento, mensagens de erro, mensagens de ajuda etc.

Ao armazenar estas informações em uma estrutura de dados separada da aplicação de RV, é possível aperfeiçoar os cenários de treinamento sem a necessidade de alterar a ferramenta utilizada pelo usuário. No entanto, para tirar proveito desta organização é necessário dispor de uma estrutura flexível para armazenar estas informações. Esta estrutura de dados deve ser capaz de representar uma grande variedade de equipamentos, máquinas e procedimentos de treinamento.

Além de uma estrutura de dados flexível, é importante que o mecanismo praticado para alterar esta estrutura seja simples, permitindo que profissionais 
da área de treinamento, sem conhecimentos avançados de computação e Realidade Virtual, sejam capazes de efetuar alterações no cenário virtual através de ferramentas desenvolvidas pelo próprio laboratório ou de forma manual.

De acordo com Blümel et al. (2004), para atingir estes objetivos na plataforma VDT, as informações utilizadas para descrever os procedimentos de treinamento foram classificadas em três diferentes camadas, conforme ilustrado na figura 2.2.

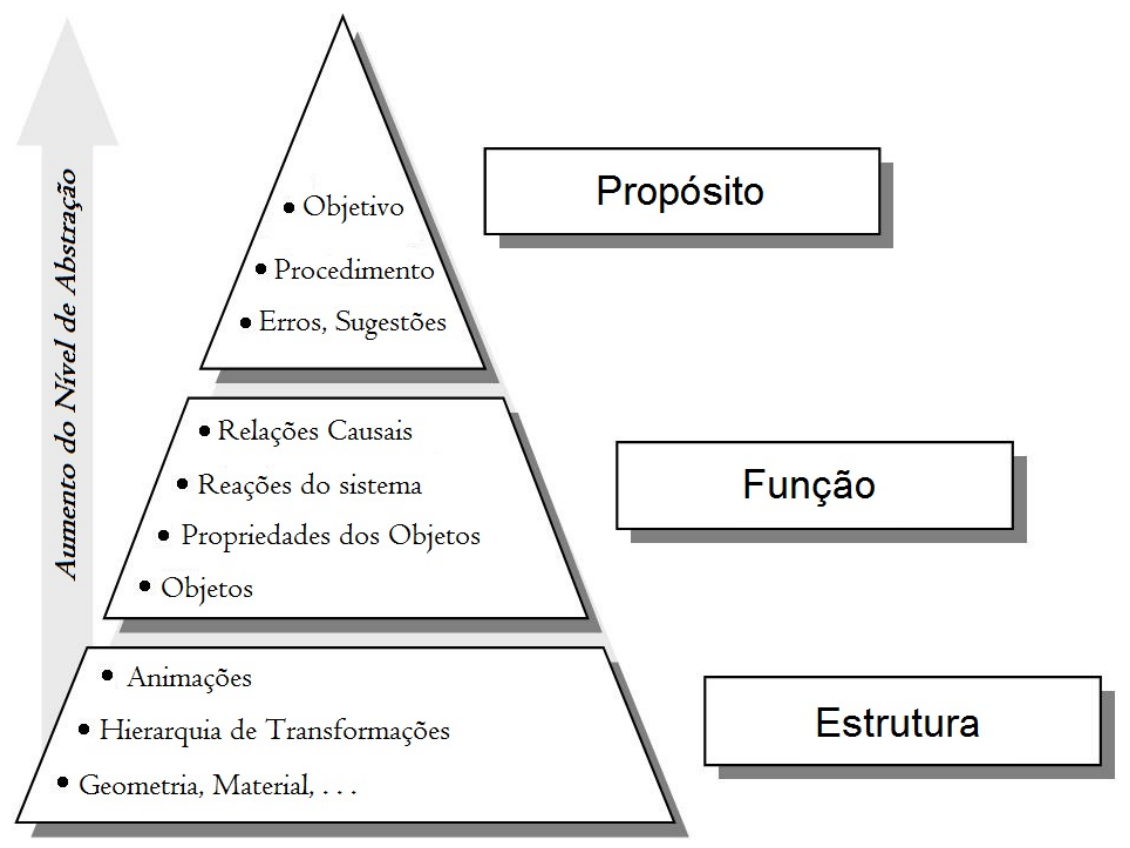

Figura 2.2: Camadas de configuração da plataforma VDT. Extraído de (BLÜMEL et al., 2005).

As informações apresentadas nesta pirâmide estão classificadas em diferentes níveis de abstração. A primeira camada, na base da pirâmide, contém informações sobre as geometrias dos objetos virtuais, seus respectivos materiais e suas animações. Segundo Blümel, estas informações são importadas de aplicações de modelagem, como o 3D Studio Max da Autodesk, ou de ferramentas de CAD. Neste caso, apenas profissionais com domínio destas ferramentas podem criar conteúdo para esta camada.

A segunda camada contém a definição funcional de todos os objetos interativos presentes no ambiente virtual. Nesta definição estão as regras de funcionamento das máquinas, peças e outros objetos do cenário de treinamento. Estas regras de funcionamento são associadas ao conjunto de geometrias que representa estes objetos. Além disto, a definição funcional também determina quais serão as reações de um determinado objeto ao ser manipulado pelo usuário. Na plataforma VDT, estas informações são preenchidas através de um software proprietário, que auxilia a construção destas regras com base nas informações geométricas e nas 
animações presentes na primeira camada.

A terceira camada contém informações sobre as atividades que o usuário deve executar para atingir os objetivos do treinamento. A descrição destas atividades contém, entre outras coisas, a sequência de ações que o usuário precisa efetuar em cada objeto do cenário virtual. Nesta camada, as informações também são preenchidas através de uma ferramenta proprietária, cujo objetivo é facilitar a participação dos profissionais especializados no assunto a ser simulado, permitindo que estes profissionais, mesmo não tendo conhecimento avançado de computação, possam contribuir na elaboração de novos procedimentos.

A organização destas informações em camadas, com diferentes níveis de abstração, facilita a criação e a edição deste conteúdo, pois as camadas superiores da pirâmide podem ser alteradas sem modificar as camadas da base, que são mais complicadas e exigem a participação de mão-de-obra especializada.

Da mesma forma, o planejamento do projeto GVT, elaborado no INRIA, estabeleceu uma arquitetura com características muito semelhantes a da plataforma VDT.

Segundo Gerbaud et al. (2008), a arquitetura do projeto GVT é composta por três motores principais: Motor do Procedimento, Motor de Interação e um Motor pedagógico, para auxiliar o usuário durante a prática dos procedimentos.

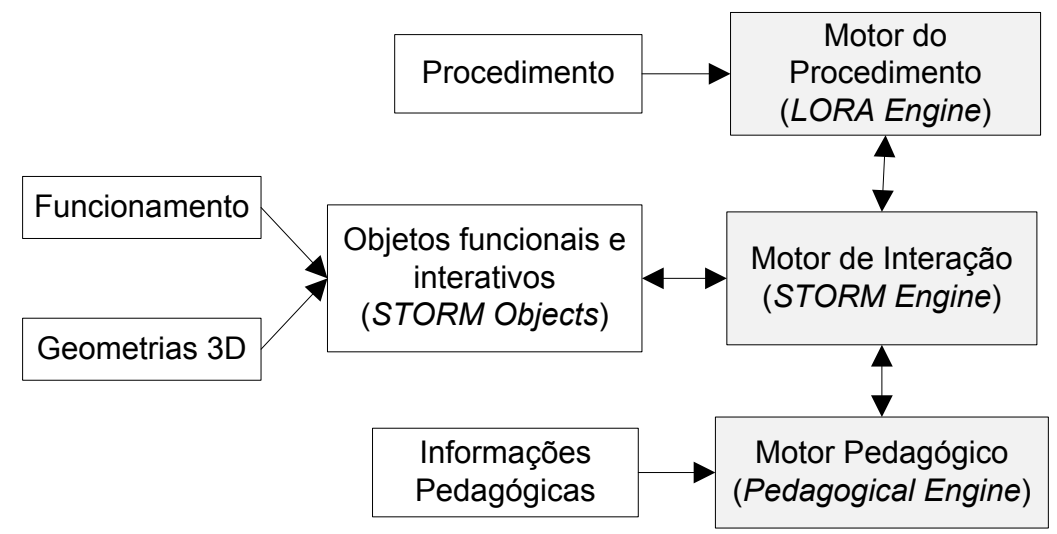

Figura 2.3: Visão geral da plataforma GVT. Extraído de (GERBAUD et al., 2008).

Conforme apresentado na figura 2.3, o Motor de Interação (STORM Engine) gerencia a manipulação dos objetos interativos no cenário virtual. Estes objetos interativos são formados a partir de geometrias 3D e informações que definem o seu funcionamento. Já o Motor do Procedimento (LORA Engine) é responsável por controlar a execução da atividade em treinamento. Estas atividades são obtidas a partir da descrição do procedimento a ser praticado pelo usuário. 
Para descrever o funcionamento dos objetos no ambiente virtual, o projeto GVT criou a linguagem STORM (Simulation and Training Object-Relation Model) (MOLLET; GERBAUD; ARNALDI, 2007). Esta linguagem permite definir o conjunto de ações que o usuário pode executar em cada objeto. Estas ações determinam quais as funções de um determinado objeto e como o mesmo irá reagir a cada interação do usuário.

Para definir o procedimento, o GVT utiliza a linguagem LORA (Language for Object-Relation Application) (MOLLET; ARNALDI, 2006). Esta linguagem permite representar graficamente as dependências existentes entre as tarefas de uma determinada atividade de treinamento. Estas dependências são utilizadas durante a execução do procedimento virtual, para avaliar as ações tomadas pelo usuário.

As técnicas utilizadas para descrever as regras de operação dos objetos virtuais e os procedimentos de treinamento são extremamente importantes, pois são as limitações destas linguagens que vão determinar a variedade de equipamentos e procedimentos que podem ser representados virtualmente.

Apesar de o projeto GVT utilizar as linguagens STORM e LORA, existem diversas alternativas descritas na literatura. Estas alternativas serão apresentadas em maior detalhe na próxima seção do documento.

\subsection{Técnicas para descrição do cenário de trei- namento}

Esta seção apresentará as principais técnicas e recursos utilizados para descrever um cenário virtual de treinamento.

De acordo com as plataformas apresentadas na seção anterior, as informações necessárias para definir um cenário de treinamento podem ser divididas em três grupos: o modelo geométrico, a descrição funcional dos objetos e a descrição do procedimento a ser treinado.

\subsubsection{Modelos geométricos}

Os modelos geométricos contêm apenas as informações visuais do cenário, como malhas poligonais, materiais, animações, texturas etc. Todas estas informações determinam o grau de realismo visual do ambiente que está sendo simulado.

Normalmente, este conteúdo é elaborado com o auxílio de ferramentas de modelagem para tempo-real, como o 3D Studio Max, o Maya ou o Blender. Caso o 
modelo da peça ou equipamento a ser utilizado no treinamento já esteja disponível em alguma ferramenta de CAD, é possível realizar a importação e a adaptação deste conteúdo para um formato de visualização em tempo-real (OLIVEIRA et al., 2007).

Além das aplicações de modelagem, existem diversas bibliotecas de software disponíveis gratuitamente para auxiliar o desenvolvimento de aplicações de RV. Estas bibliotecas, como o Ogre (JUNKER, 2006), o OpenSceneGraph (MARTZ, 2007) e o OpenSG (REINERS; VOSS; BEHR, 2002), possuem recursos para carregar o modelo geométrico elaborado pelas ferramentas de modelagem, organizar este modelo na memória do computador e apresentá-lo ao usuário usando mecanismos para otimizar o consumo de memória e o processamento da placa gráfica.

Estas bibliotecas são frequentemente utilizadas no desenvolvimento de diversos tipos de simuladores e jogos. Nestes casos, é fundamental que a biblioteca de software funcione em harmonia com a aplicação de modelagem, para que todos os objetos elaborados nesta aplicação sejam corretamente interpretados e apresentados pela biblioteca de RV.

Desta forma, para facilitar a integração entre estas duas ferramentas, é importante que o formato de arquivo utilizado para representar o modelo geométrico seja conhecido e corretamente interpretado por ambas as partes.

\subsubsection{Formatos de arquivo}

Para viabilizar esta integração, diversos plug-ins foram desenvolvidos para estas aplicações de modelagem com o intuito de converter seus formatos proprietários para outros, cuja especificação seja gratuita e esteja disponível publicamente.

Entre os formatos de padrão aberto com maior adoção, tanto por parte das aplicações de modelagem, como pelas bibliotecas de RV, é o formato VRML (Virtual Reality Modelling Language) (CAREY; BELL, 1997). Este formato apresenta recursos importantes para a visualização de cenas de grande porte, como: hierarquia de transformações, shaders, animações, instâncias de objetos e referências a arquivos externos.

O formato de arquivo VRML foi incorporado ao padrão X3D (Extensible 3D) (DALY; BRUTZMAN, 2007). Este padrão apresenta ainda duas outras alternativas para a codificação dos dados 3D, através de um formato binário ou uma sintaxe XML.

De acordo com Behr, Dähne e Roth (2004), o padrão X3D apresenta diversas 
vantagens para o desenvolvimento de aplicações em ambientes imersivos quando comparado com alternativas proprietárias:

- O X3D é padrão ISO ${ }^{5}$ e sua especificação está disponível gratuitamente na Internet (WEB3D CONSORTIUM, 2008);

- A descrição da cena no formato é independente da plataforma e de acessórios de RV;

- Existe um número crescente de aplicações de modelagem que exportam conteúdo para um dos formatos do padrão X3D;

- Disponibilidade de livros e tutoriais sobre o assunto;

Apesar do padrão X3D ter como formato principal a codificação em XML, ainda não existem muitas ferramentas para exportar conteúdo neste formato. Desta forma, a codificação VRML continua sendo a alternativa mais popular, inclusive nas aplicações de treinamento.

Outro formato muito utilizado é o OBJ (WAVEFRONT, 2010), da antiga Wavefront Technologies. Apesar de este formato ser suportado por quase todas as aplicações de modelagem e bibliotecas de RV, o mesmo não possui recursos importantes, como hierarquia de cena, animações, instâncias, entre outros. Todos estes recursos são fundamentais para a representação de cenários complexos utilizados na elaboração de jogos e aplicações de treinamento.

\subsubsection{Descrição funcional dos objetos}

Embora existam diversos formatos de arquivo para se representar o modelo geométrico de um cenário virtual, apenas algumas alternativas, como o X3D e o VRML, possuem recursos para descrever o funcionamento de seus objetos.

Quando o usuário interage com os objetos presentes em um cenário de treinamento, como apertar um determinado botão de um equipamento eletrônico, ou simplesmente ligá-lo na tomada, este objeto pode reagir a estas ações através da execução de alguma animação, por exemplo.

A utilização de um modelo para representar o funcionamento destes objetos e as suas reações é interessante, pois facilita o desenvolvimento da ferramenta de treinamento e padroniza o processo de representação de novas máquinas ou periféricos virtuais.

\footnotetext{
${ }^{5} \mathrm{ISO} / \mathrm{IEC} 19775-1.2: 2008$.
} 
A área de pesquisa cujo foco são modelos para a descrição do funcionamento de objetos complexos em ambientes virtuais é conhecida como objetos comportamentais (behavioral objects), ou modelos comportamentais (behavioral models).

O principal objetivo desta área de pesquisa é estabelecer técnicas e modelos para descrever o comportamento de agentes ou criaturas virtuais, de tal forma que este comportamento apresente características semelhantes as observadas nos seres vivos. Apesar deste objetivo não envolver a descrição do funcionamento de objetos quaisquer, como máquinas e outros equipamentos, muitos resultados obtidos nesta área de pesquisa estão sendo utilizados para este fim.

De acordo com Mollet, Gerbaud e Arnaldi (2007), os modelos mais utilizados para a descrição do comportamento de objetos virtuais podem ser classificados em três principais abordagens: rede de sensores-atuadores, sistema baseado em regras e máquina de estados.

Estas abordagens são explicadas em maior detalhe nas próximas seções deste documento.

\subsubsection{Rede de sensores-atuadores}

As abordagens que utilizam redes de sensores-atuadores, normalmente, são implementadas através de uma rede de nós interconectados. Estes nós podem ser classificados em três tipos: nós sensores (sensor nodes), nós escondidos (hidden nodes) e nós atuadores (actuator nodes).

Os nós de entrada são classificados como nós sensores e são responsáveis por obter informações sobre o estado do objeto e do ambiente virtual. Os nós de saída são classificados como nós atuadores, e realizam alterações no estado do objeto. Os nós intermediários são classificados como nós escondidos e são responsáveis por processar as informações dos sensores, através de um conjunto de operações previamente definidas, e conduzir os resultados aos atuadores.

Conforme ilustrado na figura 2.4, as redes podem assumir diversas topologias, mas são montadas de tal forma que o sinal obtido pelos sensores é processado por um conjunto de operações em cascata, que ao final, fornece os sinais para os atuadores, que determinam o comportamento do objeto que está sendo modelado.

Baseado neste modelo, Van De Panne propôs a rede SAN (Sensor-Actuator Network) (PANNE; FIUME, 1993) para controlar o comportamento de criaturas em um ambiente 3D. Outros trabalhos semelhantes ao de Panne foram desenvolvidos por Braitenberg (1986), e posteriormente por Sims (1994). 


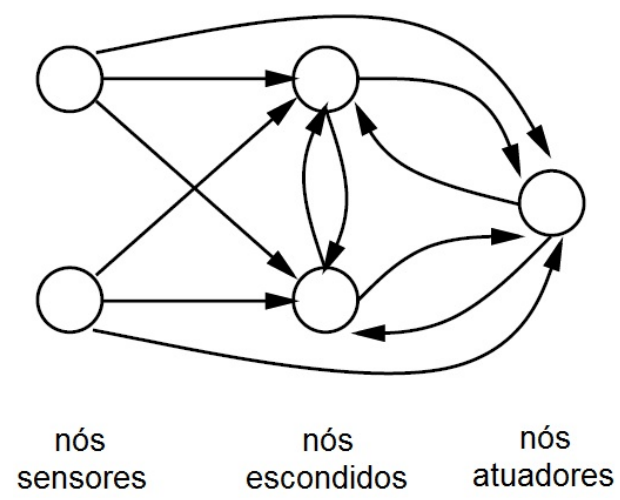

Figura 2.4: Exemplo simplificado de uma rede de sensores-atuadores.

No trabalho de Panne, diversas redes sensores-atuadores foram construídas para controlar o comportamento de pequenas criaturas virtuais. Estas redes apresentaram resultados interessantes para quase todas as criaturas elaboradas em seus testes.

No entanto, por se tratarem de sistemas não-lineares, a montagem e a parametrização destas redes são tarefas extremamente complexas para serem realizadas manualmente, mesmo se tratando de criaturas simples como aquelas apresentadas em seu trabalho. Pequenas alterações nos parâmetros de entrada destas redes podem provocar mudanças bruscas no modelo, até mesmo invalidando a sua função.

Desta forma, a montagem e a parametrização destas redes dependem de mecanismos automáticos, como a geração aleatória de parâmetros e a aplicação de algoritmos genéticos. Normalmente, estas abordagens envolvem a geração de um amplo conjunto de possibilidades, que posteriormente é selecionado por uma função de avaliação.

Este modelo se torna interessante para definir comportamentos reativos e adaptativos de criaturas arbitrárias, no entanto, não é possível exercer um controle fino sobre os resultados obtidos através deste método, o que dificulta a sua aplicação na modelagem de máquinas e periféricos com funcionamento conhecido e bem determinado.

\subsubsection{Sistema baseado em regras}

O sistema baseado em regras (rule-based system) utiliza um conjunto de condições para definir o comportamento de uma determinada criatura ou objeto virtual. Estas condições são utilizadas para verificar continuamente o estado de um determinado grupo de informações. Caso alguma destas condições seja satisfeita, 
uma determinada ação será executada.

Estes sistemas apresentam três componentes principais: um conjunto de regras (rule base), um conjunto de informações (working memory) e uma máquina de inferência (inference engine).

- Regras: O conjunto de regras representa o modelo que será usado para definir o comportamento da criatura ou objeto virtual;

- Memória: A memória contém informações relevantes a respeito do estado do objeto e do ambiente em que o mesmo está inserido;

- Máquina de Inferência: A máquina de inferência é responsável por aplicar o conjunto de regras às informações presentes na memória. Caso uma ou mais regras sejam satisfeitas, a máquina de inferência utiliza um determinado critério para escolher uma das regras satisfeitas e executar a ação associada com a mesma.

Nestes sistemas, as regras são verificadas a cada passo da simulação. Normalmente, as ações executadas pela máquina de inferência alteram o estado da memória, fazendo com que no próximo passo de execução, o grupo de regras satisfeitas seja diferente.

O trabalho realizado por Reynolds (1987) teve grande impacto no meio acadêmico ao representar o comportamento de um bando de pássaros através de um conjunto pequeno de regras distribuídas. Neste trabalho, cada pássaro de Reynolds precisa respeitar três regras básicas: Evitar colisão com outros pássaros e objetos, manter a velocidade semelhante com a dos pássaros vizinhos e procurar manter-se no centro do bando.

Ao aplicar estas três regras básicas à todos os pássaros virtuais, Reynolds mostrou que é possível obter como resultado um comportamento semelhante ao de um bando de pássaros reais.

Outro trabalho de destaque foram os peixes artificiais de Tu e Terzopoulos (1994). Estes peixes têm o seu comportamento, ou as suas intenções, representados por um sistema baseado em uma hierarquia de regras.

Conforme apresentado na figura 2.5, em um sistema onde as regras estão dispostas de forma hierárquica, cada regra pode causar a verificação de outras, e assim sucessivamente, até que uma determinada regra execute uma ação. Neste momento, a ação executada poderá alterar as informações presentes na memória. 


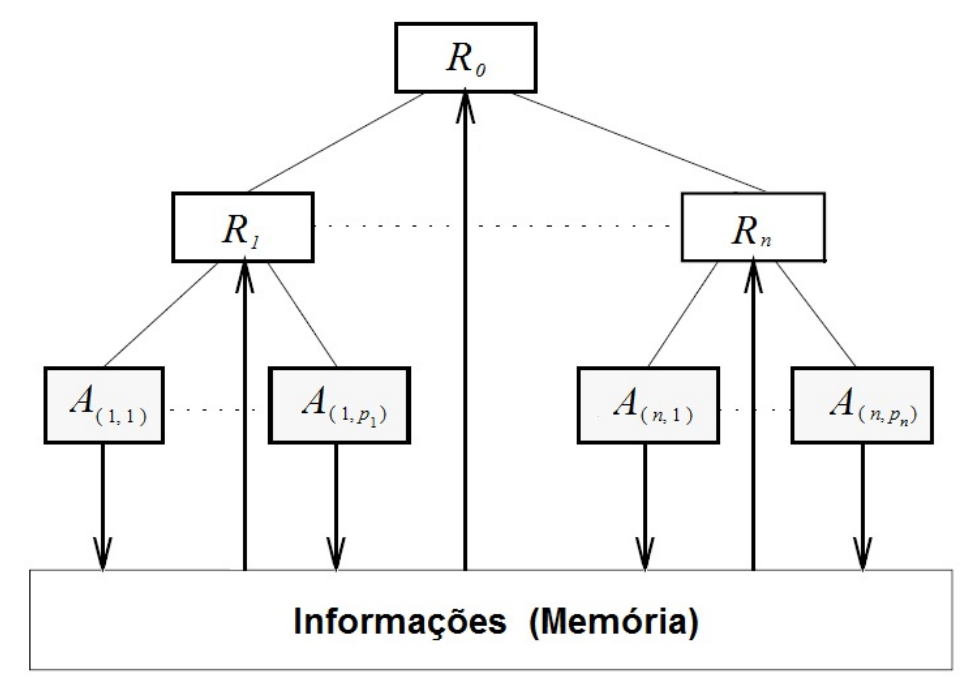

Figura 2.5: Sistema de regras em hierarquia.

A abordagem de se representar uma criatura virtual através de um sistema de regras se mostra como uma alternativa interessante, pois provê um mecanismo com controle mais fino sobre os resultados desejados quando comparado com uma rede de sensores-atuadores.

No entanto, esta abordagem não é muito utilizada para descrever o funcionamento de objetos e máquinas, isto porque este modelo se mostra mais adequado para controlar sistemas que executam continuamente no tempo e cujo comportamento é influenciado por um conjunto de fatores que podem ser alterados fora do escopo do objeto simulado.

Desta forma, caso o comportamento de uma criatura ou o funcionamento de um objeto dependa de fatores que possam ser alterados sem o seu conhecimento, será necessário verificar todos estes fatores em todos os passos da simulação para determinar alterações no seu comportamento. Estas características favorecem a aplicação do sistema baseado em regras.

No entanto, o funcionamento de máquinas e ferramentas utilizadas em aplicações de treinamento normalmente não apresenta esta característica, prejudicando a aplicação deste modelo nestes casos.

Apesar disto, esta técnica tem sido usada com sucesso para representar criaturas e agentes virtuais cujo comportamento é fortemente influenciado por fatores externos (TU; TERZOPOULOS, 1994; DEV et al., 2007).

No trabalho de Dev et al. (2007), desenvolvido na escola de medicina de Stanford, sistemas baseados em regras são utilizados para modelar o comportamento de pacientes virtuais em uma aplicação para o treinamento de equipes médicas. 
Neste trabalho, Dev Parvati comenta que apesar da flexibilidade desta técnica, para obter comportamentos mais interessantes é necessário considerar muitas variações dos parâmetros do cenário, tornando o modelo extremamente complexo, de difícil entendimento e manutenção.

\subsubsection{Máquina de estados}

A máquina de estados é o modelo mais tradicional para representar o funcionamento de objetos, máquinas e ferramentas. Este modelo é composto por três elementos principais: estados, transições e ações.

O funcionamento de uma máquina de estados é determinado pela sequencia de símbolos presentes na sua entrada de dados. A cada interação, um símbolo é retirado da entrada e utilizado para determinar qual transição será efetuada para desativar o estado corrente e determinar o novo estado a ser ativado.

Este modelo ainda prevê que ações sejam associadas aos principais eventos de uma máquina de estados. Estas ações podem ser classificadas da seguinte forma:

- Ação de Entrada de Estado: É executada ao entrar em um determinado estado. Neste caso, a ação a ser executada depende unicamente do estado ativado, não sendo considerada a transição usada para ativá-lo;

- Ação de Saída de Estado: Esta ação é executada sempre ao sair de um determinado estado, independente de qual transição foi usada para desativálo;

- Ação de Entrada de Dados: A ação a ser executada neste caso, depende do estado corrente e do símbolo obtido;

- Ação de Transição: É executada sempre que uma determinada transição ocorrer;

A representação de uma máquina de estados pode ser feita através de uma tabela ou através de um diagrama, como no exemplo da figura 2.6. Neste exemplo, o modelo macro de uma máquina é apresentado de forma simples, identificando apenas os seus principais estados de operação.

Embora o diagrama observado na figura 2.6 seja simples e de fácil compreensão, ao representar o funcionamento de sistemas mais complicados, o modelo tradicional de máquina de estados se mostra inapropriado, apresentando resultados difíceis de compreender e documentar. Isto ocorre porque o modelo tradicional 


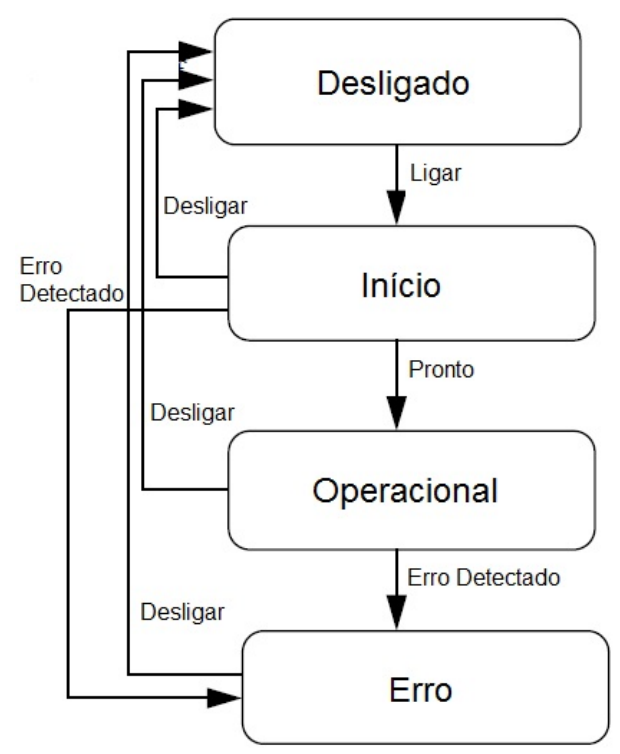

Figura 2.6: Exemplo de uma máquina de estados. Extraído de (DOUGLASS, 2001).

apresenta dois problemas fundamentais: a ausência de níveis de abstração e a falta de estados concorrentes (DOUGLASS, 2001).

O problema da ausência de níveis de abstração é evidenciado ao representar um sistema complexo, que é composto por um conjunto de subsistemas. Por exemplo, o modelo de uma aeronave pode ser interpretado como uma composição dos modelos do seu subsistema elétrico, mecânico, hidráulico entre outros.

Neste caso, ao modelar o funcionamento destes objetos, todos os seus estados serão representados da mesma forma, sem nenhum recurso para ilustrar os diferentes níveis de abstração presentes nestes objetos, o que complica a interpretação do diagrama resultante.

A falta de estados concorrentes, outro problema fundamental deste modelo, pode ser observado por um efeito conhecido como "explosão do número de estados". Suponha, por exemplo, que o equipamento apresentado na figura 2.6 possa funcionar de duas formas: na tomada, ou com o auxílio de uma bateria. Para representar estes dois modos de funcionamento, foi necessário duplicar o número de estados presentes no modelo original, como ilustrado na figura 2.7.

Em 1987, com o intuito de superar os problemas encontrados nas máquinas de estados tradicionais, David Harel propôs uma linguagem gráfica conhecida como Statecharts (HAREL, 1987). Esta linguagem contém todos os recursos do modelo tradicional de máquina de estados, porém, com alguns conceitos adicionais, entre eles, a possibilidade de criar máquinas hierárquicas e concorrentes. 


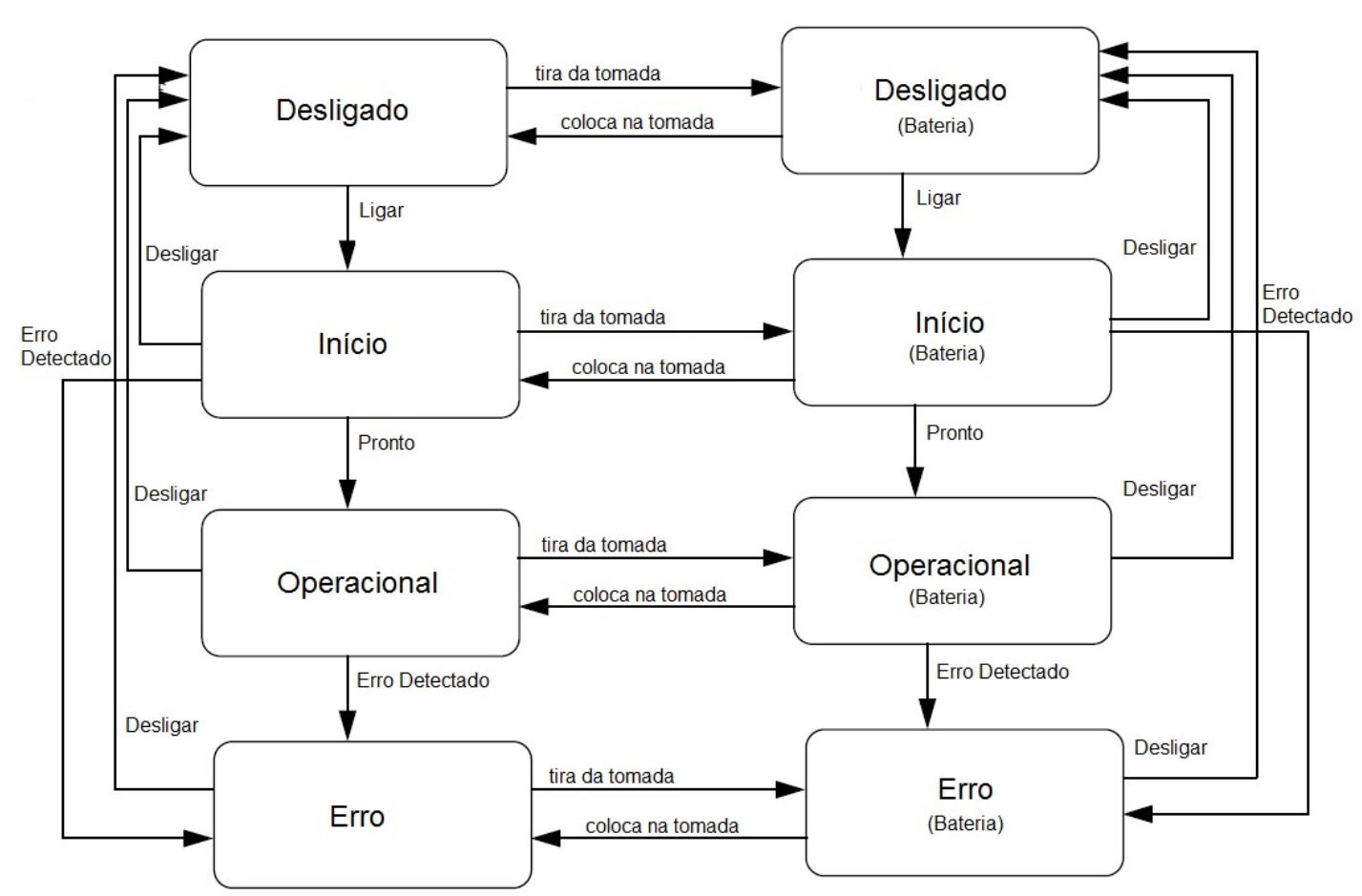

Figura 2.7: Máquina de estados para equipamento com bateria. Extraído de (DOUGLASS, 2001).

As contribuições de David Harel foram posteriormente adaptadas e incluídas no padrão UML (Unified Modeling Language) versão 2 (OMG, 2010).

O trabalho apresentado por Ahmad et al. (1994), e posteriormente revisitado por Cremer, Kearney e Papelis (1995), propõe um modelo conhecido como HCSM (Hierarchical Concurrent State Machines). Este modelo apresenta características semelhantes ao proposto por David Harel, incluindo as suas duas principais contribuições: hierarquia e concorrência.

No modelo HCSM, os diagramas resultantes são muito semelhantes aos obtidos com o modelo tradicional, com exceção de alguns elementos que foram incluídos. Por exemplo, para representar o conceito de hierarquia, cada estado de uma determinada máquina pode conter outra máquina de estados, de forma recursiva. Este recurso permite modelar sistemas com diversas camadas e níveis de abstração, incluindo seus subsistemas sem prejudicar a interpretação do diagrama.

Já o conceito de concorrência permite que uma determinada máquina tenha diversos estados ativos simultaneamente, desde que estes estados não estejam interconectados por nenhuma transição. Sendo assim, estas máquinas podem ser classificadas de duas formas: sequencial ou paralela.

Uma máquina é considerada sequencial quando todos os seus estados estão 
conectados por transições. Quando não existirem transições entre dois grupos quaisquer de estados, estes poderão ser ativados simultaneamente e, portanto, a máquina é considerada paralela. Este recurso permite representar sistemas complexos, sem multiplicar o número de estados utilizados.

Além disso, cada estado representado através do modelo HCSM contém três novos conceitos: um conjunto de Entradas e Saídas, uma Função de Atividade e um Painel de Controle. Estes três novos conceitos são apresentados a seguir:

- Entradas e Saídas de Dados: Cada estado da máquina de Cremer apresenta um conjunto de Entradas e Saídas. Estas portas de Entrada e Saída são usadas criar um fluxo de dados, transmitindo informações através de conexões entre estados da mesma máquina. Desta forma, os estados de uma determinada máquina estão conectados não somente através de transições, mas também através de canais de comunicação;

- Função de Atividade: A função de Atividade de um estado é uma rotina que determina o funcionamento do objeto que está sendo modelado. Cada estado pode conter uma Função de Atividade diferente. Uma das responsabilidades desta função é determinar os valores das portas de Saída do seu estado, podendo utilizar para isto, os valores presentes nas suas portas de Entrada e nas portas de Saída dos seus estados filhos;

- Painel de Controle: O Painel de Controle de um determinado estado contém informações para alterar o funcionamento do mesmo. O mecanismo de hierarquia permitiu que diversos sistemas fossem modularizados e reutilizados em diversas partes do modelo. Este painel de controle permite que estes módulos sejam parametrizados para o contexto em que os mesmos estão sendo utilizados;

O exemplo ilustrado na figura 2.8, apresenta dois tipos de diagrama para uma mesma máquina de estados. O primeiro diagrama (esquerda) apresenta a hierarquia e as transições, identificando as submáquinas sequenciais e as paralelas. O segundo diagrama (direita) apresenta o fluxo de dados e a função atividade.

A principal motivação para o trabalho de Cremer era obter mecanismos para representar o comportamento de motoristas virtuais no simulador de veículos da Universidade de Iowa (KUHL et al., 1995).

Na mesma época, Donikian e Rutten (1995) propuseram o modelo HPTS (Hierarchical Parallel Transition System). Este modelo é extremamente seme- 


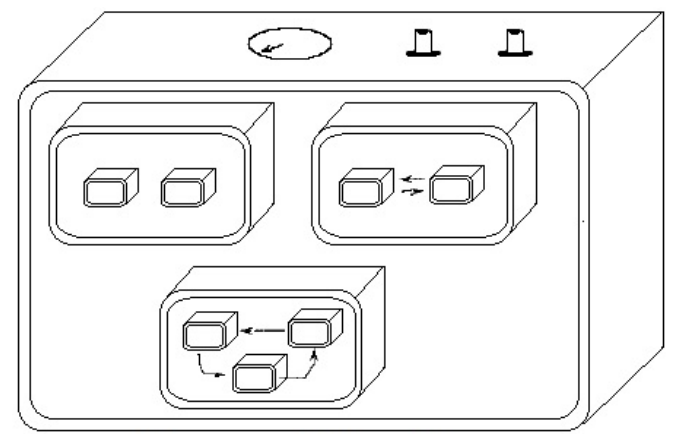

Diagrama de Transição

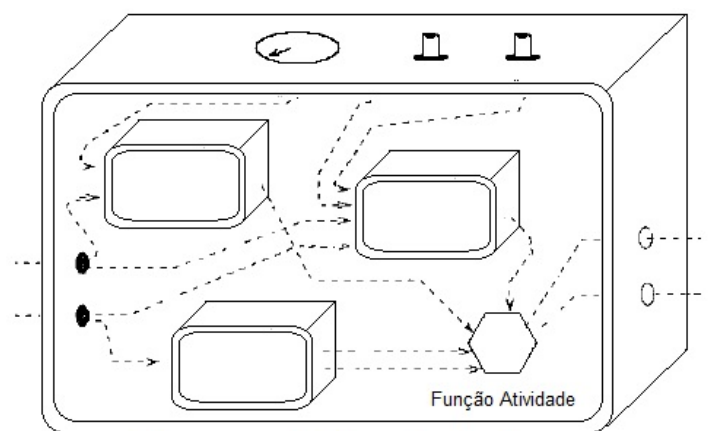

Diagrama de Fluxo de Dados

Figura 2.8: Máquina de estados hierárquica e concorrente. Extraído de (CREMER; KEARNEY; PAPELIS, 1995).

lhante ao HCSM, e também utiliza máquinas de estados hierárquicas, e com fluxo de dados.

Além disto, Donikian (2001) também propôs uma linguagem de programação em script para a representação destas máquinas. Neste caso, um pré-compilador interpretava o programa elaborado em script e gerava um código equivalente na linguagem de programação $\mathrm{C}++$.

Os conceitos apresentados por Cremer e Donikian, como hierarquia e paralelismo de estados, resolvem os principais problemas do modelo tradicional. O que torna possível representar objetos complexos sem comprometer o entendimento, a documentação e a manutenção destes modelos.

\subsubsection{STORM}

O modelo STORM (MOLLET; GERBAUd; ARNALDI, 2007) é utilizado para descrever os objetos no projeto GVT. Este modelo descreve os objetos do cenário de treinamento através de suas capacidades. Estas capacidades podem ser interpretadas como o conjunto de ações que o usuário pode exercer em um determinado objeto.

Conforme ilustrado na figura 2.9, os objetos STORM contém os seguintes elementos: Atividade, Interface e Capacidade.

As atividades são rotinas que alteram o comportamento do objeto modelado. Algumas destas rotinas são conhecidas apenas internamente e, portanto, não podem ser utilizadas diretamente pelo usuário da aplicação.

A Interface é o mecanismo que torna uma determinada Atividade pública, ou seja, apenas através de uma Interface o usuário poderá ter acesso a uma 
determinada Atividade. A Capacidade é o nome dado a uma Atividade mais a sua respectiva Interface.

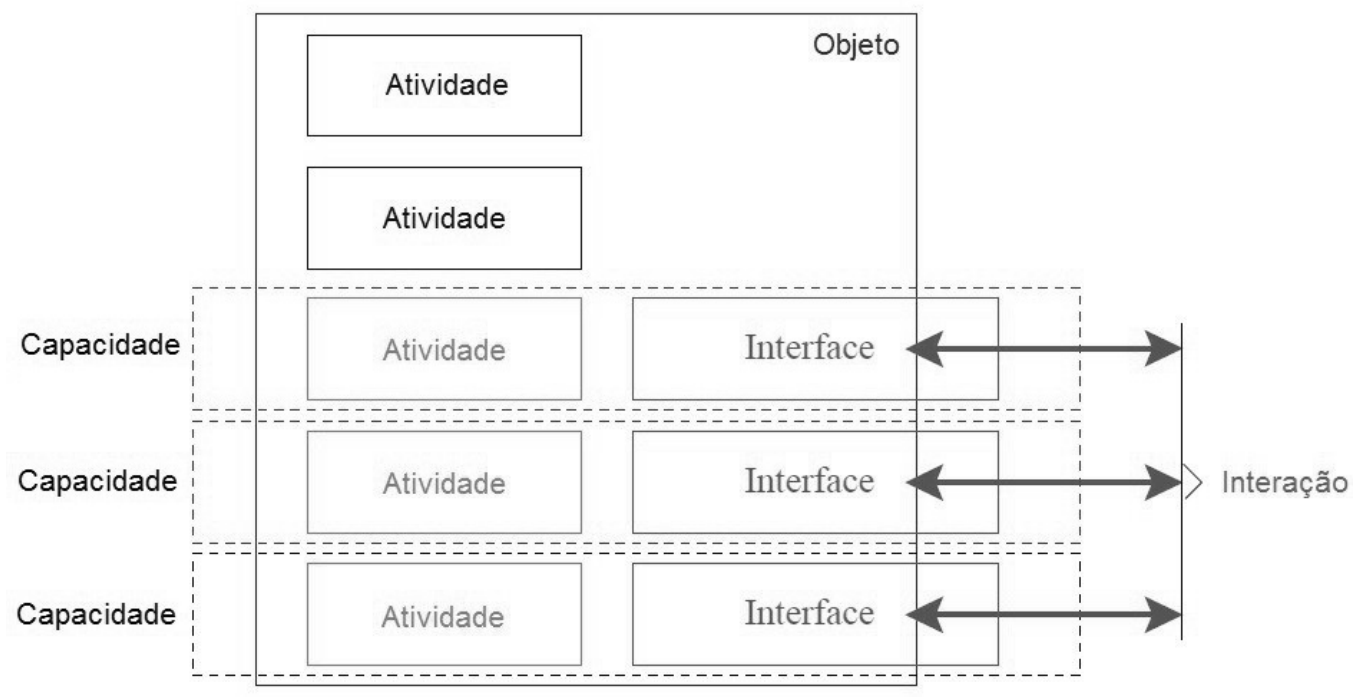

Figura 2.9: Descrição do objeto STORM. Extraído de (MOLLET; GERBAUD; ARNALDI, 2007).

Segundo Mollet, Gerbaud e Arnaldi (2007), o modelo STORM não impõe nenhuma restrição quanto a técnica usada para modelar o funcionamento destes objetos. Embora a técnica mais utilizada no projeto GVT seja o HPTS (DONIKIAN, 2001), contendo máquinas de estados paralelas e hierárquicas, é possível utilizar outras ou até mesmo várias técnicas em conjunto.

Desta forma, o modelo STORM é apenas um mecanismo de abstração para separar os recursos oferecidos por um determinado objeto, dos detalhes da sua implementação. Esta técnica foi usada também por Kallmann e Thalmann (1998), no seu trabalho conhecido como Objetos Inteligentes (Smart-Objects).

A plataforma GVT foi planejada exclusivamente para o treinamento de procedimentos, este fato é reforçado pelo paradigma de interação usado pela ferramenta. Para manipular os objetos presentes no cenário, basta clicar no objeto desejado e um menu dinâmico será apresentado contendo todas as opções de interação declaradas através da linguagem STORM.

Nesta abordagem, todos os objetos do cenário virtual são manipulados através da sua interface, ocultando os detalhes da sua implementação. A concentração destas informações no próprio objeto facilita a sua reutilização e enfatiza o encapsulamento de dados, o que remete aos conceitos de programação orientada a objetos e suas vantagens. 


\subsubsection{Descrição do procedimento}

Após a descrição do funcionamento de objetos virtuais, é necessário definir o procedimento que o usuário deve executar para atingir os objetivos do treinamento.

A descrição do procedimento deve conter, entre outras coisas, a sequência de operações a serem executadas pelo usuário. Esta sequência permite que o usuário seja ensinado ou avaliado, dependendo do modo de funcionamento da ferramenta. A descrição do procedimento ainda pode conter textos e imagens para auxiliar no processo de aprendizagem.

Conforme a pirâmide apresentada na figura 2.2, é importante que este procedimento seja elaborado utilizando ferramentas com maior nível de abstração. Esta abstração facilita a criação destes procedimentos por parte dos profissionais da área de treinamento, reduzindo sempre que possível a participação de cientistas da computação e programadores especializados na ferramenta.

As seções seguintes apresentam algumas técnicas utilizadas para descrever estes procedimentos.

\subsubsection{Objetivos e Restrições}

A técnica conhecida como Objetivos e Restrições (Goals and Constraints) é um mecanismo bastante utilizado no meio acadêmico para descrever os procedimentos de um treinamento. Esta técnica foi usada em trabalhos como Steve (RICKEL; JOHNSON, 1998), e em outras aplicações semelhantes (WASFY; WASFY; NOOR, 2004; QUERREC; CHEVAILLIER, 2001; BADLER; ERIGNAC; LIU, 2002).

Esta técnica consiste em descrever as etapas de um determinado procedimento através das suas pré-condições e dos seus efeitos. Neste caso, uma etapa pode ser interpretada como uma ação que o usuário precisa executar em um determinado objeto virtual.

Desta forma, toda a ação possui um conjunto de pré-condições, e somente quando estas pré-condições forem verdadeiras, a ação estará disponível para execução. Já os efeitos de uma ação, por sua vez, determinam os resultados que serão obtidos ao final da sua execução.

As pré-condições podem conter, por exemplo, a verificação de propriedades que representam o estado de um determinado objeto do cenário. Já os efeitos, podem implicar na modificação destas propriedades.

Neste modelo, o procedimento a ser executado pelo usuário não é declarado 
de forma explícita. O procedimento é representado por um conjunto de condições que precisa estar satisfeito ao final do treinamento. O usuário deve, portanto, encontrar uma sequência de ações que satisfaça as condições estabelecidas pelo procedimento.

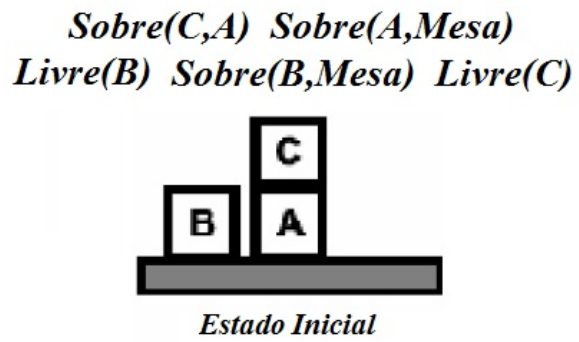

Sobre(x,z) Livre(x)

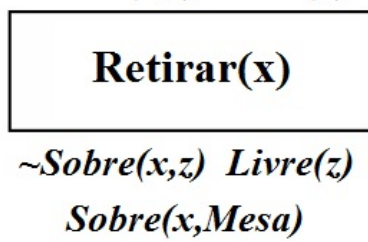

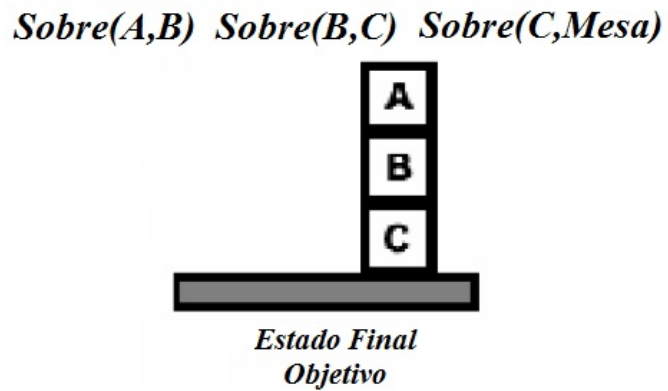

Livre(x) Sobre(x,z) Livre(y) Empilhar(x,y)

$\sim$ Sobre $(x, z) \sim \operatorname{Livre}(y)$

Livre(z) Sobre(x,y)

Figura 2.10: Exemplo de Objetivos e Restrições.

A figura 2.10 apresenta um exemplo que contém o estado inicial e final para a posição dos blocos $A, B$ e $C$. Neste caso, o usuário deve manipular estes blocos para colocá-los na posição final, executando apenas as ações Retirar e Empilhar. Cada uma destas ações contém o seu conjunto de pré-condições e efeitos, também ilustrados na figura.

Normalmente, as pré-condições e os efeitos de uma determinada ação, são representados utilizando variáveis (como $x, y$ e $z$ ). Ao aplicar estas ações, as variáveis são substituídas pelos nomes dos objetos envolvidos na operação.

Como o procedimento não é declarado explicitamente, para que a própria ferramenta de treinamento tenha condições de demonstrar a execução das atividades, é necessário aplicar um algoritmo de planejamento.

Os algoritmos de planejamento são aplicados para encontrar uma sequência de ações, que ao ser executada, atinja as metas do procedimento. Nesta área de pesquisa, podemos destacar o método de Planejamento por Ordenação Parcial (Partial Order Plannning) (RUSSELL; NORVIG, 2009).

Na figura 2.11, demonstramos uma sequência de ações que resolve o problema apresentado anteriormente. Apesar de o exemplo apresentar um problema trivial, é importante observar que, dependendo do número de ações disponíveis 


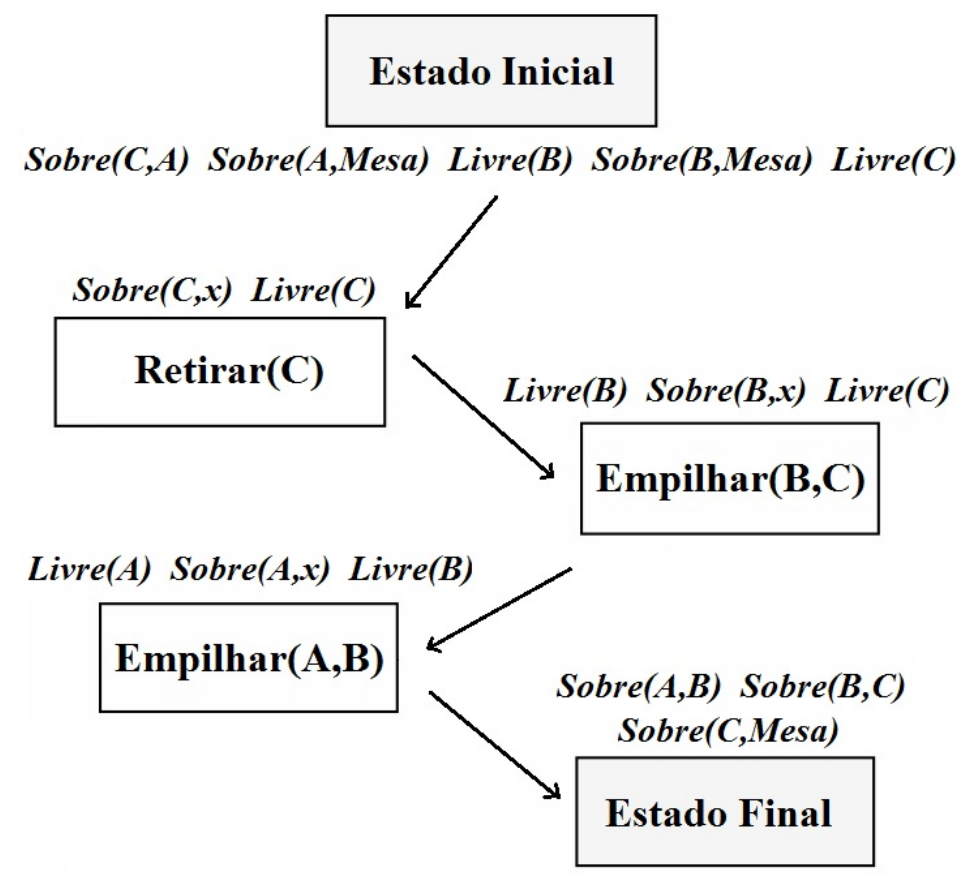

Figura 2.11: Solução para exemplo de Objetivos e Restrições.

no sistema, podem existir inúmeras soluções para o mesmo problema. Ou seja, é possível que diversas sequências diferentes de ações sejam capazes de atingir os objetivos do treinamento.

Este modelo ainda permite que as etapas do procedimento sejam organizadas de forma hierárquica. Neste caso, cada etapa pode ser interpretada como uma composição de outras etapas, ao invés de uma única ação do usuário. Esta organização favorece a criação de módulos de atividades que podem ser reaproveitados em diferentes procedimentos.

Segundo Gerbaud et al. (2008), apesar de flexível e modular, este modelo pode se mostrar desnecessariamente complexo na representação de alguns procedimentos, principalmente aqueles cuja sequência de ações é simples e bem definida.

Nestas situações, ao invés de declarar explicitamente o procedimento, como é feito em outros modelos, a técnica de Objetivos e Restrições exige que um conjunto de etapas seja definido, cada etapa com pré-condições e efeitos, e ainda garantir que apenas as soluções desejáveis sejam encontradas pelo algoritmo de planejamento.

Por conta disto, o uso deste método pode ser desfavorecido em algumas aplicações, como no treinamento de atividades de risco, uma vez que este tipo de treinamento possui instruções bem definidas e, portanto, raramente envolve soluções com trajetos alternativos. 


\subsubsection{Grafos}

O modelo apresentado por Ponder et al. (2003) representa de forma explícita as relações de dependência existentes entre todas as etapas do procedimento. Esta representação é feita através de grafos, que determinam a ordem dos passos da atividade.

Estes grafos, ilustrados na figura 2.12, possuem quatro elementos principais: a etapa do procedimento (step), a transição (transition), a ação (decision) e o grupo de ações (decision set).

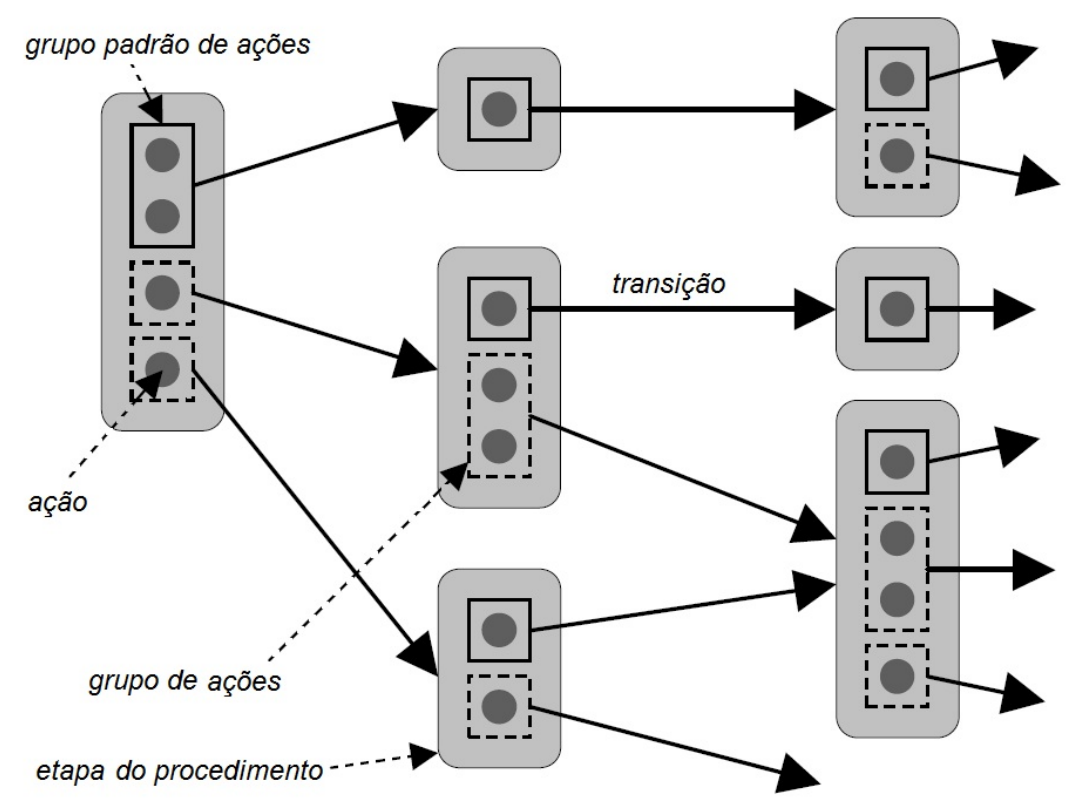

Figura 2.12: Representação do procedimento através de grafos. Extraído de (PONDER et al., 2003).

De acordo com a definição de Ponder, cada etapa do procedimento pode conter um número arbitrário de ações. Estas ações são divididas em grupos, e cada grupo está conectado à próxima etapa do procedimento através de uma transição.

Durante o treinamento, o usuário pode executar qualquer ação que pertença à etapa corrente do procedimento. Quando todas as ações de um determinado grupo forem executadas, a transição associada com este grupo irá determinar a próxima etapa do procedimento. Como cada grupo de ações contém a sua própria transição, este mecanismo disponibiliza diversas alternativas para o usuário concluir o treinamento.

Neste modelo, as ações contidas em um determinado grupo podem ser executadas em qualquer ordem. Sendo assim, sempre que for necessário impor uma 
ordem entre duas ações distintas, estas ações precisam ser colocadas em etapas diferentes do procedimento.

O grupo padrão de ação (default), ilustrado na figura 2.12 por retângulos de borda contínua, é utilizado apenas para sinalizar para a própria ferramenta de treinamento, qual o grupo de ações que a mesma deve executar quando o usuário apresentar dificuldades e solicitar ajuda sobre como avançar no procedimento.

Esta representação permite descrever de forma clara as dependências existentes entre as etapas do procedimento e as ações contidas em cada uma destas etapas. Além disto, esta representação permite colocar caminhos alternativos de forma simples, interessante para situações em que existe mais de uma maneira de cumprir com os objetivos do treinamento.

Apesar de a representação ser um pouco diferente, os grafos de Ponder podem ser interpretados como uma máquina de estados, onde uma etapa do procedimento é um estado da máquina e um grupo de ações estabelece as condições para que uma determinada transição seja efetuada.

Por conta da sua simplicidade, o modelo de Ponder apresenta algumas limitações. Estas limitações podem restringir a aplicação deste modelo, ou aumentar desnecessariamente a complexidade dos grafos do procedimento.

A primeira ilustração da figura 2.13 (esquerda), apresenta uma etapa com dois grupos de ações, o primeiro grupo contém as ações $\{A, B\}$ e o segundo contém as ações $\{C, D\}$. De acordo com Ponder, o usuário pode completar esta etapa executando apenas as ações do primeiro grupo, independente da ordem. No entanto, neste modelo, o usuário pode proceder executando a ação $A$, em seguida a ação $C$, e apenas depois concluir a etapa executando a ação $B$. Neste caso, apesar de concluir a etapa, o usuário abandonou uma das alternativas de forma incompleta, executando parcialmente o segundo grupo de ações.

Este comportamento pode ser considerado inapropriado em algumas atividades de treinamento. Para corrigir este problema, seria necessário declarar que estes grupos são mutuamente exclusivos, ou seja, ao iniciar a execução de um dos grupos, o usuário deve concluí-lo, ou desfazer o que foi feito antes de iniciar outra alternativa.

Como o modelo de Ponder não possui este recurso, a segunda ilustração da figura 2.13 (direita) apresenta uma alternativa para contornar este problema. Nesta alternativa, os grupos originais foram separados em diversas etapas. A primeira etapa apresenta todas as ações originais, porém, cada ação em um grupo 
individual. Nas etapas seguintes, apenas a ação necessária para concluir os grupos originais foi disponibilizada, impedindo o usuário de iniciar uma nova alternativa.

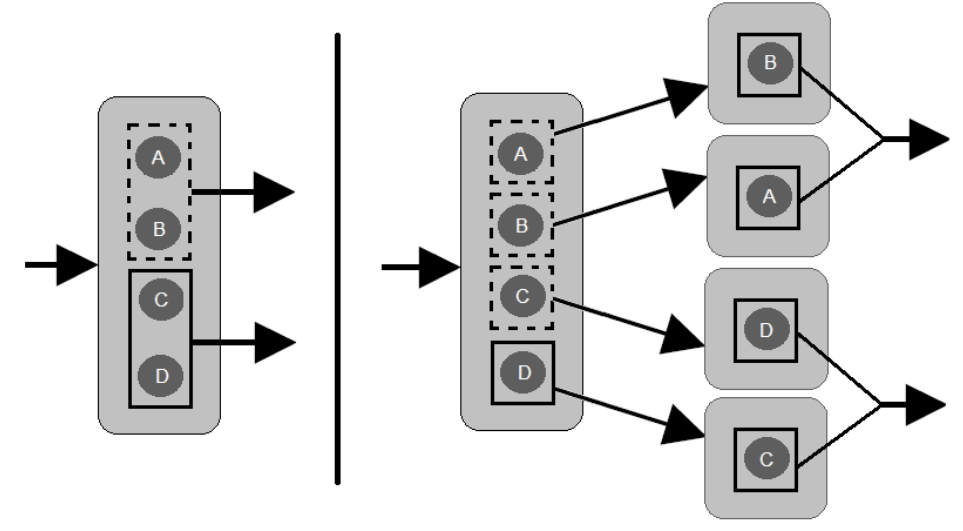

Figura 2.13: Dois grupos de ações, mutuamente exclusivos.

O exemplo ilustrado apresenta uma solução relativamente simples, pois envolve grupos de decisão com apenas duas ações. No entanto, caso seja necessário proteger a execução de grupos com diversas ações, o número de combinações aumenta consideravelmente, prejudicando a interpretação dos grafos ou até mesmo inviabilizando a sua implementação.

Apesar destas limitações, a solução de Ponder apresenta um modelo simples para a declaração de procedimentos, facilitando a criação de novos cenários por profissionais sem conhecimento técnico da ferramenta.

\subsubsection{Diagrama LORA}

A alternativa apresentada por Mollet e Arnaldi (2006) é o diagrama LORA. Este diagrama é utilizado para representar de forma explícita as relações existentes entre as diferentes etapas de um procedimento. Atualmente, este diagrama é utilizado para descrever as atividades de treinamento do projeto GVT (GERBAUD et al., 2008).

O diagrama LORA contém dois elementos principais: os blocos, que representam as etapas do procedimento (steps), e as conexões (links), que definem as relações de dependência entre estes blocos.

Para determinar as relações de dependência entre as etapas do procedimento, este modelo utiliza o conceito de sinal, que se propaga pelo diagrama seguindo as regras dos seus principais elementos.

De acordo com a figura 2.14, o elemento do diagrama que representa as conexões possui um número arbitrário de entradas e saídas. Neste elemento, o sinal 


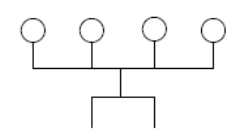

Figura 2.14: Conector do diagrama LORA. Extraído de (MOLLET; ARNALDI, 2006).

será transmitido para todas as suas saídas apenas quando todas as suas entradas estiverem com sinal disponível.

Os blocos que representam as ações do usuário contêm apenas uma entrada e uma saída. Quando o sinal está presente em sua entrada, a tarefa fica disponível para execução. Apenas quando esta tarefa terminar de executar o sinal será transmitido para a sua saída.

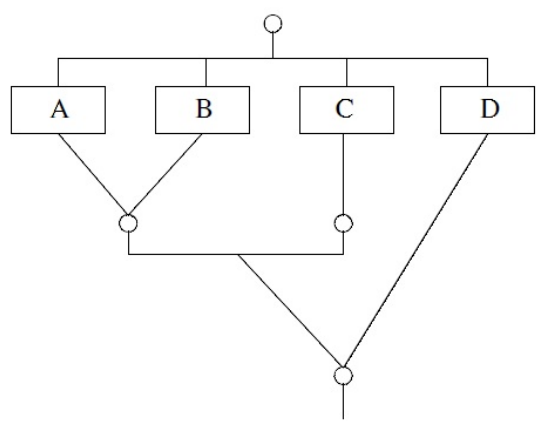

Figura 2.15: Diagrama do modelo LORA. Extraído de (MOLLET; ARNALDI, 2006).

O exemplo apresentado na figura 2.15 representa um procedimento que será concluído apenas quando as suas tarefas forem executadas de acordo com a lógica $(((A$ ou $B)$ e $C)$ ou $D)$.

O diagrama LORA ainda contém outros blocos que podem desempenhar funções específicas, entre elas: verificar determinada propriedade do cenário ou alterar alguma propriedade do cenário.

Os blocos do diagrama que verificam propriedades do cenário possuem uma entrada e duas saídas. A condição será verificada assim que o sinal estiver disponível em sua entrada. Uma das saídas terá o sinal ativado apenas se a condição for verdadeira, e a outra apenas se for falsa.

Os blocos que alteram propriedades do cenário contêm apenas uma entrada e uma saída. A propriedade será alterada logo que houver sinal em sua entrada e em seguida, o sinal será transmitido para a sua saída.

O exemplo ilustrado na figura 2.16 demonstra uma atividade que possui três 


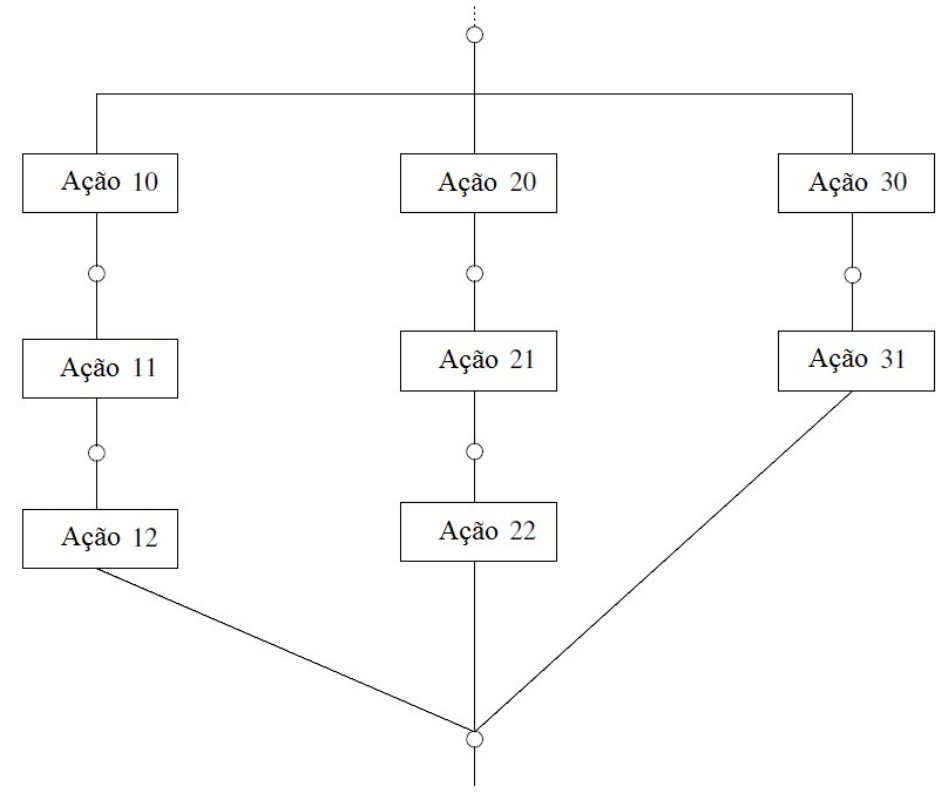

Figura 2.16: Diagrama LORA com percursos alternativos. Extraído de (MOLLET; ARNALDI, 2006).

alternativas para a sua conclusão. Neste caso, o usuário pode optar por executar as ações do trecho $1 i$, $2 i$ ou $3 i$.

Neste último exemplo, as alternativas disponíveis não são mutuamente exclusivas, ou seja, o usuário pode interromper a execução de um determinado trecho e iniciar a execução de outro, criando uma situação onde duas alternativas estão sendo efetuadas simultaneamente.

No entanto, caso isto não seja apropriado, este modelo permite proteger a execução de trechos através de blocos com funções específicas. Por exemplo, é possível inserir um bloco que verifique o valor de uma propriedade antes de entrar no trecho a ser protegido, desta forma, basta alterar o valor desta propriedade para impedir que este trecho do diagrama permaneça disponível.

Apesar de este modelo permitir a implementação de trechos mutuamente exclusivos com certa facilidade, o conceito de sinais impede a representação de procedimentos onde o usuário possa desfazer as atividades já realizadas. Este recurso é interessante em atividades que possuem diversas alternativas, como apresentado na figura 2.16 .

Neste caso, se o usuário iniciar a execução de um determinado trecho e não conseguir completá-lo, é interessante permitir que o mesmo possa desfazer as ações que foram efetuadas, antes de tentar outra alternativa, principalmente se estes trechos forem mutuamente exclusivos. No entanto, o conceito de sinais utilizado em LORA impede que diagramas com estas características sejam elaborados. 
Este modelo ainda apresenta recursos de hierarquia, ou seja, uma determinada tarefa pode corresponder a uma ação do usuário, ou a uma composição de outras tarefas representadas por outro diagrama.

Apesar de algumas limitações, o modelo LORA contém um conjunto amplo de recursos e, portanto, pode ser usado para descrever diversos procedimentos, inclusive de maior complexidade.

\subsubsection{Redes de Petri}

O trabalho apresentado por Lin et al. (2002) utiliza redes de Petri para representar as relações existentes entre as tarefas de um determinado procedimento. Neste trabalho, Lin desenvolve atividades para treinar a operação de uma máquina fresadora de pequeno porte.

Uma Rede de Petri é composta por três elementos: nós de posição (places), transições (transitions) e arcos direcionados (directed arcs).

O elemento transição é utilizado para representar uma tarefa do procedimento, e os nós de posição são usados para definir as pré-condições e os efeitos desta tarefa. Os arcos direcionados, por sua vez, são usados para conectar estas pré-condições e efeitos às suas respectivas tarefas, representando as dependências existentes entre elas.

As redes de Petri também foram usadas no trabalho de Chen et al. (2008). Neste trabalho, Chen desenvolveu um ambiente virtual para treinar a operação de diversos equipamentos complexos.

Conforme ilustrado na figura 2.17, as Redes de Petri possuem uma representação gráfica que pode auxiliar a sua utilização por profissionais sem conhecimento técnico avançado da ferramenta.

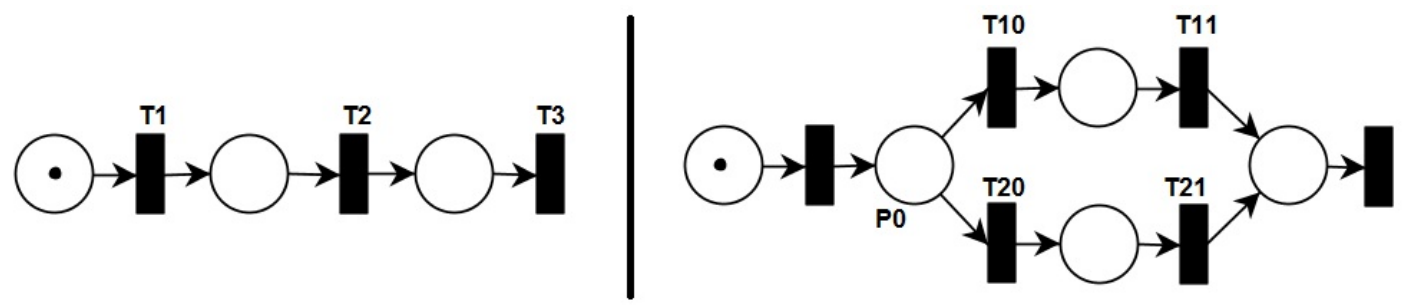

Figura 2.17: Exemplo de Redes de Petri.

A primeira ilustração desta figura (esquerda), apresenta um procedimento puramente sequencial. Neste caso, o usuário deve executar as ações correspondentes às transições T1, T2 e T3, nesta ordem, para completar a atividade. A 
segunda ilustração (direita), apresenta um procedimento com dois trechos alternativos. Neste caso, o usuário pode escolher se executará a ação correspondente às transições $T 1 i$ ou T2i.

Neste último exemplo, o diagrama que apresenta as duas alternativas foi implementado para que os trechos T1i e T2i sejam mutuamente exclusivos, ou seja, o usuário poderá executar apenas uma destas alternativas. Isto ocorre, pois ambos os trechos iniciam no mesmo nó de posição $P 0$. Desta forma, quando o usuário iniciar a execução de um dos trechos, o marcador presente na posição $P 0$ será retirado, evitando que a segunda alternativa permaneça disponível.

As redes de Petri permitem ainda que as tarefas de um determinado procedimento sejam organizadas de forma hierárquica. Esta possibilidade foi apresentada formalmente em outro trabalho de Lin (1998), que mostra que uma transição pode ser interpretada como uma ação do usuário ou como um conjunto de outras tarefas, representadas por outra rede de Petri.

Além disso, este modelo também permite representar procedimentos com caminhos de retorno, ou seja, permitindo que o usuário desfaça as ações já efetuadas e escolha outra alternativa para concluir o procedimento.

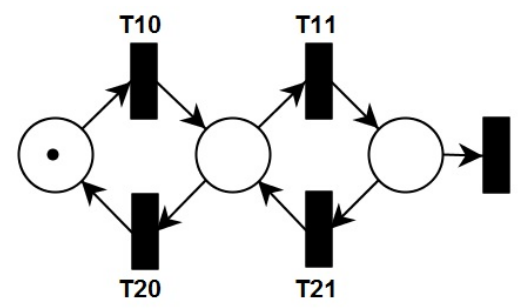

Figura 2.18: Rede de Petri com caminho de retorno.

O exemplo da figura 2.18 demonstra a implementação de um caminho de retorno. Neste exemplo, note que os arcos do trecho T2 $i$ apontam para o sentido contrário dos arcos do trecho T1i. Desta forma, o usuário pode utilizar as ações representadas pelo trecho T2i para retornar a execução do procedimento.

De acordo com os trabalhos estudados, as redes de Petri se mostram como uma alternativa interessante para realizar a representação de procedimentos, pois além de possuírem recursos suficientes para descrever relações complexas de dependência, o seu uso já foi consolidado em diversas outras áreas do conhecimento, o que promove a disponibilização de livros e tutoriais, além de softwares e ferramentas gratuitas sobre o tema. 


\subsubsection{Análise comparativa}

Esta seção do documento apresenta uma análise comparativa entre as técnicas envolvidas na criação de cenários de treinamento. Esta comparação foi elaborada utilizando os trabalhos acadêmicos comentados nas seções anteriores deste capítulo.

Tabela 2.1: Técnicas para descrição funcional de objetos virtuais.

\begin{tabular}{lccc}
\hline & $\begin{array}{c}\text { Rede de } \\
\text { Sensores } \\
\text { Atuadores }\end{array}$ & $\begin{array}{c}\text { Sistema } \\
\text { Baseado } \\
\text { em Regras }\end{array}$ & $\begin{array}{c}\text { Máquina } \\
\text { de Estados }\end{array}$ \\
\hline $\begin{array}{l}\text { Controle fino do resultado } \\
\text { Camadas de abstração }\end{array}$ & Sim & Sim & Sim \\
$\begin{array}{l}\text { Frequência de utilização em } \\
\text { criaturas ou agentes virtuais }\end{array}$ & Baixa & Alta & Sim \\
$\begin{array}{l}\text { Frequência de utilização em } \\
\text { máquinas ou ferramentas }\end{array}$ & Baixa & Baixa & Alta \\
\hline
\end{tabular}

A tabela 2.1 compara as alternativas para realizar a descrição funcional dos objetos. O modelo STORM (MOLLET; GERBAUD; ARNALDI, 2007) não foi inserido nesta tabela, pois este modelo pode ser usado com qualquer uma das outras alternativas.

As linhas da tabela que mencionam a frequência de utilização destas técnicas, referem-se apenas à sua utilização no escopo de trabalhos de treinamento. Esta frequência foi avaliada de forma qualitativa, observando unicamente os trabalhos em que as mesmas foram aplicadas.

Tabela 2.2: Técnicas para descrição do procedimento.

\begin{tabular}{lcccc}
\hline & $\begin{array}{c}\text { Objetivos } \\
\text { e } \\
\text { Restrições }\end{array}$ & Grafos & LORA & $\begin{array}{c}\text { Rede de } \\
\text { Petri }\end{array}$ \\
\hline $\begin{array}{l}\text { Representação explícita das } \\
\text { dependências }\end{array}$ & Não & Sim & Sim & Sim \\
$\begin{array}{l}\text { Organização em hierarquia } \\
\text { Caminho de retorno }\end{array}$ & Sim & Sim & Sim & Sim \\
$\begin{array}{l}\text { Trechos mutuamente exclu- } \\
\text { sivos }\end{array}$ & Sim & Narcial & Não & Sim \\
Complexidade de utilização & Alta & Baixa & Média & Média \\
\hline
\end{tabular}

1) Os grafos de Ponder suportam caminhos de retorno, porém com algumas limitações.

A tabela 2.2 resume as características das principais opções para descrever os procedimentos de treinamento. A complexidade destas técnicas também foi 
classificada de forma qualitativa, avaliando a quantidade de conceitos envolvidos na utilização destes modelos em casos reais.

\subsection{Síntese}

Este capítulo apresentou uma revisão sobre os principais trabalhos acadêmicos na área de treinamento de procedimentos em Realidade Virtual. Estes trabalhos tiveram início, de forma mais efetiva, no começo da década de 90, com o surgimento de aplicações como Steve, desenvolvido para realizar o treinamento de operações de manutenção em compressores HPAC.

Apesar do surgimento de trabalhos de treinamento para segmentos específicos da indústria, as principais plataformas de software para este tipo de aplicação tiveram início no ano de 2001. Nesta década, institutos importantes como o Fraunhofer IFF da Alemanha, e o INRIA da França, iniciaram trabalhos no desenvolvimento de arquiteturas para facilitar e acelerar a criação de aplicações de treinamento em RV.

As principais arquiteturas desenvolvidas por estes institutos foram o GVT (Generic Virtual Training), do INRIA, e a plataforma VDT (Virtual Development and Training), do Fraunhofer IFF.

Embora os trabalhos acadêmicos sobre estas plataformas não apresentem detalhes sobre as suas arquiteturas, é possível concluir que ambas estão organizadas em três camadas principais, contendo as seguintes informações: As geometrias do cenário, descrição dos objetos virtuais e suas regras de operação, e a descrição do procedimento a ser treinado.

A partir desta organização, outros trabalhos acadêmicos foram revisados para identificar técnicas e modelos que pudessem auxiliar a estruturação e a descrição das informações presentes em cada uma destas camadas.

As alternativas encontradas para representar e organizar estas informações foram apresentadas neste capitulo. Embora alguns modelos tenham pouca aplicação nas ferramentas de treinamento, outros modelos foram extraídos de trabalhos acadêmicos desta área de pesquisa e, portanto, possuem aplicação já comprovada.

O próximo capítulo utiliza as técnicas e modelos apresentados neste, para estruturar uma arquitetura de software cujo objetivo é facilitar a construção de aplicações de treinamento em RV, e promover o uso destas tecnologias no cenário nacional. 


\section{Arquitetura do arcabouço}

Este capítulo irá apresentar uma proposta para a arquitetura de software cujo objetivo é auxiliar no desenvolvimento de aplicações de treinamento em Realidade Virtual, com foco na prática de procedimentos. Este tipo de treinamento tem características peculiares, pois não envolve o aperfeiçoamento da coordenação motora do usuário, mas sim a sua compreensão a respeito de uma determinada atividade.

Desta forma, o treinamento de procedimentos não impõe requisitos elevados na elaboração de mecanismos sofisticados de interação, o que reduz o investimento necessário para o desenvolvimento e a implantação destas soluções.

No entanto, outras características se mostram importantes, como o fato de que muitos segmentos promissores para a aplicação das tecnologias de RV em treinamento exigem a reprodução de dezenas ou até centenas de procedimentos no ambiente virtual.

Portanto, a arquitetura deve facilitar a criação de novos procedimentos, reduzindo quando possível a participação de cientistas da computação e programadores, garantindo a autonomia dos profissionais da área de treinamento (subject matter experts (SME)).

Para elaborar esta arquitetura, diversas técnicas e conceitos apresentados no capítulo anterior foram utilizados integralmente ou adaptados em alguns aspectos. A próxima seção do documento apresenta uma visão geral sobre a organização desta arquitetura.

\subsection{Visão geral}

Para facilitar o processo de criação de novos cenários de treinamento, a organização desta arquitetura possui características semelhantes aos trabalhos mencionados no capítulo 2, onde todas as informações a respeito do cenário são interpretadas em tempo de execução pela biblioteca de simulação de procedimentos. 
De acordo com a figura 3.1, esta arquitetura contém três componentes principais: o Cenário de Treinamento, o gerenciador de procedimentos e um gerenciador de todos os objetos interativos presentes no cenário.

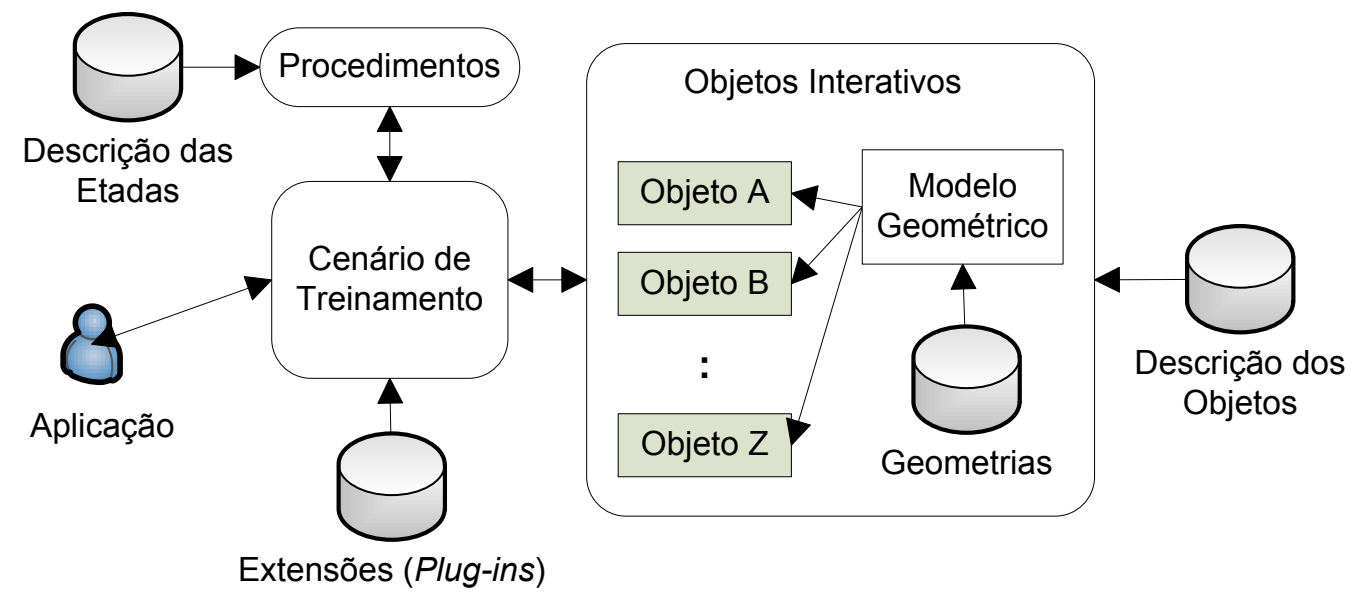

Figura 3.1: Visão geral da arquitetura.

O Cenário de Treinamento é o componente que estabelece a interface com a aplicação. Através desta interface, a aplicação pode controlar o processo de treinamento do usuário, acessando todos os objetos interativos do cenário e todos os procedimentos disponíveis.

Os objetos interativos contêm todos os seus modelos geométricos e as suas regras de funcionamento. Estes objetos interativos precisam de duas estruturas de dados: as geometrias, para a composição do modelo geométrico, e a descrição dos objetos, que identifica quais destas geometrias são objetos interativos e quais as suas principais características de funcionamento.

Os procedimentos, por sua vez, contêm informações a respeito das atividades que o usuário precisa executar nos treinamentos disponíveis. A descrição destas atividades faz referência aos objetos interativos presentes no cenário e estabelece as relações de dependência para manipular estes objetos.

A principal motivação para adotar esta estrutura foi separar as informações dos objetos interativos das informações que envolvem a descrição de uma nova atividade de treinamento. Esta separação permite que estes conteúdos sejam elaborados de forma independente, pois cada conteúdo exige a participação de profissionais com perfis diferentes.

A criação de novos objetos interativos, por exemplo, requer a realização de tarefas mais complexas e trabalhosas, exigindo a utilização de mão-de-obra especializada, normalmente, programadores e modeladores de conteúdo 3D. No entanto, a criação destes objetos ocorre com menor frequência, uma vez que um 
determinado cenário interativo pode acomodar um número arbitrário de novos procedimentos.

Já a reprodução de novas atividades envolve a realização de tarefas mais simples e, portanto, reduz a necessidade de mão-de-obra especializada. Esta característica permite que estes procedimentos sejam criados com mais rapidez, facilitando o trabalho dos profissionais da área de treinamento.

Os detalhes desta arquitetura são apresentados nas seções seguintes.

\subsection{Cenário de Treinamento}

O Cenário de Treinamento é o componente que oferece todos os recursos para que a aplicação possa elaborar de forma fácil um ambiente para treinamento virtual. Nesta arquitetura, o Cenário funciona como uma interface entre a aplicação e os outros elementos do treinamento, como os procedimentos e os objetos interativos.

Através desta interface, a aplicação pode consultar todos os objetos disponíveis no cenário e obter informações sobre como estes objetos podem ser manipulados. Além disto, a aplicação pode obter informações sobre os procedimentos disponíveis e determinar quais destes procedimentos serão praticados pelo usuário.

Esta interface foi elaborada para permitir que diversos tipos de objetos interativos e diversos tipos de procedimentos sejam utilizados, sem afetar a estrutura da aplicação. Conforme mencionado no capítulo anterior, existem diversos modelos para descrever as regras de funcionamento dos objetos, e também diversas alternativas para definir as etapas de um procedimento.

Cada uma destas alternativas apresenta vantagens e desvantagens que devem ser consideradas dependendo do caso de uso. No entanto, para não adotar uma única técnica ou modelo, e consequentemente restringir o uso desta arquitetura, a interface do Cenário foi elaborada para que as diversas técnicas, tanto para descrição de objetos como procedimentos, possam ser utilizadas simultaneamente, no mesmo ambiente virtual.

Desta forma, a ferramenta de treinamento pode manipular um conjunto amplo de objetos e procedimentos, independente da técnica utilizada para representar o seu funcionamento. Apesar da flexibilidade desta abordagem, ao implementar esta arquitetura, não será possível antecipar todos os casos de uso e desenvolver todas as técnicas necessárias. 
Além disto, com o passar do tempo, muitas destas técnicas serão aprimoradas e novas alternativas serão desenvolvidas. Para que estas novas alternativas sejam incorporadas facilmente nos novos cenários de treinamento, a arquitetura prevê o uso de extensões (plug-ins).

\subsubsection{Extensões (plug-ins)}

As Extensões (plug-ins) são normalmente implementadas através de bibliotecas de ligação dinâmica (dynamic-link libraries), disponíveis em sistemas operacionais modernos. Este recurso permite que uma determinada aplicação possa ter o seu conjunto de recursos ou funcionalidades ampliado, sem que esta aplicação precise ser alterada.

Desta forma, ao utilizar o conceito de extensões, esta arquitetura permite que uma possível implementação possa manter os seus modelos de objetos e procedimentos atualizados, ou adaptá-los para um caso de uso específico.

\subsection{Modelo geométrico}

O modelo geométrico contém todas as informações visuais do ambiente virtual, como malhas poligonais, materiais, luzes, texturas etc. Estas informações podem ser elaboradas por softwares de modelagem poligonal, ou importadas de ferramentas de CAD.

Independente do processo utilizado para construir o ambiente virtual, para o correto funcionamento desta arquitetura, é importante que a cena resultante seja capaz de representar as seguintes informações: hierarquia de transformações, animações e instâncias. Estes três recursos permitem que cenas complexas sejam representadas de forma organizada e sem redundâncias.

Existem diversas bibliotecas de software, disponíveis gratuitamente, que facilitam a construção de um cenário virtual. Todas estas bibliotecas funcionam de forma muito semelhante - as informações do cenário são carregadas de um determinado arquivo e organizadas na memória principal do computador para serem enviadas à placa gráfica no processo de renderização da cena.

Conforme ilustrado na figura 3.2, a organização da cena de forma hierárquica é a estrutura mais utilizada para representar os elementos do ambiente virtual. Esta organização facilita a manipulação dos elementos da cena e a aplicação de algoritmos para otimizar o processo de renderização. 


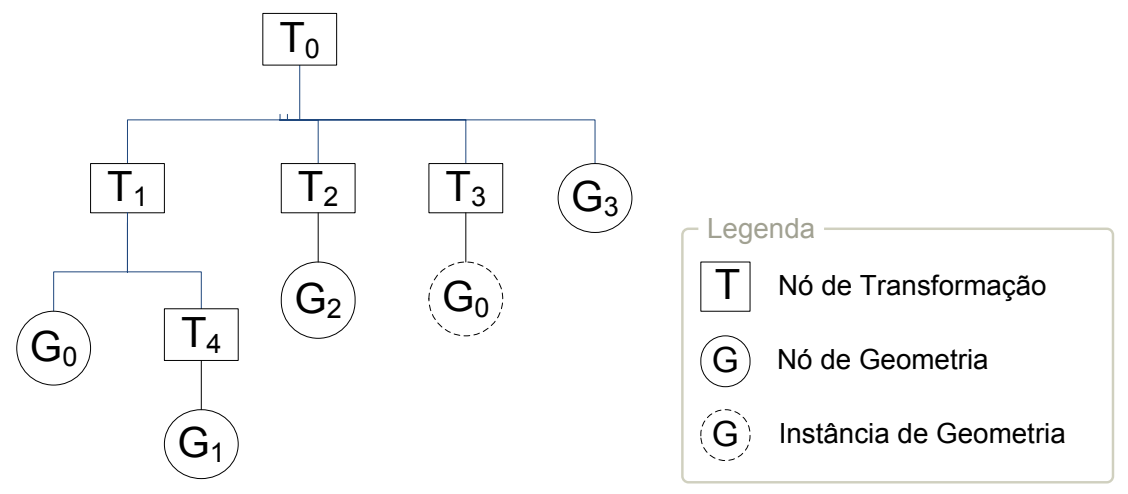

Figura 3.2: Hierarquia da cena.

Esta hierarquia, também conhecida como grafo de cena (scene graph), é composta por um conjunto de nós distintos, onde cada nó desempenha uma função diferente nesta organização. $\mathrm{O}$ dois tipos de nós mais frequentes na hierarquia são: os nós de transformação e os nós de geometria.

Os nós de geometria contêm a rede poligonal utilizada para descrever o formato dos objetos, além de conter a cor dos vértices, a textura e outras características do material. Os nós de transformação, por sua vez, contêm uma matriz cujo objetivo é alterar a posição de todas as geometrias conectadas abaixo desta transformação.

Desta forma, as geometrias são os últimos elementos desta árvore hierárquica, acima delas existe um conjunto de transformações, cujas matrizes serão aplicadas sucessivamente no momento da renderização, para determinar a posição definitiva destas geometrias no ambiente virtual.

Esta organização facilita a composição de movimentos relativos, e permite que objetos poligonais mais complexos sejam construídos através da composição de objetos poligonais mais simples.

Outra característica desta organização em hierarquia é a geração de Volumes Delimitadores (Bounding Volumes). Estes volumes são criados para marcar os limites de um determinado objeto poligonal. Todos os nós desta árvore possuem volumes delimitadores, cada qual envolvendo todo o conteúdo de geometrias abaixo do seu respectivo nó.

Estes volumes normalmente são representados por caixas (bounding box). Estas caixas são usadas para otimizar os algoritmos de colisão e os processos de renderização. Por exemplo, caso seja identificado que o conteúdo de uma determinada caixa não está no campo de visão do usuário da aplicação, todos os elementos presentes dentro desta caixa e, portanto, conectados abaixo do nó cor- 
respondente, não precisam ser enviados para a placa gráfica.

Esta organização em hierarquia é um fator importante na composição dos elementos geométricos em um ambiente virtual e, portanto, influenciou a arquitetura adotada na elaboração dos objetos do treinamento, a serem explicados na próxima seção.

\subsection{Objetos interativos}

Em uma aplicação de treinamento de procedimentos, um objeto interativo pode ser interpretado como qualquer elemento da cena que o usuário precise manipular para cumprir com os objetivos do treinamento. Nesta arquitetura, a interação com estes objetos será realizada de forma muito semelhante com o modelo STORM (MOLLET; GERBAUD; ARNALDI, 2007), utilizado na plataforma GVT (GERBAUD et al., 2008).

Toda a interação realizada com um determinado objeto interativo da cena será através de uma Ação. Desta forma, o conjunto de ações disponíveis em um determinado objeto determina o que o usuário pode fazer através deste.

As ações de um objeto podem ser classificadas como públicas ou privadas. Apenas as ações públicas estarão visíveis para o usuário em treinamento. Já as ações privadas existem apenas para que outros objetos do cenário possam executálas. Desta forma, o mecanismo de ações estabelece uma interface uniforme de comunicação, não apenas entre o objeto e o usuário, mas também entre todos os objetos presentes no cenário.

Os objetos contêm uma lista fixa de ações, onde cada uma destas ações pode estar disponível ou indisponível. Este controle de disponibilidade, aplicado nas ações públicas e privadas, é utilizado para evitar que o usuário tenha a sua disposição uma ação inconsistente com o estado do objeto. Por exemplo, suponha que um objeto interruptor tenha duas ações: Ligar e Desligar. Caso o interruptor já esteja ligado, não faz sentido manter a ação Ligar disponível para ser executada.

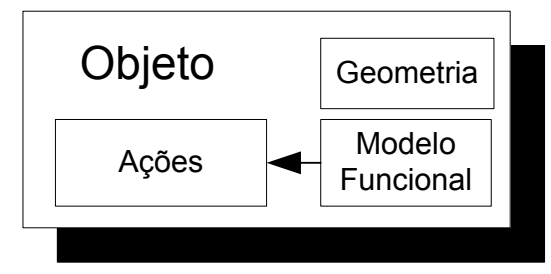

Figura 3.3: Objeto do procedimento. 
Conforme ilustrado na figura 3.3, qualquer objeto desta arquitetura contém, entre outras coisas, uma geometria associada, um conjunto de ações e um modelo funcional (behavioral model). Este modelo determina quais são as regras de funcionamento deste objeto. Uma das responsabilidades deste modelo é definir quais ações estarão disponíveis para o usuário ao longo do treinamento.

Assim como apresentado em STORM (MOLLET; GERBAUD; ARNALDI, 2007), esta arquitetura não impõe restrições quanto a técnica que será usada para descrever o modelo funcional. Desta forma, qualquer uma das alternativas apresentadas no capítulo 2 pode ser utilizada, desde que considerada a sua adequação às necessidades do caso de uso.

No entanto, em um determinado cenário de treinamento podem existir diversos objetos do mesmo tipo. Estes objetos, apesar de exercerem funções diferentes no cenário de treinamento, podem apresentar as mesmas regras de funcionamento.

Por exemplo, um cenário pode conter diversos interruptores, ou diversos disjuntores, cada um destes desempenhando uma função diferente no procedimento, no entanto, todos possuem as mesmas regras de funcionamento. Para tratar objetos com modelos funcionais semelhantes, esta arquitetura utiliza o conceito de Classes de Funcionamento.

\subsubsection{Classes de Funcionamento}

Para evitar que o modelo funcional de um grupo de objetos seja definido, repetidas vezes, todos os objetos do cenário serão, na verdade, instâncias de uma determinada Classe de Funcionamento. A Classe de Funcionamento é um elemento que contém todas as informações que descrevem o funcionamento de um grupo de objetos, incluindo o seu modelo funcional e o seu conjunto de ações.

Conforme ilustrado na figura 3.4, além das ações, uma classe pode conter um número arbitrário de propriedades. As Propriedades são características específicas de uma determinada classe de objetos e podem ser usadas para alterar a aparência ou o funcionamento de suas instâncias.

Desta forma, a definição de uma Classe de Funcionamento pode ser parametrizada em função de algumas variáveis, representadas nesta arquitetura pelo conceito de Propriedades. Este mecanismo remete aos conceitos de programação orientada a objetos, evitando o retrabalho, facilitando a documentação, a manutenção e promovendo o reaproveitamento de componentes.

Para definir as regras de operação de um determinado objeto, a sua Classe 


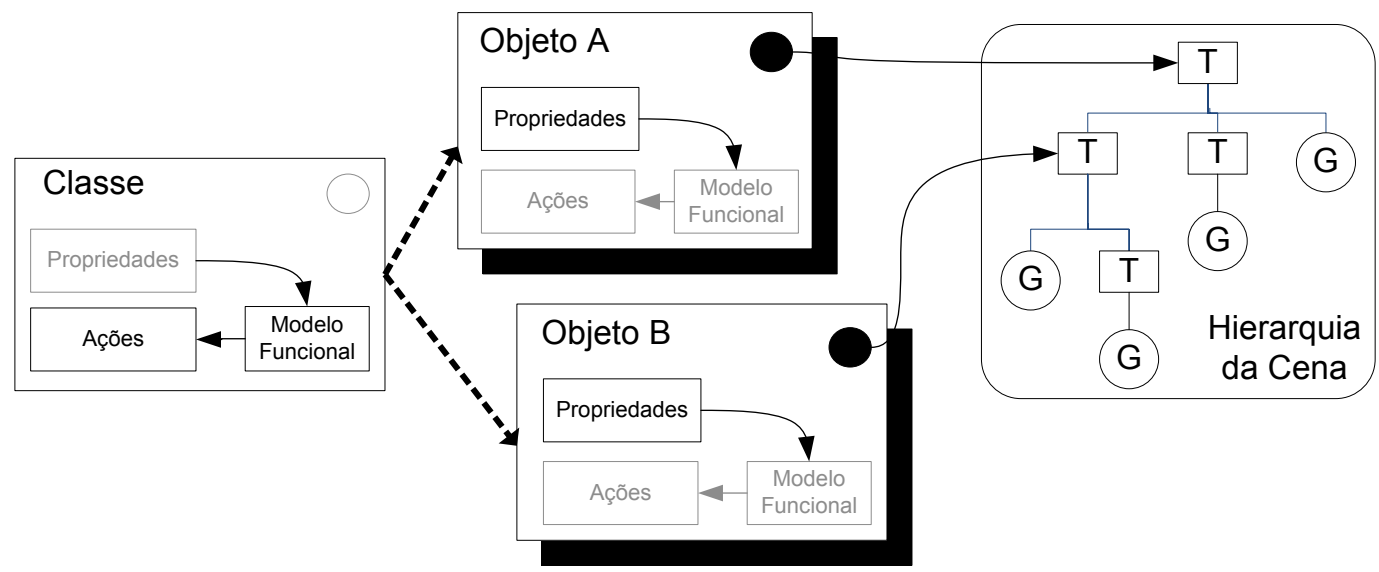

Figura 3.4: Classes de funcionamento.

de Funcionamento pode fazer uso de elementos presentes no modelo geométrico, como animações, para representar alterações realizadas durante o treinamento.

Sendo assim, todo o objeto do cenário aponta para um nó de transformação presente na hierarquia da cena. Este nó de transformação contém todas as geometrias que representam este objeto no ambiente virtual.

Desta forma, a composição de objetos é feita através da própria hierarquia da cena. De acordo com a figura 3.4, o Objeto A é composto por diversas geometrias, incluindo àquelas pertencentes ao Objeto B.

Para facilitar a compreensão e evitar interferências indesejáveis entre os diversos elementos interativos do cenário, os objetos devem modificar apenas os elementos geométricos que estiverem abaixo do seu respectivo nó de transformação, na hierarquia da cena. Além disto, estes objetos não devem alterar elementos que pertençam a outros objetos.

Portanto, de acordo com o exemplo, o Objeto A pode alterar qualquer elemento abaixo do seu nó de transformação, desde que este elemento não pertença ao Objeto B, ou seja, desde que o elemento a ser alterado não esteja abaixo do nó de transformação referenciado pelo Objeto B.

\subsubsection{Ações}

A definição de uma ação em uma determinada Classe de Funcionamento envolve a programação de uma rotina. Esta rotina deve implementar a reação do objeto à execução desta ação.

Na maioria dos casos, quando o usuário executar uma determinada ação de um objeto, este irá reagir através de uma sequência de animações. No entanto, 
outras alterações na aparência do objeto podem ser efetuadas, como mudança de textura, cor, posição etc.

Além disto, esta rotina ainda pode executar ações ou alterar propriedades de outros objetos presentes no ambiente virtual.

\subsubsection{Modelo funcional}

Nesta arquitetura, a descrição do funcionamento de um determinado objeto será realizada na sua respectiva Classe de Funcionamento. Desta forma, diversas classes poderão ser implementadas, cada classe com um modelo diferente de comportamento.

Assim como as ações, o modelo funcional também pode ser parametrizado em função das propriedades da Classe de Funcionamento. Desta forma, embora dois objetos sejam instâncias da mesma classe, os dois podem ter um comportamento ligeiramente diferente, dependendo dos valores de suas propriedades.

Apesar desta arquitetura não impor nenhuma restrição quanto a técnica a ser usada para descrever o funcionamento dos objetos, segundo a pesquisa realizada no capítulo anterior, o uso de máquina de estados pode facilitar a descrição do comportamento de máquinas e outras ferramentas convencionais.

Neste caso, a biblioteca a ser desenvolvida irá disponibilizar uma Classe de Funcionamento, cujo modelo funcional será baseado em uma máquina de estados. A máquina de estados será utilizada, basicamente, para determinar quando as ações de um determinado objeto estarão disponíveis.

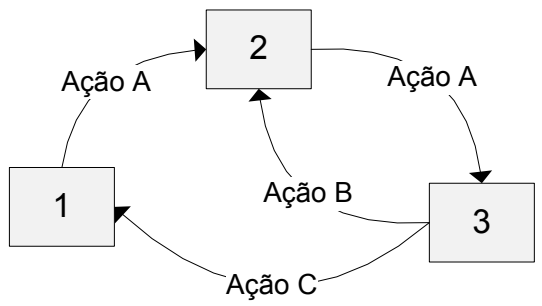

Figura 3.5: Máquina de estados de funcionamento.

De acordo com a figura 3.5, este controle pode ser implementado de forma simples através das transições. Ao associar uma ação com uma determinada transição da máquina de estados, esta ação estará disponível apenas quando a transição puder ser efetuada, o que dependerá do estado ativo da máquina.

Desta forma, por exemplo, caso o objeto esteja nos estados 1 ou 2 , apenas a 
ação $A$ estará disponível, enquanto que no estado 3, as ações $B$ e $C$ do objeto estarão disponíveis.

Embora a arquitetura tenha adotado o modelo de máquinas de estados como a técnica padrão para descrever o funcionamento dos objetos, caso este modelo se mostre inadequado para atender as necessidades de um caso de uso específico, outras técnicas podem ser utilizadas através do desenvolvimento de novas classes de funcionamento.

Neste caso, estas novas classes seriam inseridas na ferramenta de simulação através do mecanismo de extensões (plug-ins), disponíveis no Cenário de Treinamento.

\subsection{Procedimentos}

Os procedimentos contêm informações sobre as atividades que serão praticadas pelo usuário no ambiente virtual. As principais informações contidas em um determinado procedimento são as relações de dependência existentes entre as ações dos objetos interativos.

Estas relações de dependência determinam quais ações o usuário deve executar em cada objeto do cenário para cumprir com os objetivos do treinamento. Conforme apresentado no capítulo 2, existem diversas técnicas para se representar estas relações de dependência.

Para não comprometer a flexibilidade da arquitetura neste aspecto, a mesma também permitirá que diferentes técnicas sejam implementadas através do mecanismo de extensões. No entanto, independente da alternativa, é importante que a técnica adotada disponha dos seguintes requisitos mínimos:

- Verificar se a ação escolhida pelo usuário está correta;

- Sugerir uma ação para avançar no procedimento;

- Sugerir uma ação para retroceder no procedimento;

Estes recursos foram estabelecidos como requisitos mínimos, pois permitem que a ferramenta de treinamento disponha dos principais modos de operação: o modo Demonstração e o modo Avaliação. Estes dois modos estão disponíveis em grande parte das ferramentas de treinamento apresentadas no capítulo anterior. 
No modo Demonstração, a aplicação executa todas as atividades necessárias para completar o treinamento, sem a necessidade de intervenção do usuário. Neste caso, a aplicação utiliza o recurso do procedimento que sugere as próximas ações a serem executadas. Já no modo Avaliação, o usuário precisa executar todo o procedimento sem o auxílio da ferramenta, e neste caso, as suas ações são avaliadas de acordo com a descrição do procedimento.

De acordo com estes requisitos, por exemplo, o diagrama LORA não se mostra como uma alternativa adequada para esta arquitetura, uma vez que este diagrama não suporta caminhos de retorno e, portanto, impede que a ferramenta de treinamento sugira ações para retroceder nestes procedimentos.

Desta forma, esta arquitetura irá usar redes de Petri como alternativa padrão para representar as suas atividades. A rede de Petri foi escolhida, pois esta representação oferece um mecanismo simples e flexível para declarar de forma explícita as dependências existentes entre todas as etapas do procedimento.

A figura 3.6 apresenta um exemplo simplificado de procedimento. Observe que cada transição está associada com uma ação, neste caso, dos objetos A e B. As transições de volta permitem com que o usuário execute ações que retrocedam na atividade, desfazendo as ações executadas anteriormente.

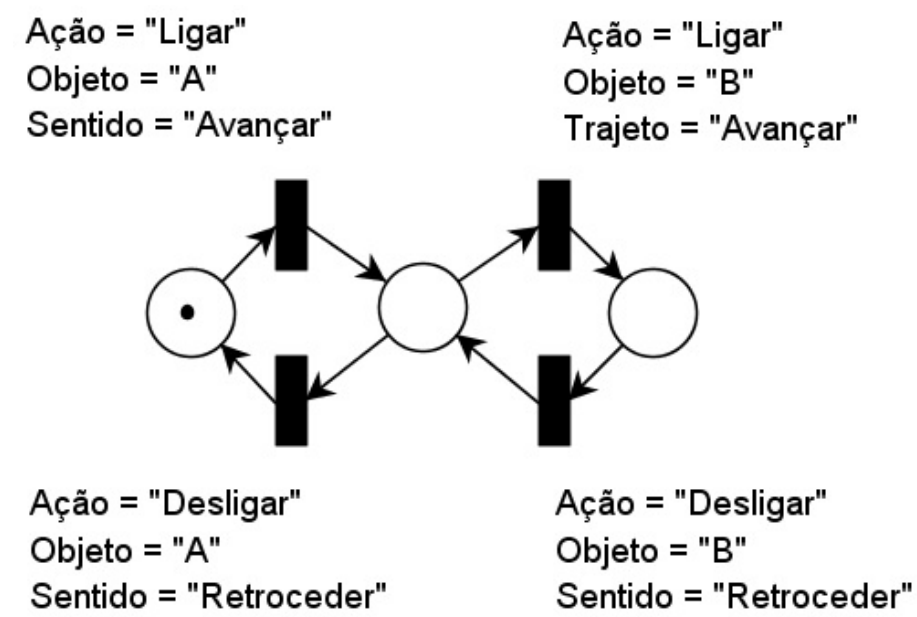

Figura 3.6: Rede de Petri com anotações.

Conforme ilustrado nesta figura, para utilizar o caminho de volta não é necessário introduzir nenhuma extensão conceitual no modelo, basta colocar as transições desejadas.

Todas as transições de uma rede de Petri estão associadas com ações de objetos presentes no cenário virtual. Caso uma determinada transição da rede esteja disponível para execução, a sua ação correspondente será considerada como 
uma alternativa correta para avançar ou retroceder no procedimento.

Desta forma, para permitir que a ferramenta ajude o usuário nos momentos em que o mesmo apresentar dúvida e não souber avançar no procedimento, é necessário anotar nas transições da rede, indicando em cada uma delas se a mesma promove o avanço ou o retrocesso do procedimento.

\subsection{Síntese}

Este capítulo apresentou a arquitetura que será praticada no desenvolvimento de uma biblioteca de software, cujo objetivo é facilitar a criação de aplicações de treinamento. Esta arquitetura apresentou recursos para evitar o retrabalho na elaboração de objetos interativos e facilitar a introdução de novos procedimentos.

A criação de novos objetos, apesar de menos frequente, é um processo trabalhoso e de maior complexidade, pois envolve atividades de modelagem de conteúdo 3D e a programação das suas regras de funcionamento. No entanto, como muitos objetos possuem regras de operação semelhantes, esta arquitetura introduziu o conceito de Classes de Funcionamento, para evitar o retrabalho nestas atividades.

As Classes de Funcionamento permitem que novos objetos utilizem regras de operação já desenvolvidas e validadas. Desta forma, estas Classes podem ser organizadas em uma biblioteca de recursos, para que com o passar do tempo, novos objetos possam ser elaborados de forma mais rápida e fácil.

Outra característica importante desta arquitetura é a flexibilidade com relação a técnica para se representar os procedimentos. Cada caso de uso pode escolher a técnica mais adequada para resolver o seu problema, desde que a alternativa adotada disponha dos requisitos mínimos mencionados.

Esta flexibilidade é viabilizada pelo mecanismo de extensões (plug-ins), que permite que novas Classes de Funcionamento e novos tipos de procedimentos sejam inseridos na ferramenta de treinamento, sem que a mesma precise ser modificada.

Esta arquitetura foi considerada no planejamento e no desenvolvimento de uma biblioteca de software, cujo projeto e os detalhes da implementação serão apresentados no próximo capítulo deste documento. 


\section{Considerações sobre a implementação}

Este capítulo apresenta o projeto de uma biblioteca de software para a construção de aplicações de treinamento em RV. As características da arquitetura, apresentadas no capítulo anterior, foram consideradas no planejamento e no desenvolvimento desta biblioteca.

Os resultados do planejamento são apresentados através de diagramas de classe no padrão UML. Para simplificar a representação e enfatizar os principais elementos dos diagramas, algumas classes são ilustradas de forma resumida, apresentando apenas os seus métodos e atributos principais.

O desenvolvimento desta biblioteca foi realizado utilizando a linguagem de programação $\mathrm{C}++$, com o auxílio de outras bibliotecas distribuídas gratuitamente, como o STL (Standard Template Library) (PLAUGER et al., 2000) e o Ogre (JUNKER, 2006). A ferramenta SCons (SCONS, 2010) foi adotada para organizar o sistema de compilação deste projeto.

O SCons possui suporte para diversos compiladores, entre eles, podemos destacar as versões mais recentes do Microsoft Visual Studio, para Windows, e a alternativa gratuita do projeto GNU, o GCC (GNU Compiler Collection) ${ }^{1}$, disponível para todos os principais sistemas operacionais, como Linux, MacOS X e Microsoft Windows inclusive.

Apesar da flexibilidade do SCons, esta biblioteca foi compilada e testada apenas nos sistemas operacionais Microsoft Windows e Linux. Além disto, o projeto a ser apresentado neste capítulo não contém instruções para a criação da interface gráfica com o usuário ou manipulação de periféricos, como teclado, mouse ou outra tecnologia de interação. O uso destes recursos ficará a critério da aplicação, que avaliará os requisitos do seu caso de uso para escolher as ferramentas mais adequadas.

\footnotetext{
${ }^{1}$ Página web do compilador GCC: http://gcc.gnu.org/. Acessado em Agosto/2010.
} 
Desta forma, esta biblioteca se concentra nos elementos que estão associados com o treinamento e a capacitação do usuário, como o modelo virtual, os objetos interativos e as atividades de treinamento.

\subsection{Cenário de treinamento}

O Cenário de Treinamento é o elemento principal desta biblioteca de software. Através deste elemento, a aplicação pode criar um ambiente de treinamento, consultar e manipular os objetos interativos presentes neste ambiente, e escolher os procedimentos que serão praticados pelo usuário. Nos diagramas que serão apresentados, a interface do Cenário de Treinamento é representada pela classe Scenario.

Esta classe, cujo principal diagrama está ilustrado na figura 4.1, foi elaborada utilizando o padrão Facade de projeto de software (GAMMA et al., 1994). Neste padrão de projeto, todas as principais funcionalidades de uma determinada biblioteca são disponibilizadas através de uma única classe, com o propósito de facilitar a sua compreensão e o seu uso.

\begin{tabular}{|l|l|}
\hline \multicolumn{1}{|c|}{ Scenario } & \multicolumn{1}{c|}{ Plugin } \\
\hline -_scene: SceneNode* & \multicolumn{1}{c|}{$\begin{array}{c}\text { ProcedureManager } \\
\text {-_object_manager: ObjectManager }\end{array}$-_procedure_manager: ProcedureManager* } \\
-_current_procedure: Procedure*
\end{tabular}

Figura 4.1: Diagrama de classe do Cenário de treinamento.

Cada cenário de treinamento criado pela aplicação deve ser uma instância distinta da classe Scenario. Cada instância desta classe contém um elemento para gerenciar todos os objetos interativos, o ObjectManager, e um elemento para gerenciar todos os procedimentos disponíveis, o ProcedureManager. 
Além disto, cada Cenário pode conter um número arbitrário de extensões (plug-ins). Estas extensões, ilustradas no diagrama através da classe Plugin, são usadas para inserir novos recursos na biblioteca, sem alterar a sua implementação. Através destas extensões, é possível criar novas Classes de Funcionamento, utilizando técnicas diferentes para descrever as regras de operação dos objetos, ou inserir novos modelos para definir os procedimentos.

De acordo com o diagrama, a classe Scenario contém um conjunto amplo de rotinas. Para facilitar a compreensão, estas rotinas foram classificadas em dois grupos: as que são utilizadas para construir o ambiente de treinamento, e as usadas para conduzir o processo de treinamento.

Para construir um ambiente de treinamento, a aplicação deve executar os seguintes passos:

Tabela 4.1: Passos para a construção de um ambiente de treinamento.

\begin{tabular}{|c|c|c|}
\hline Passo & Descrição & Função \\
\hline 1 & $\begin{array}{l}\text { Criar uma instância da classe Scenario, pas- } \\
\text { sando o nó raiz do modelo geométrico no seu } \\
\text { construtor. }\end{array}$ & Scenario (..) \\
\hline 2 & $\begin{array}{l}\text { Instalar as extensões que serão utilizadas nos } \\
\text { objetos e procedimentos. }\end{array}$ & InstallPlugin (..) \\
\hline 3 & Criar os objetos interativos do cenário. & CreateObject(..) \\
\hline 4 & $\begin{array}{l}\text { Carregar os procedimentos das atividades } \\
\text { que serão praticadas. }\end{array}$ & CreateProcedure(..) \\
\hline
\end{tabular}

A ordem de execução das etapas mencionadas na tabela 4.1 é importante, pois cada uma delas depende de informações carregadas em passos anteriores. Por exemplo, para criar os objetos interativos no terceiro passo, é imprescindível que as extensões necessárias já tenham sido instaladas. Caso contrário, a biblioteca não reconhecerá a técnica utilizada para descrever o funcionamento dos objetos.

Durante este processo de inicialização, muitos elementos são alocados dinamicamente na memória, principalmente através das funções CreateObject() e CreateProcedure(). Estes elementos são gerenciados internamente pela biblioteca e, portanto, a aplicação não precisa apagá-los. Ao finalizar o treinamento, a aplicação precisa apenas eliminar a instância da classe Scenario, e todos os elementos criados através desta instância serão automaticamente apagados.

Apesar da biblioteca não exigir que a aplicação apague os elementos alocados dinamicamente, a interface da classe Scenario possui funções como DestroyObject() e DestroyProcedure(). Estas funções podem ser usadas quando se mostrar necessário remover a interatividade de algum objeto ou desativar um determinado procedi- 
mento, sem apagar todo o cenário de treinamento.

Após construir o cenário de treinamento, a aplicação pode escolher qualquer um dos procedimentos carregados para praticar. Embora o cenário disponha de vários procedimentos, apenas um pode ser executado de cada vez. Escolhido o procedimento, a aplicação deverá executar os seguintes passos:

Tabela 4.2: Passos para a condução de um treinamento.

\begin{tabular}{|c|c|c|}
\hline Passo & Descrição & Função \\
\hline 1 & $\begin{array}{l}\text { Iniciar o procedimento escolhido pelo usuá- } \\
\text { rio. }\end{array}$ & StartProcedure(..) \\
\hline $\begin{array}{c}2 \\
\text { (Opção 1) }\end{array}$ & $\begin{array}{l}\text { No modo Avaliação: Identificar os objetos } \\
\text { que o usuário deseja manipular, e quais ações } \\
\text { devem ser executadas. }\end{array}$ & FindObject(..) \\
\hline $\begin{array}{c}2 \\
\text { (Opção 2) }\end{array}$ & $\begin{array}{l}\text { No modo Demonstração: Obter automatica- } \\
\text { mente a ação a ser executada, para demons- } \\
\text { trar o procedimento ao usuário. }\end{array}$ & $\begin{array}{l}\text { ForwardHint () ou } \\
\text { BackwardHint }()\end{array}$ \\
\hline 3 & $\begin{array}{l}\text { Executar a ação determinada pelo usuário ou } \\
\text { automaticamente pela ferramenta. }\end{array}$ & Execute(..) \\
\hline 4 & $\begin{array}{l}\text { Repetir os passos } 2 \text { e } 3 \text { até encerrar o proce- } \\
\text { dimento, seja através da sua conclusão ou do } \\
\text { seu cancelamento. }\end{array}$ & \\
\hline $\begin{array}{c}5 \\
(\text { Opção 1) }\end{array}$ & $\begin{array}{l}\text { Concluir o procedimento. O procedimento } \\
\text { só pode ser concluído quando todas as suas } \\
\text { etapas forem executadas. }\end{array}$ & ConcludeProcedure() \\
\hline $\begin{array}{c}5 \\
\text { (Opção 2) }\end{array}$ & Cancelar a execução do procedimento. & CancelProcedure() \\
\hline
\end{tabular}

Conforme apresentado na tabela 4.2, os passos para conduzir um determinado procedimento podem variar de acordo com o modo de funcionamento da aplicação.

No modo avaliação, a biblioteca de treinamento assume que os objetos com os quais o usuário desejar interagir serão identificados através de suas geometrias no cenário virtual. Desta forma, por exemplo, caso a aplicação utilize um mouse convencional, o usuário poderá fazer uso do cursor para apontar para as geometrias que o mesmo deseja manipular.

Neste caso, a aplicação utilizará a função FindObject(..) para determinar qual objeto interativo contém as geometrias apontadas pelo usuário, para em seguida determinar as ações disponíveis neste objeto. Após obter estas ações, a aplicação pode apresentá-las ao usuário, para que este escolha qual das alternativas deve ser executada.

Escolhida a ação do objeto, a aplicação pode executá-la através do método Execute(..). Este método retorna um valor booleano, que se for verdadeiro, indica 
que a ação pôde ser executada com sucesso, mas se for falso, indica que a ação escolhida não está de acordo com a descrição do procedimento. Neste último caso, nada é alterado no ambiente virtual, apenas o usuário é informado de seu erro.

Caso a aplicação esteja funcionando em modo demonstração, o mecanismo a ser utilizado é mais simples — basta que a aplicação execute as ações sugeridas pela função ForwardHint() para avançar no procedimento, ou BackwardHint() para retroceder no procedimento.

Conforme mencionado na tabela 4.2, para encerrar o treinamento, a aplicação pode executar as funções ConcludeProcedure() ou CancelProcedure(). No entanto, a função ConcludeProcedure() concluirá o procedimento apenas quando não houver nenhuma ação pendente a ser executada. Caso contrário, esta função retornará um valor booleano falso, indicando que não foi possível encerrar a atividade.

Outro método importante, apesar de não mencionado nesta última tabela, é o Update(dt:Float). Este método deve ser usado para atualizar as animações e outros efeitos dinâmicos do cenário e, portanto, deve ser chamado pela aplicação antes da renderização de todos os seus quadros (frames). O único parâmetro desta função é usado para informar ao cenário de treinamento quanto tempo se passou desde a sua última atualização, ou seja, quanto tempo ${ }^{2}$ se passou desde que esta função foi chamada pela última vez.

Normalmente, o método Update(..) é usado pelos objetos interativos para atualizar as suas animações ou alterar outros parâmetros do modelo geométrico, simulando o funcionamento de máquinas ou outros periféricos do ambiente virtual.

\subsection{Modelo geométrico}

O modelo geométrico contém a representação visual de todos os elementos do cenário. Conforme mencionado na arquitetura, é importante que este modelo esteja organizado de forma hierárquica, e seja capaz de representar instâncias e animações. No entanto, estes recursos básicos e muitos outros já estão disponíveis através de diversas bibliotecas de software distribuídas gratuitamente, como o Ogre (JUNKER, 2006), o OpenSG (REINERS; VOSS; BEHR, 2002) e o OpenSceneGraph (MARTZ, 2007).

Desta forma, para simplificar o desenvolvimento e focar nas funcionalidades que são mais relevantes para este trabalho, a implementação deste projeto optou

\footnotetext{
${ }^{2}$ Neste caso, o tempo deve ser informado em milissegundos.
} 
por usar uma destas alternativas. Neste caso, a biblioteca Ogre foi escolhida em função da grande quantidade de documentação disponível e da facilidade de utilização. Apesar desta escolha, as outras alternativas também poderiam ser usadas sem prejudicar o desenvolvimento deste projeto em nenhum aspecto.

Conforme ilustrado no diagrama da classe Scenario, não existem rotinas nesta classe para criar ou carregar o modelo geométrico. Esta etapa deve ser realizada pela própria aplicação, com o auxílio dos recursos disponíveis na biblioteca do Ogre.

O Cenário de Treinamento só pode ser criado após a organização do modelo geométrico. Neste momento, ao criar uma instância da classe Scenario, o construtor desta classe recebe um ponteiro do tipo SceneNode*. Este ponteiro deve conter o nó raiz da hierarquia da cena do Ogre - abaixo deste nó estarão todas as malhas poligonais que serão usadas pelos objetos interativos do cenário.

\subsection{Objetos interativos}

De acordo com a arquitetura, todo objeto interativo do cenário virtual pertence a uma determinada Classe de Funcionamento. Esta Classe de Funcionamento contém as regras de operação do objeto e a definição das suas ações, permitindo que todos os objetos que tenham o mesmo comportamento utilizem uma única Classe de Funcionamento.

No diagrama da figura 4.2, a classe abstrata Object representa a interface para o desenvolvimento de novas Classes de Funcionamento. Esta classe abstrata contém todos os recursos necessários para que as suas especializações possam definir a suas regras de operação, além de efetuar o registro de novas propriedades e ações.

Após a implementação de uma determinada Classe de Funcionamento, a mesma deve ser colocada em uma extensão (plug-in), para que quando um cenário de treinamento precisar de um objeto com estas características, bastará instalar esta extensão no cenário. Esta instalação permite que a biblioteca reconheça os objetos que pertencem a esta nova Classe.

No momento em que uma Classe de Funcionamento é colocada em uma determinada extensão, é necessário atribuir um nome a esta Classe. Este nome deve ser único, e será usado para identificar este tipo de objeto na composição de um novo cenário de treinamento. 
Todos os objetos interativos de um determinado cenário são criados e gerenciados pelo ObjectManager. Para criar um determinado objeto, o ObjectManager precisa de duas informações: o nome da Classe do objeto, que corresponde ao nome registrado na extensão, e o nome a ser dado ao próprio objeto.

Para criar uma instância da Classe de Funcionamento, a biblioteca utiliza o padrão Factory de projeto de software (GAMMA et al., 1994). Este padrão foi implementado na classe ObjectFactory, e permite que objetos sejam criados a partir do nome de sua Classe.

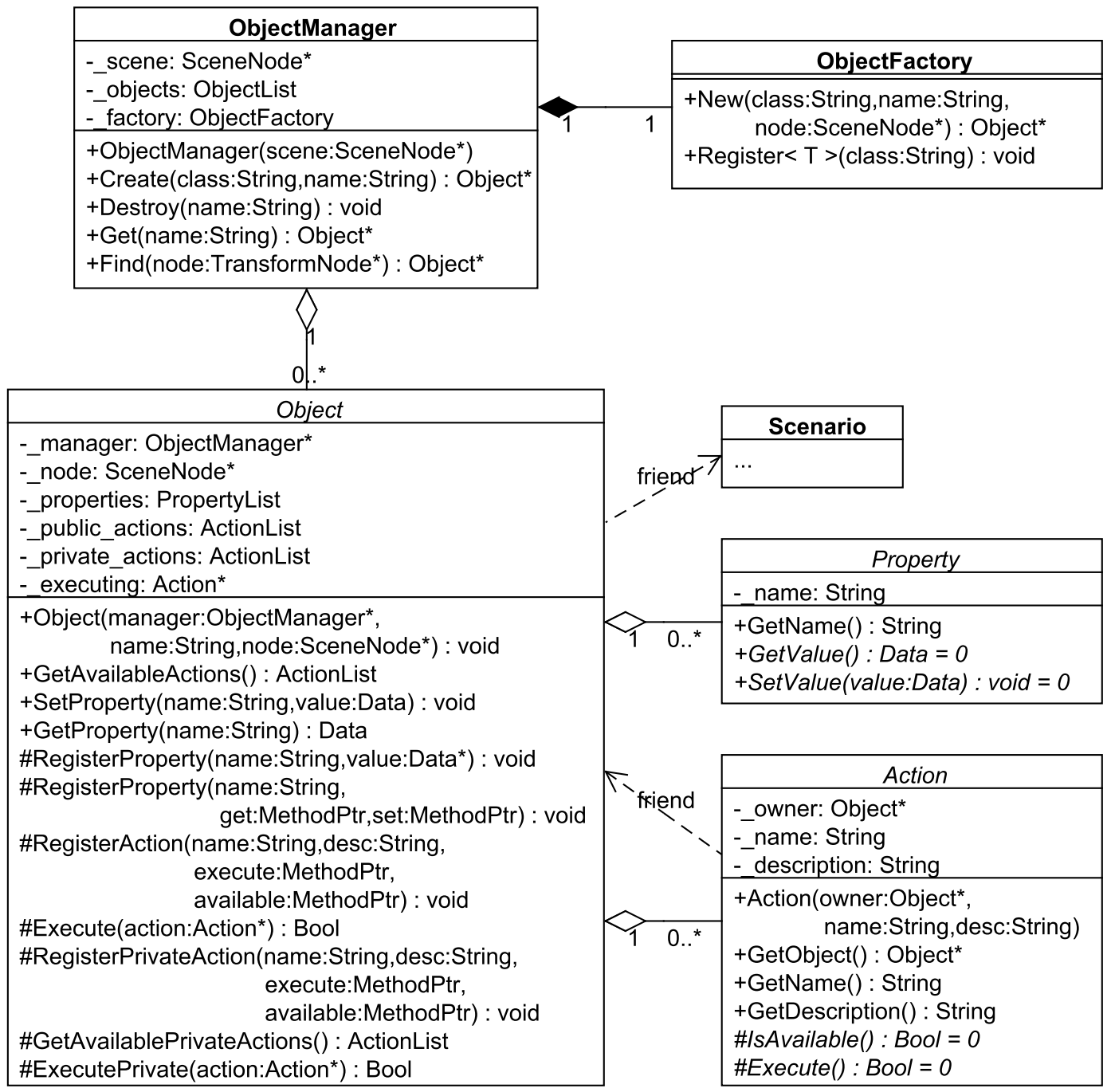

Figura 4.2: Diagrama de classe dos objetos interativos.

Durante o processo de criação, o objeto recebe através do construtor um ponteiro para o próprio ObjectManager. Este ponteiro pode ser utilizado para consultar a existência de outros objetos no cenário e, quando necessário, executar ações nestes objetos.

Ainda no construtor, o objeto recebe um ponteiro do tipo TransformNode*. Este ponteiro contém o nó de transformação da cena do Ogre. Abaixo deste 
nó, estão todas as geometrias que representam visualmente este objeto. Desta forma, estas geometrias podem ser manipuladas pela Classe de Funcionamento para representar as mudanças de estado deste objeto.

\subsubsection{Propriedades}

As propriedades representam atributos de um objeto que podem ser alterados em tempo de execução. Estas propriedades são definidas na implementação de uma Classe de Funcionamento e devem ser registradas na classe básica Object. Os valores destas propriedades podem ser usados para parametrizar o comportamento e as ações dos objetos.

Conforme ilustrado no diagrama da figura 4.3, a interface básica da propriedade é representada pela classe abstrata Property. Toda propriedade contém um nome, que a identifica dentro do objeto, e contém um valor. O valor de uma propriedade pode ser armazenado em lugares diferentes, dependendo da necessidade da Classe de Funcionamento.

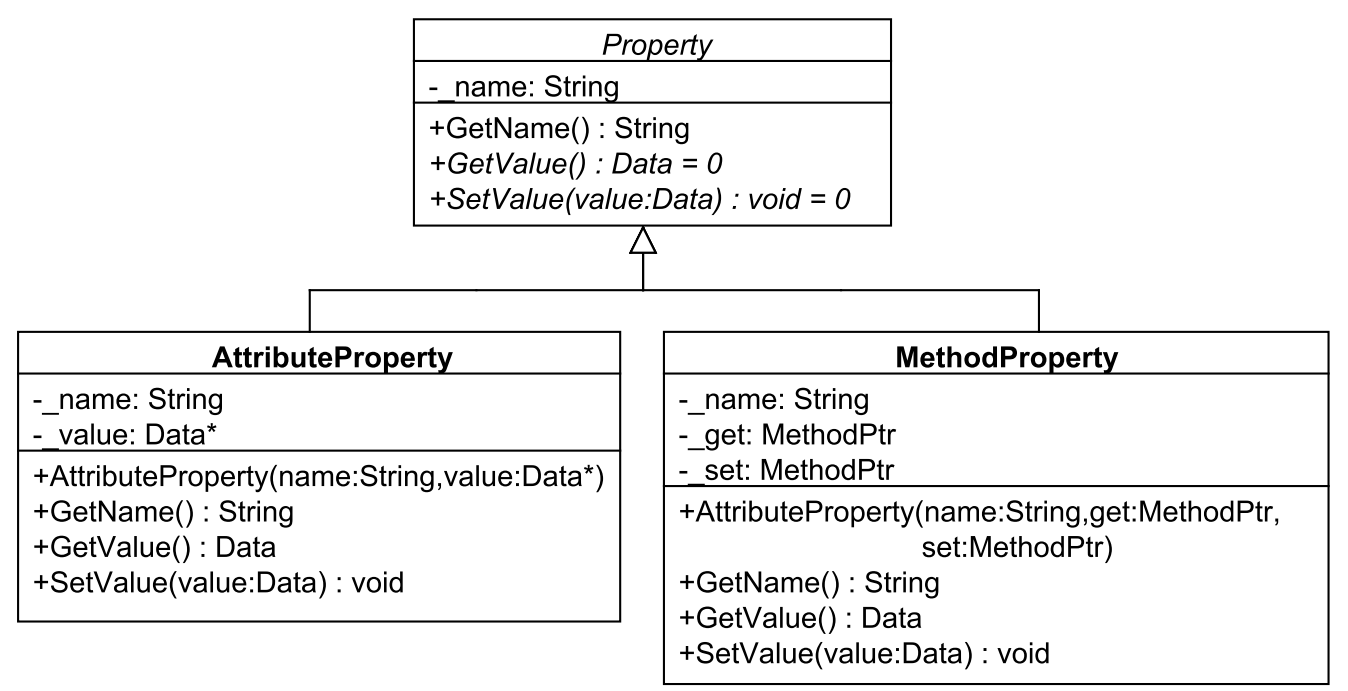

Figura 4.3: Diagrama de classe das propriedades.

O diagrama da figura 4.3 apresenta dois tipos de propriedade: AttributeProperty e MethodProperty. Cada um destes tipos possui um mecanismo diferente para ler e alterar o seu valor.

A classe AttributeProperty contém um ponteiro para uma posição de memória que armazena o valor da propriedade. Normalmente, esta posição de memória irá corresponder à um atributo da sua respectiva Classe de Funcionamento, que por sua vez, será uma especialização da classe Object.

Quando a posição de memória onde está o valor da propriedade não é conhe- 
cida, a classe MethodProperty pode ser usada. Esta classe contém ponteiros para duas funções, responsáveis por ler e alterar o valor da propriedade. Estas funções podem ser implementadas na própria Classe de Funcionamento e serão chamadas sempre que este valor precisar ser acessado.

\subsubsection{Ações}

As ações de um determinado objeto representam a sua interface de interação, e podem ser classificadas em dois grupos: públicas ou privadas. Apenas as ações públicas do objeto estarão visíveis para o usuário da ferramenta de treinamento, enquanto que suas ações privadas estarão visíveis apenas para os outros objetos do cenário. Desta forma, este mecanismo de ações estabelece uma interface uniforme para manipulação dos objetos interativos.

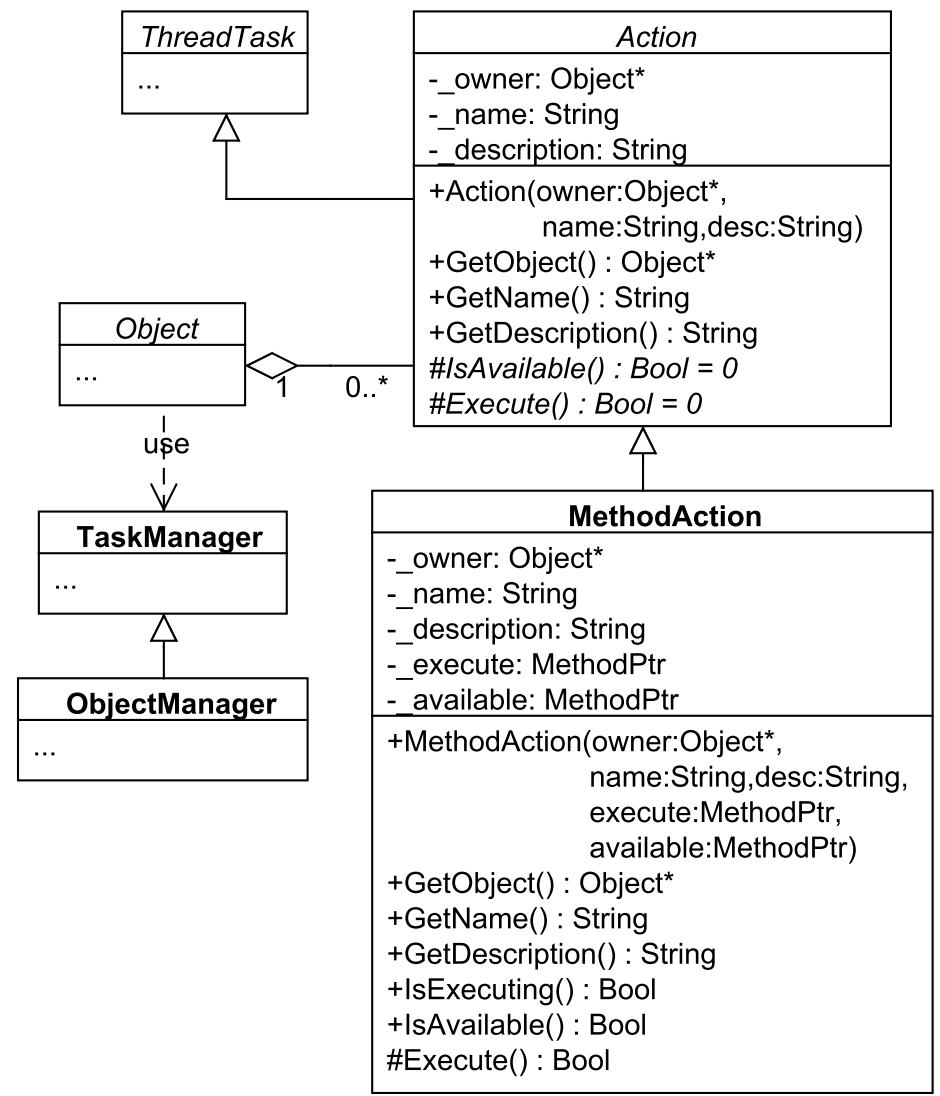

Figura 4.4: Diagrama de classe das ações.

Ao executar uma ação, esta pode mudar o estado de funcionamento do objeto e manifestar estas mudanças através de alterações no seu modelo geométrico. O desenvolvimento destas ações e seus efeitos são realizados na Classe de Funcionamento e devem ser registradas na classe básica Object.

Conforme o diagrama da figura 4.4, a interface para o desenvolvimento de novas ações é representada pela classe abstrata Action. Nesta classe, o método 
IsAvailable(), responsável por verificar a disponibilidade da ação, e o método Execute(), responsável por executar a ação, são puramente virtuais, ou seja, a Classe de Funcionamento pode especializar a classe Action para determinar como as suas ações irão funcionar.

No entanto, para facilitar o desenvolvimento, a classe MethodAction implementa um tipo de ação cujas rotinas IsAvailable() e Execute() são repassadas para outras rotinas dentro da Classe de Funcionamento. Desta forma, todas as funções que implementam as ações do objeto ficam concentradas na própria Classe de Funcionamento, e não espalhadas em diversas especializações da classe Action.

Normalmente, os efeitos implementados em uma determinada ação, como animações, podem necessitar de um longo intervalo de tempo para concluir a sua execução. Durante este intervalo, para que estas animações sejam percebidas e visualizadas pelo usuário, a aplicação não pode interromper o seu processo de renderização.

Conforme ilustrado na figura 4.5, para contornar este problema, a execução de uma ação poderia ser realizada em outro thread ${ }^{3}$, que executaria em paralelo com o processo de renderização da aplicação.

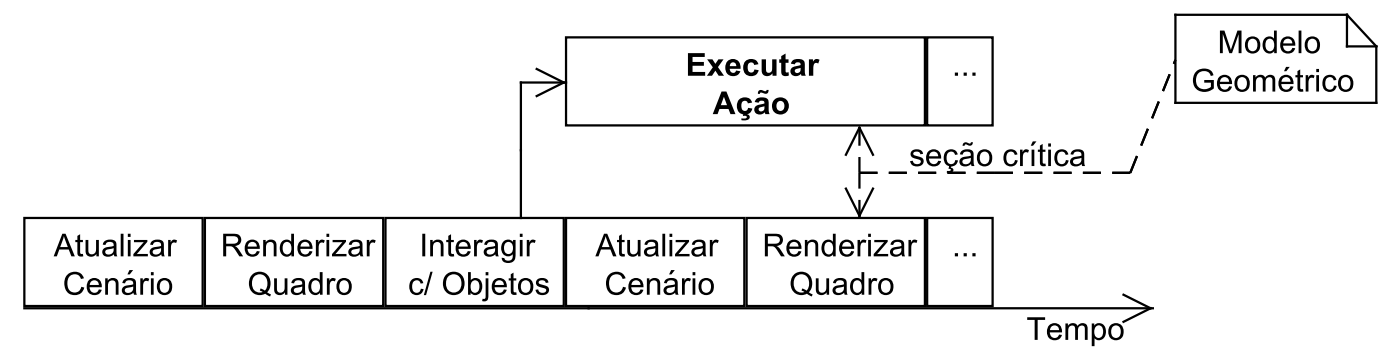

Figura 4.5: Principais tarefas do loop da aplicação.

No entanto, estas duas tarefas compartilham os mesmos recursos para cumprir com o seus objetivos, por exemplo, para efetuar uma animação é necessário alterar a posição dos elementos geométricos da cena, enquanto que o processo de renderização precisa obter estas mesmas geometrias para desenhar o próximo quadro (frame).

Sendo assim, para executar estas duas tarefas em threads concorrentes, seria necessário gerenciar seções críticas para acesso ao modelo geométrico, o que aumentaria consideravelmente a complexidade envolvida na implementação destas ações.

\footnotetext{
${ }^{3} \mathrm{O}$ thread, ou linha de execução, é um recurso que permite que uma aplicação possa executar duas ou mais tarefas de forma concorrente.
} 
Para facilitar a implementação, a biblioteca disponibiliza um mecanismo simplificado de gerenciamento de tarefas. Este mecanismo de gerenciamento permite que tarefas sejam executadas de forma fragmentada, sem interromper o processo de renderização da aplicação.

\subsubsection{Tarefas}

O mecanismo de tarefas foi desenvolvido para facilitar a implementação de rotinas que precisam executar sem interromper os outros processos conduzidos pela aplicação, por exemplo, a renderização contínua da cena virtual. Para não interromper os processos da aplicação, a alternativa convencional é criar um conjunto de threads e executar estas tarefas de forma concorrente.

No entanto, como a maioria destas tarefas utiliza o mesmo conjunto de informações, por exemplo, o modelo geométrico, o gerenciamento de regiões críticas ficaria demasiadamente complexo. Para contornar este problema, a biblioteca dispõe de um mecanismo de gerenciamento de tarefas. Cada uma destas tarefas é implementada para executar por partes, de tal forma que a cada passo ou ciclo da aplicação, apenas uma parte da tarefa é executada.

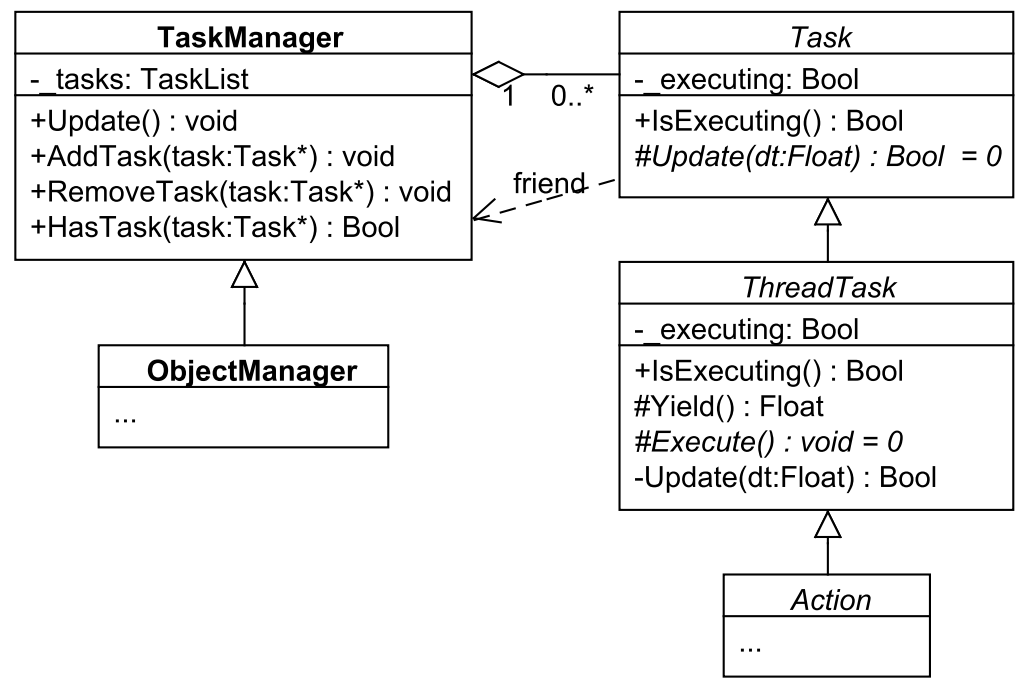

Figura 4.6: Diagrama do gerenciador de tarefas.

De acordo com o diagrama de classe apresentado na figura 4.6, a classe TaskManager é responsável por gerenciar as tarefas existentes. Cada tarefa, representada pela classe abstrata Task, possui um método Update(dt:Float) que será chamado pelo gerenciador sempre que esta tarefa puder executar.

Desta forma, a cada chamada da função Update(dt:Float), a tarefa deve executar apenas parte de suas atividades e retornar rapidamente, evitando que a aplicação 
demore longos intervalos de tempo para atualizar o próximo quadro.

Ao fragmentar a execução de uma determinada tarefa em diversas partes, se torna possível implementar ações com longas animações de reação, sem a necessidade de gerenciar o acesso à regiões críticas.

No entanto, ao fragmentar a execução de uma determinada tarefa, se torna necessário controlar o seu estado de execução, para que quando a sua função Update(dt:Float) for chamada, a tarefa consiga identificar quais passos já foram realizados e quais ainda precisam ser efetuados.

Apesar do controle de estado ser trivial para tarefas mais simples, a implementação deste tipo de controle pode se mostrar muito inconveniente e confusa para tarefas mais longas e complicadas. Desta forma, para simplificar ainda mais o desenvolvimento das tarefas, a biblioteca dispõe do recurso de tarefas em threads.

As tarefas em threads estão representadas no diagrama de classe da figura 4.6 através da classe abstrata ThreadTask. Este tipo de tarefa, apesar de estar em outro thread, executa de forma sequencial com a aplicação para evitar o problema de gerenciamento de seções críticas.

Desta forma, o único motivo pelo qual este tipo de tarefa executa em um thread separado da aplicação, é evitar o controle de estados durante a fragmentação, facilitando ainda mais a sua implementação.

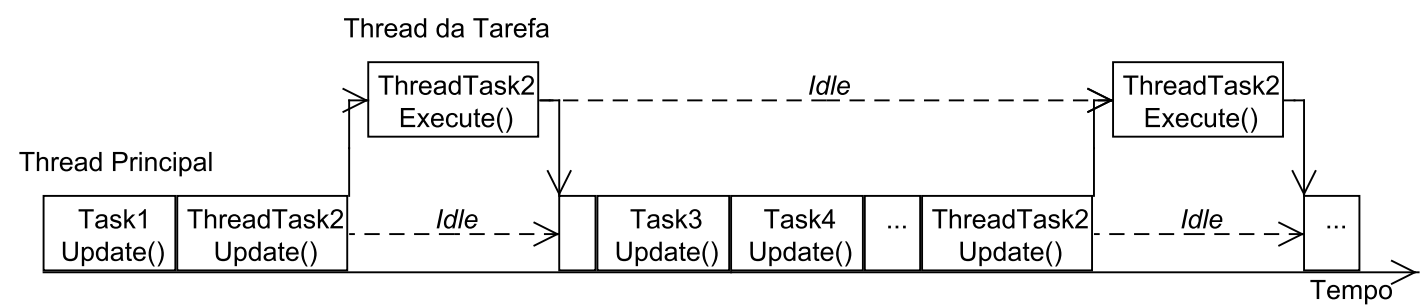

Figura 4.7: Execução de tarefas normais e em thread.

A figura 4.7 apresenta um exemplo com 4 tarefas, sendo que apenas a tarefa de número 2 é do tipo ThreadTask. Neste caso, todas as tarefas executam de forma sequencial, porém a tarefa de número 2 possui um thread separado, e quando esta tarefa está em execução, o resto da aplicação aguarda (idle), e vice-versa.

Conforme o diagrama de classe da figura 4.6, para simplificar a implementação das Classes de Funcionamento e suas ações, a classe básica Action é uma especialização da classe ThreadTask. Desta forma, toda ação de um objeto executa em um thread separado, porém, de forma sequencial com a aplicação.

Através dos mecanismos disponíveis na classe básica ThreadTask, as ações po- 
dem utilizar longas animações de reação em seus objetos, sem comprometer o processo de renderização da aplicação, sem efetuar o gerenciamento de seções críticas e evitando o controle de estados, comum na implementação de tarefas assíncronas.

\subsection{Procedimentos}

O planejamento da interface dos procedimentos foi realizado para que o Cenário de Treinamento funcionasse com uma grande variedade de técnicas usadas para descrever estes procedimentos. No entanto, para o correto funcionamento do Cenário, é imprescindível estabelecer uma interface comum para todas estas técnicas.

No diagrama da figura 4.8, a interface dos procedimentos está representada pela classe abstrata Procedure. Esta classe possui um conjunto de funções puramente virtuais - estas funções devem ser implementadas nas especializações desta interface, ao desenvolver um modelo específico para descrever os procedimentos.

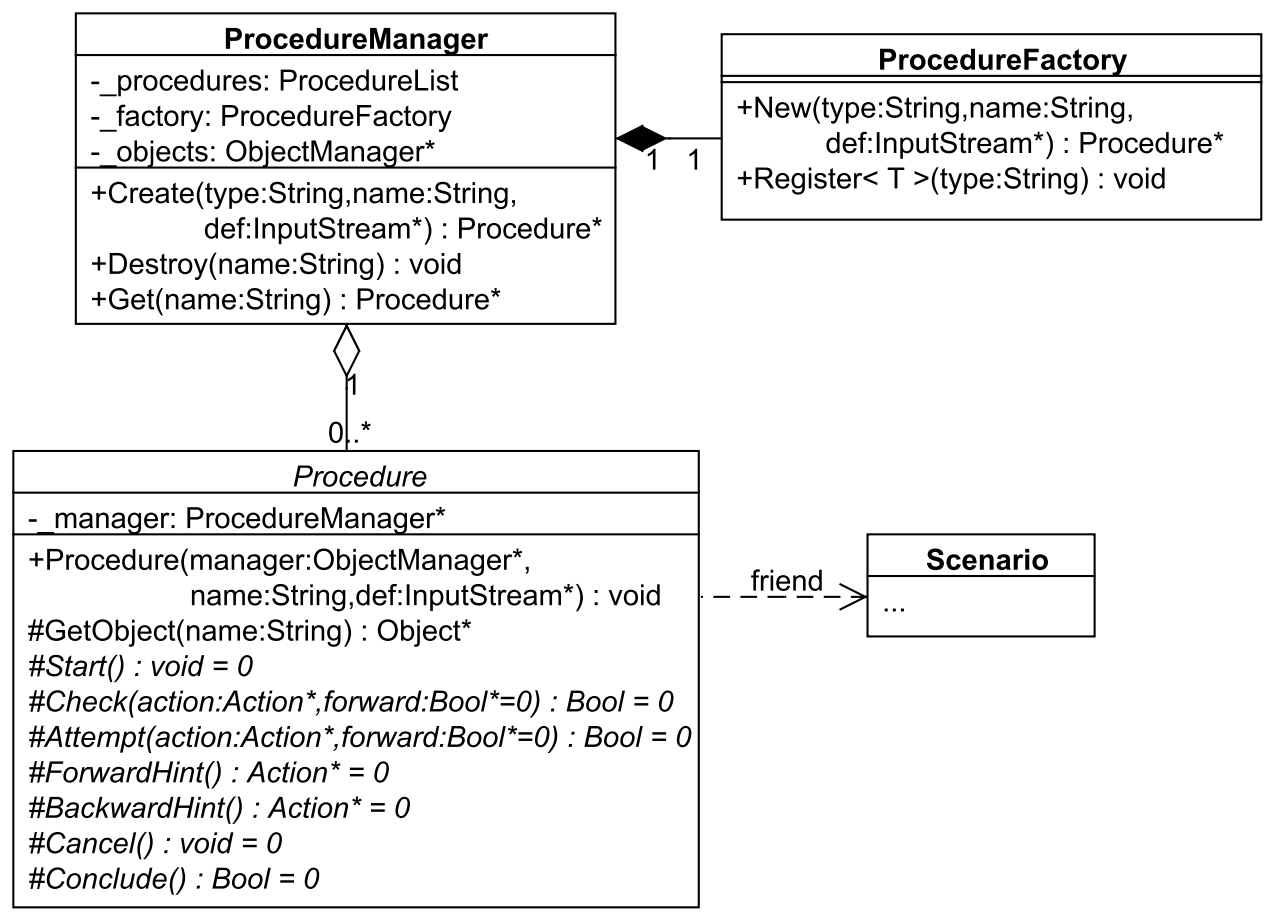

Figura 4.8: Diagrama de classe dos procedimentos.

Para que a biblioteca consiga identificar os novos tipos de procedimentos, as especializações da classe Procedure devem ser colocadas em uma extensão (plug-in). Neste momento, cada especialização deve receber um nome, que irá identificá-la na montagem de um novo cenário de treinamento. 
A classe ProcedureManager é responsável por gerenciar todas as instâncias de procedimentos usados em um determinado cenário. Para criar estas instâncias, a classe ProcedureFactory utiliza o padrão Factory de projeto de software (GAMMA et al., 1994), onde o procedimento é criado a partir do nome registrado em sua extensão.

Apesar da flexibilidade oferecida pelo mecanismo de extensões (plug-ins), a biblioteca adotou a Rede de Petri como técnica padrão para representar as relações de dependência entre as etapas do procedimento. A rede de Petri foi escolhida levando em consideração os recursos disponíveis nesta técnica e a sua simplicidade.

\subsubsection{Redes de Petri}

Para descrever um procedimento utilizando redes de Petri, foi necessário inserir na biblioteca recursos para interpretar e executar este tipo de representação.

\begin{tabular}{|c|c|c|c|}
\hline \multicolumn{2}{|l|}{ Net } & & \\
\hline \multicolumn{2}{|l|}{$\begin{array}{l}\text {-_arcs: ArcList } \\
\text {-_places: PlaceList } \\
\text {-_transitions: TransitionList }\end{array}$} & & \\
\hline \multirow{4}{*}{\multicolumn{2}{|c|}{ 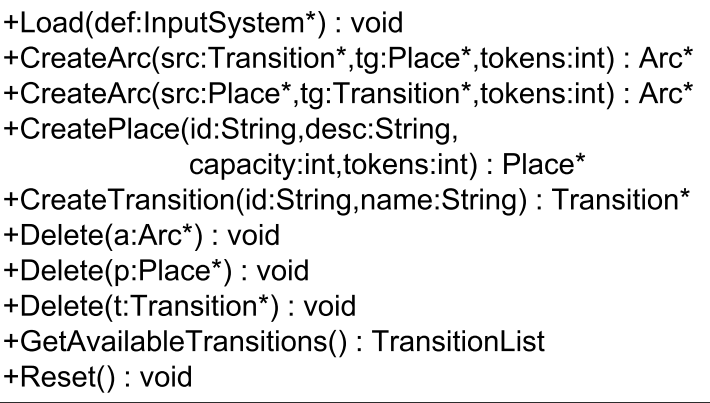 }} & \multicolumn{2}{|r|}{ Node } \\
\hline & & \multicolumn{2}{|c|}{$\begin{array}{l}\text {-_id: String } \\
\text {-_description: String } \\
\text {-_inputs: ArcList } \\
\text {-_outputs: ArcList }\end{array}$} \\
\hline & & \multicolumn{2}{|c|}{$\begin{array}{l}\text { +Node(net:Net }{ }^{*}, \text { id:String, desc:String) } \\
\left.\text { +Addlnput(a:Arc }{ }^{*}\right) \text { : void } \\
\left.\text { +AddOutput(a:Arc }{ }^{*}\right) \text { : void }\end{array}$} \\
\hline & & \multicolumn{2}{|c|}{$Z_{1} \quad \Delta$} \\
\hline Arc & \multicolumn{2}{|c|}{ Place } & Transition \\
\hline $\begin{array}{l}\text {-_multiplicity: int } \\
\text {-_source: Node* } \\
\text {-_target: Node* }\end{array}$ & \multicolumn{2}{|c|}{$\begin{array}{l}\text {-_capacity: int } \\
\text {-_tokens: int }\end{array}$} & $\begin{array}{l}\text { +Execute() : Bool } \\
\text { +IsAvailable() : Bool }\end{array}$ \\
\hline $\begin{array}{l}\text { +Arc(src:Transition }{ }^{*}, \text { tgt:Place*, } \\
\text { multiplicity:int) } \\
\text { +Arc(src:Place*,tgt:Transition*, } \\
\text { multiplicity:int) }\end{array}$ & \multicolumn{2}{|c|}{$\begin{array}{l}\text { +SetCapacity(c:int) : void } \\
\text { +InsertTokens(tokens:int) : void } \\
\text { +RemoveTokens(tokens:int) : void }\end{array}$} & \\
\hline
\end{tabular}

Figura 4.9: Diagrama de classes para rede de Petri.

O diagrama da figura 4.9 contém as principais classes utilizadas no desenvolvimento deste recurso. A classe Net representa uma rede completa, com posições, transições e arcos. Esta classe possui todas as rotinas necessárias para realizar a montagem de uma determinada rede, tanto de forma manual, como através de um arquivo contendo a descrição. 
Para maior compatibilidade com ferramentas já existentes, esta biblioteca possui recursos para interpretar o formato de arquivo PNML (Petri Net Markup Language) - formato padrão $\mathrm{ISO}^{4}$ e baseado na sintaxe XML.

Com o auxílio deste formato, os procedimentos podem ser elaborados e verificados em diversas aplicações, inclusive em alternativas gratuitas, como o Netlab ${ }^{5}$ e o Pipe ${ }^{6}$. Depois de consolidados, os procedimentos podem ser salvos no formato PNML e interpretados pela biblioteca de treinamento.

\subsection{Síntese}

Este capítulo apresentou o projeto de uma biblioteca de software para auxiliar o gerenciamento de cenários de treinamento em RV. Esta biblioteca possui recursos para facilitar o desenvolvimento e reduzir o retrabalho na implementação de objetos interativos, além de facilitar a criação de novos procedimentos de treinamento.

O projeto da biblioteca foi elaborado conforme as características da arquitetura apresentada no capítulo 3, e ilustrado através de diagramas de classe no padrão UML.

Uma das principais características deste projeto foi o estabelecimento de interfaces, como aquelas disponibilizadas através das classes Object e Procedure. Estas interfaces permitem que um determinado Cenário de Treinamento funcione de forma adequada, independente da técnica utilizada para descrever os objetos interativos e, independente do modelo usado para definir as etapas do procedimento e as suas relações de dependência.

Através do mecanismo de extensões (plug-ins), a biblioteca pode interpretar novos tipos de objetos e procedimentos, aumentando a sua flexibilidade e permitindo que a ferramenta de treinamento escolha as técnicas que melhor se adequam as necessidades do seu caso de uso.

Além da flexibilidade, o projeto também inclui recursos para facilitar a implementação de extensões. O mecanismo simplificado de gerenciamento de tarefas, disponibilizado através das classes Task e ThreadTask, possui recursos para facilitar a implementação de ações, permitindo o uso de efeitos com longa duração e sem interferir nas outras atividades da aplicação, por exemplo, a renderização.

\footnotetext{
${ }^{4}$ ISO/IEC 15909-1:2004

${ }^{5}$ Página da ferramenta Netlab: http://www.irt.rwth-aachen.de/en/downloads/petri-nettool-netlab.html. Acessado em Agosto/2010.

${ }^{6}$ Página do Pipe: http://pipe2.sourceforge.net/. Acessado em Agosto/2010.
} 
O próximo capítulo irá apresentar o desenvolvimento de duas aplicações de treinamento, que utilizaram a biblioteca de software para definir as regras de funcionamento dos seus objetos interativos e executar os seus procedimentos. 


\section{Casos de uso - Aplicações de treinamento no Setor de Energia Elétrica}

Este capítulo apresentará o uso da biblioteca de software, cuja implementação foi ilustrada no capítulo 4, no desenvolvimento de duas aplicações de treinamento de procedimentos em Realidade Virtual.

A primeira aplicação contempla a prática de uma atividade de risco, que consiste na manutenção da infra-estrutura das redes de distribuição de energia elétrica, para auxiliar no processo de capacitação dos funcionários da empresa AES Eletropaulo. Este estudo de caso será apresentado em maior detalhe, pois envolve a execução de um procedimento de maior complexidade e a manipulação de diferentes tipos de objetos interativos.

O segundo estudo de caso consiste em uma aplicação para demonstrar os elementos que compõem uma Unidade Geradora Hidrelétrica. Esta ferramenta contém procedimentos para realizar a montagem e a desmontagem de uma Unidade Geradora, e foi desenvolvida para enriquecer o processo de treinamento da empresa Furnas Centrais Elétricas.

Apesar da complexidade das máquinas e peças envolvidas neste segundo estudo de caso, os procedimentos elaborados nesta aplicação compreendem apenas a execução de atividades macro, com finalidade meramente didática. Sendo assim, o desenvolvimento deste estudo de caso será comentado de forma sucinta, pois o mesmo envolve a modelagem de procedimentos mais simples e um conjunto reduzido de objetos interativos.

Este capítulo termina com uma avaliação do processo de desenvolvido praticado nos estudos de caso, ao utilizar a biblioteca de treinamento. Esta avaliação verifica como o arcabouço de treinamento, concretizado através da biblioteca de software, auxiliou a criação destas ferramentas, reduzindo o esforço de desenvolvimento e, consequentemente, o investimento necessário para a implantação destas 
soluções.

\subsection{Estudo de caso AES Eletropaulo}

A ferramenta de treinamento para a empresa AES Eletropaulo foi desenvolvida no contexto de um projeto de P\&D financiado pela ANEEL (Agência Nacional de Energia Elétrica), através do convênio de número 0390-001/2006. O projeto tem como objetivo aprimorar o processo de capacitação das equipes de manutenção, através do desenvolvimento de aplicações em Realidade Virtual.

A crescente demanda por serviços de qualidade no fornecimento de energia elétrica têm aumentado a utilização, pelas concessionárias, dos procedimentos de manutenção em linhas de distribuição energizadas. Estes procedimentos de manutenção evitam o corte no suprimento de energia elétrica aos consumidores, no entanto, envolvem a realização de atividades de risco que exigem o uso de mão-de-obra extremamente qualificada.

Este fato tem se agravado nos últimos anos devido à aposentadoria de um grande número de profissionais experientes, associado às limitações do processo de treinamento efetuado atualmente.

Desta forma, o protótipo a ser desenvolvido neste capítulo explora um cenário real para a aplicação do treinamento em RV, cujos objetivos seriam acelerar o processo de capacitação da mão-de-obra, reduzir os custos associados e promover maior retenção da memória operativa da empresa.

Apesar de existir um número enorme de atividades de manutenção em redes de distribuição, todos envolvendo a prática de procedimentos de risco, este protótipo contemplará o treinamento de apenas uma atividade.

Para identificar uma atividade de treinamento que contribua de forma significativa para o processo de capacitação dos funcionários, a próxima seção apresenta uma visão geral sobre o perfil das redes de distribuição da AES Eletropaulo.

\subsubsection{Redes de distribuição}

A AES Eletropaulo distribui energia nas tensões de $3,8 \mathrm{kV}, 13,8 \mathrm{kV}, 23,0 \mathrm{kV}$ e $34,5 \mathrm{kV}$, utilizando redes de distribuição aéreas em dois padrões: convencional e compacta.

Na rede aérea convencional, as fases do primário utilizam condutores nus (sem 
revestimento isolante), apoiados em isoladores cerâmicos fixados em cruzetas de madeira. Já na rede compacta, as fases do primário são revestidas por um material isolante (polietileno termofixo), e são sustentadas por um cabo mensageiro de aço através de espaçadores plásticos.

Com esta configuração, a rede compacta oferece inúmeras vantagens em relação à rede convencional, principalmente na segurança e na redução dos custos operacionais. O isolamento e o cabo mensageiro da rede compacta tornam este tipo de instalação mais resistente a queda de galhos e outras intempéries, o que reduz o seu custo de manutenção preventiva e corretiva.

Além disto, as fases da rede compacta utilizam cabos revestidos de material isolante, de tal forma que a manipulação deste tipo de instalação oferece menos risco aos profissionais de manutenção.

Tabela 5.1: Extensão da rede de distribuição aérea. Extraído de (ELETROPAULO, 2007a).

\begin{tabular}{lrrrrr}
\hline & \multicolumn{4}{c}{ Tensões } & \multirow{2}{*}{$\begin{array}{l}\text { Extensão } \\
\end{array}$} \\
\cline { 2 - 5 } & $3,8 \mathrm{kV}$ & $13,8 \mathrm{kV}$ & $23,0 \mathrm{kV}$ & $34,5 \mathrm{kV}$ & Total \\
\hline Convencional & $377,1 \mathrm{~km}$ & $16.107,3 \mathrm{~km}$ & $22,1 \mathrm{~km}$ & $474,7 \mathrm{~km}$ & $16.981,2 \mathrm{~km}$ \\
Compacta & $11,3 \mathrm{~km}$ & $727,4 \mathrm{~km}$ & $0,3 \mathrm{~km}$ & $44,1 \mathrm{~km}$ & $783,0 \mathrm{~km}$ \\
Total & $388,4 \mathrm{~km}$ & $16.834,6 \mathrm{~km}$ & $22,4 \mathrm{~km}$ & $518,8 \mathrm{~km}$ & $17.764,2 \mathrm{~km}$ \\
Percentual & $2,19 \%$ & $94,77 \%$ & $0,13 \%$ & $2,92 \%$ & \\
\hline
\end{tabular}

No entanto, conforme observado na tabela 5.1, quase toda a rede de distribuição aérea da AES Eletropaulo está implementada no padrão convencional e operando com tensão 13,8 kV. Esta configuração é dominante, pois apesar das suas desvantagens, o seu custo de instalação é consideravelmente inferior ao da rede compacta.

Devido a extensão deste tipo de instalação, a maioria das atividades de manutenção ocorre em redes convencionais, cujas fases não estão revestidas de material isolante, caracterizando um cenário de maior risco para a equipe de manutenção.

Desta forma, é importante dispor de mecanismos e ferramentas que auxiliem a capacitação de funcionários que trabalham na manutenção deste tipo de rede.

Sendo assim, a atividade de manutenção escolhida para ser praticada neste estudo de caso foi a substituição de cruzeta simples em linha viva. Esta atividade é realizada em redes de distribuição convencionais e envolve a manipulação das fases do primário sem interromper o fornecimento de energia elétrica. Os detalhes desta atividade são apresentados na seção seguinte. 


\subsubsection{Atividade de manutenção}

A atividade de substituição de cruzeta simples em linha viva envolve a execução de um procedimento demorado e de alto risco. Este procedimento consiste em realizar a troca da cruzeta de um poste, sem interromper o fornecimento de energia elétrica aos consumidores.

Conforme ilustrado na figura 5.1, a cruzeta é usada para sustentar todas as fases da rede primária. Em uma rede de distribuição convencional, estas fases não são revestidas por nenhum material isolante e estão fixadas diretamente em isoladores cerâmicos presos na cruzeta de madeira.

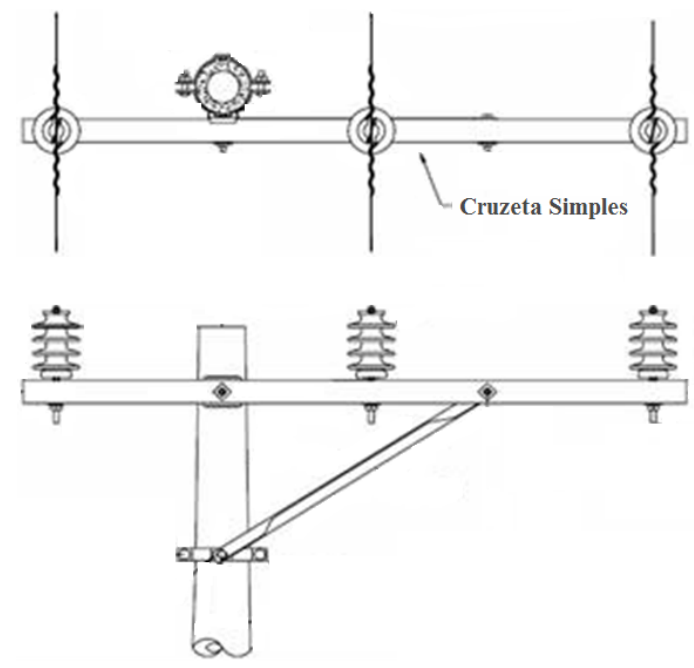

Figura 5.1: Poste com cruzeta simples.

Outra característica desta configuração, é o fato de que a cruzeta se localiza na parte mais alta do poste. Desta forma, para executar qualquer procedimento de manutenção na rede primária, é necessário fazer uso de um caminhão com cesta aérea.

A cesta aérea permite que o usuário seja erguido até a posição adequada para executar as suas atividades. A posição desta cesta é controlada pelo próprio funcionário, através de pequenas alavancas. Devido a complexidade destas atividades, estas são normalmente executadas por duas pessoas, sendo que uma delas permanece no solo para auxiliar no posicionamento da cesta e na transferência de equipamentos e peças de reposição.

A tabela 5.2 apresenta uma lista das principais tarefas que o usuário precisa executar no procedimento de troca de cruzeta em linha viva. Neste procedimento, o funcionário utiliza um conjunto de elevação, que é uma estrutura fixada no poste de forma temporária, apenas para sustentar as fases do primário enquanto 
Tabela 5.2: Passos para a troca de cruzeta em linha viva.

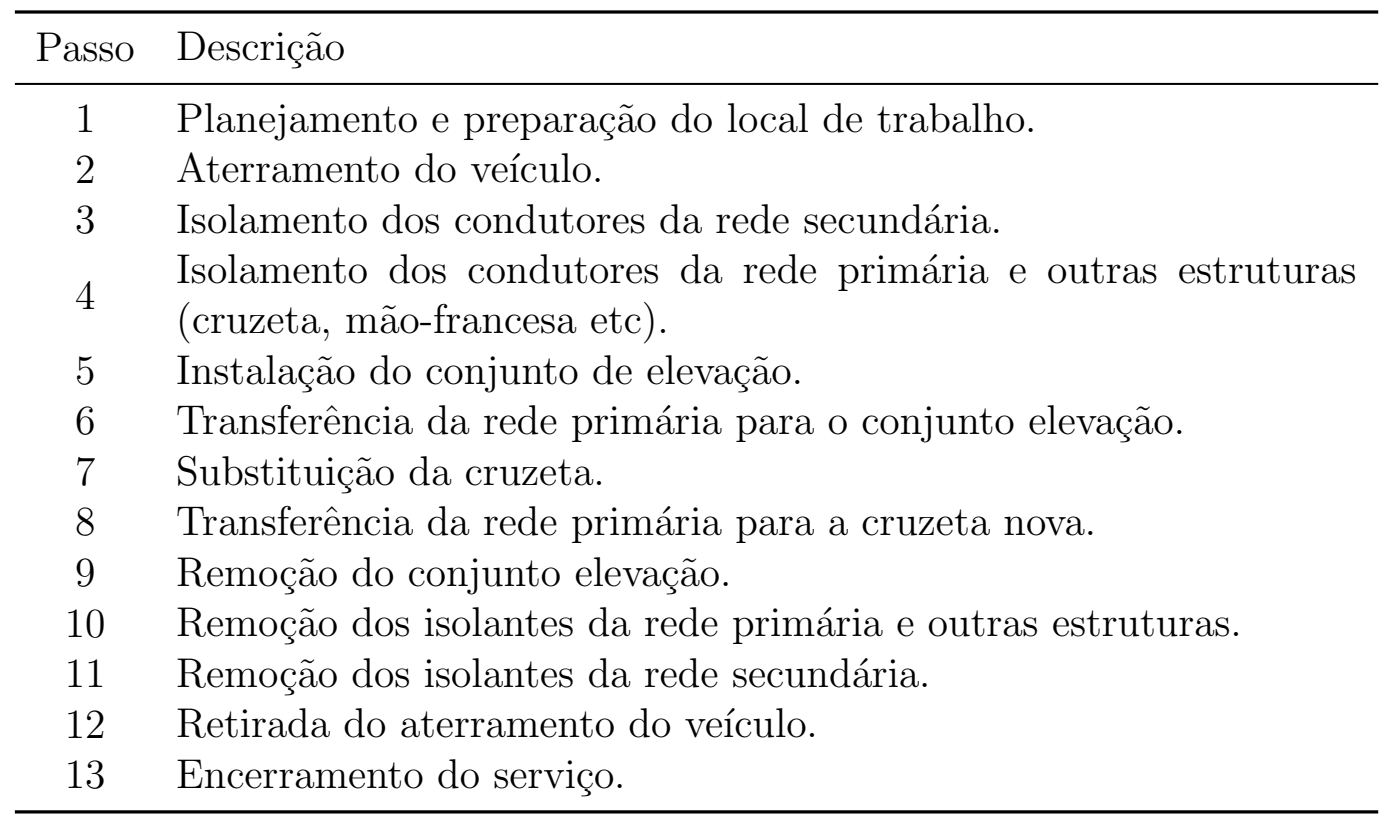

a cruzeta é substituída.

Como este procedimento é realizado em uma rede aérea convencional, a maioria das atividades mencionadas nesta tabela envolve a manipulação de materiais para a isolação dos condutores e outras estruturas. Estes materiais de isolação são fundamentais e garantem a segurança do usuário ao longo de todo o procedimento.

É extremamente importante que o funcionário aplique a isolação de forma adequada e na ordem correta. A ordem na aplicação dos isolantes garante que todos os procedimentos executados pelo usuário sejam realizados com segurança, envolvendo apenas a manipulação de cabos e outras estruturas devidamente isoladas.

Para garantir a segurança dos funcionários, todas estas atividades de manutenção foram padronizadas e estão descritas em manuais de procedimentos técnicos elaborados pela AES Eletropaulo (ELETROPAULO, 2007b).

A figura 5.2 ilustra o procedimento de troca de cruzeta em linha viva. Nesta figura, é possível observar que as fases da rede secundária e da rede primária já foram isoladas. Além disto, o conjunto de elevação está instalado e o usuário já iniciou o processo de transferir as fases da rede primária para o conjunto de elevação.

Para facilitar a documentação destes procedimentos, cada fase da rede de distribuição está associada com uma letra do alfabeto. As fases da rede secundária são identificadas pelas letras A, B e C. Sendo a fase C a mais baixa e próxima do 


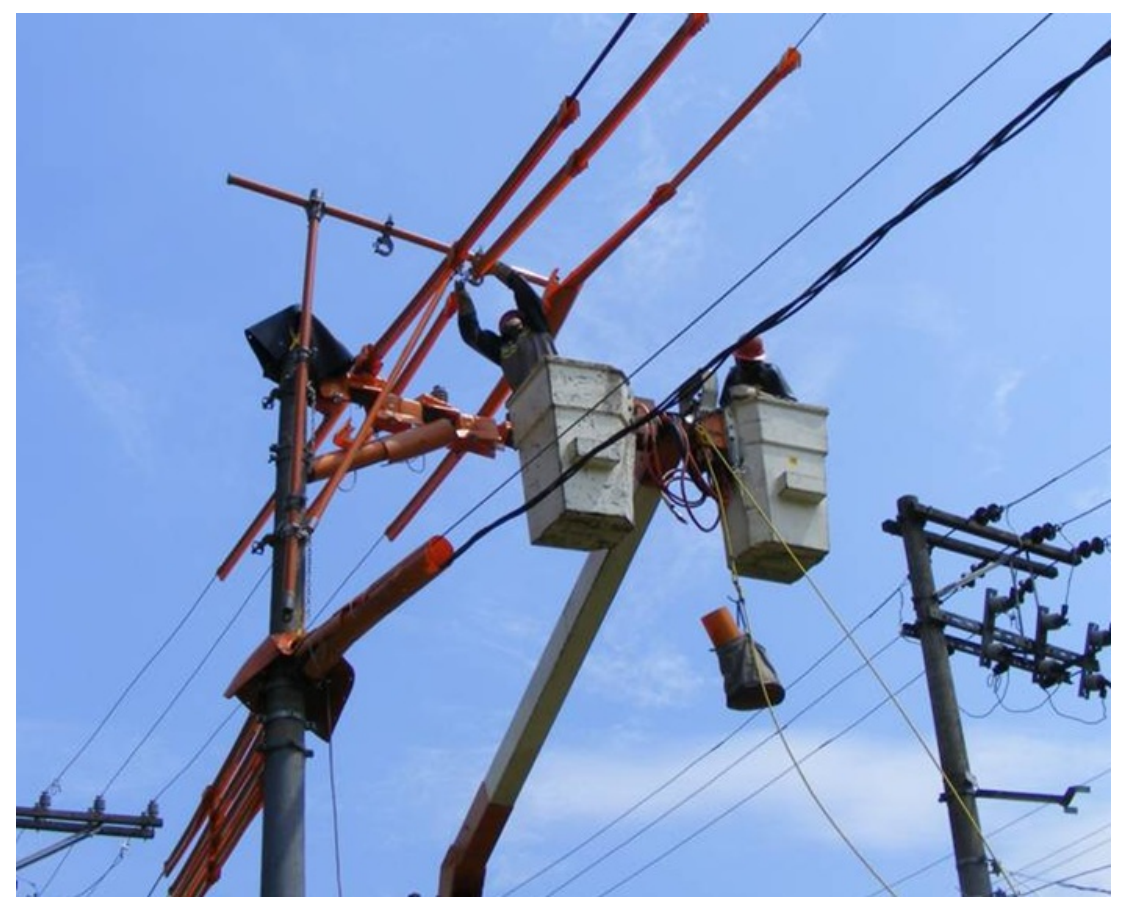

Figura 5.2: Realização da troca de cruzeta em linha viva. Extraído de (ELETROPAULO, 2007a)

solo, e a fase A a mais alta e próxima do primário.

A fases do primário são identificadas pelas letras D, E e F. Sendo que a fase D está do lado da rua, a fase E está no centro e a fase F está do lado das residências. Esta identificação é conhecida por todos os funcionários e é usada como referência nos manuais técnicos de operação.

Estes manuais técnicos de operação determinam que ao isolar e rede secundária, a fases devem ser isoladas na ordem C, B e A, ou seja, de baixo para cima, para prevenir que a cesta aérea do caminhão entre em contato com um condutor não isolado.

Da mesma forma, ao isolar a rede primária, os condutores devem ser isolados na ordem D, E e F, ou seja, da rua para a residência, evitando que o funcionário fique de costas para qualquer condutor não isolado.

A figura 5.3 apresenta a identificação usada para as fases da rede secundária e primária. Nesta figura, a rede secundária já foi isolada, e o funcionário está isolando a rede primária, iniciando corretamente pela fase D.

Para auxiliar na memorização destas etapas, a aplicação de treinamento desenvolvida permite com que o usuário pratique o procedimento completo de troca de cruzeta. Os detalhes sobre a arquitetura e o desenvolvimento desta aplicação são apresentados na seção seguinte. 


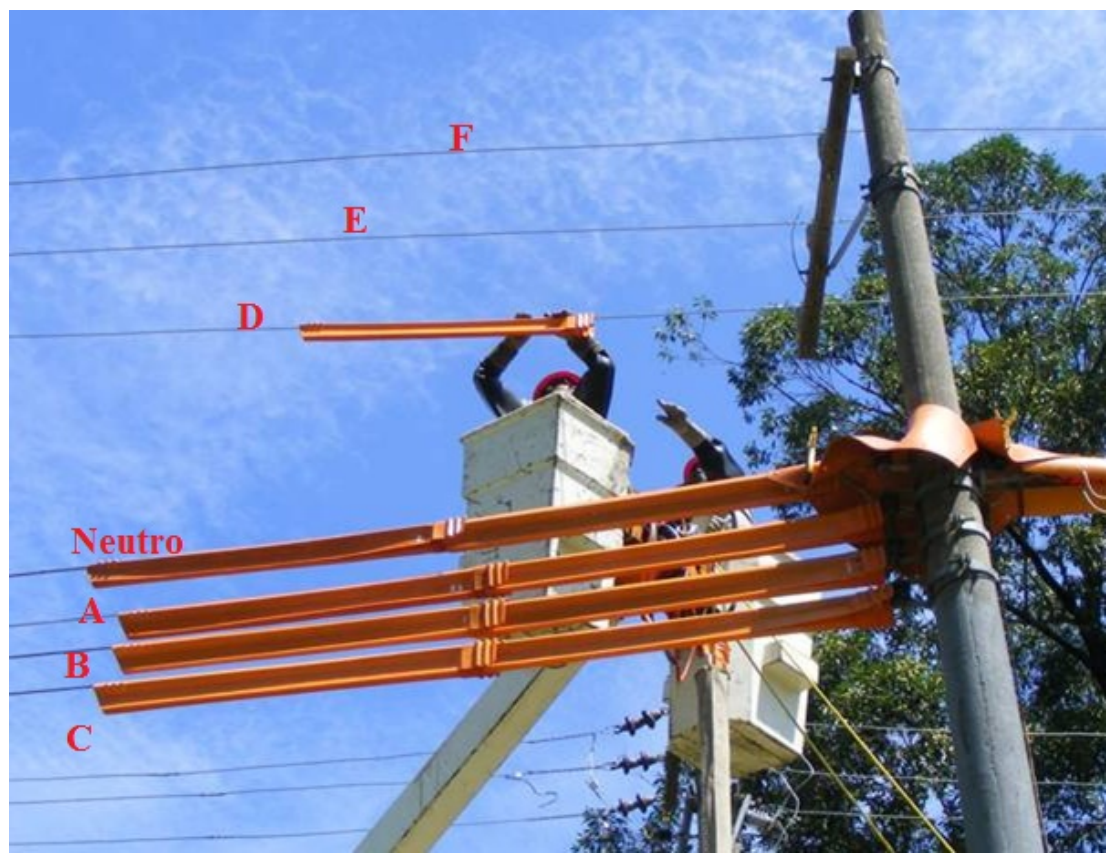

Figura 5.3: Identificação das fases da rede secundária e primária. Extraído de (ELETROPAULO, 2007a)

\subsubsection{Aplicação de treinamento}

A ferramenta de treinamento foi planejada e desenvolvida para ser executada em um sistema de realidade virtual simplificado ou em um computador convencional. Desta forma, a aplicação pode tirar proveito dos recursos de estereoscopia presentes na infraestrutura de projeção instalada nas dependências da Eletropaulo, e também ser executada em uma infraestrutura simples, contendo apenas um monitor ou projetor convencional.

A aplicação contém todos os recursos necessários para criar um ambiente virtual para simulação de procedimentos e foi concebida para prover uma interface de operação simples e amigável, viabilizando a sua utilização por usuários pouco familiarizados com aplicações de conteúdo 3D.

\subsubsection{Arquitetura}

O planejamento da aplicação foi realizado com base na biblioteca de software apresentada no capítulo 4. De acordo com a figura 5.4, a arquitetura desta aplicação possui três módulos principais: o Módulo de Interação, o Módulo de Apresentação e o Módulo de Controle da atividade de treinamento.

A arquitetura da ferramenta é apresentada de forma simples, pois grande parte da complexidade deste diagrama foi transferida para a arquitetura da bi- 


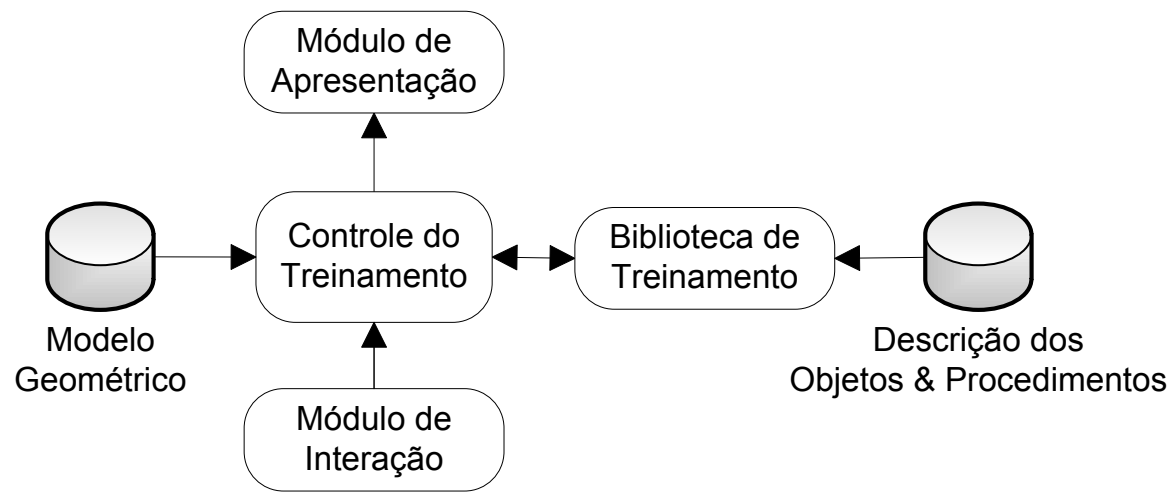

Figura 5.4: Arquitetura da aplicação de treinamento.

blioteca de treinamento.

Neste diagrama, o Módulo de Apresentação é responsável por disponibilizar todo o conteúdo envolvido no treinamento para o usuário. Este conteúdo pode ser classificado como objeto 3D, texto, áudio, vídeo e elementos da interface gráfica, como botões, menus, caixas de diálogo, entre outros.

O Módulo de Apresentação utiliza o Ogre como biblioteca de grafo de cena, para renderizar objetos 3D em tempo-real e manter a compatibilidade com a biblioteca de treinamento. Além disto, para apresentar conteúdo de áudio, vídeo e interface gráfica, este módulo utiliza a biblioteca Hikari ${ }^{1}$.

O Hikari é uma biblioteca de software que possui recursos para interpretar e executar arquivos em Flash, da Adobe. Além de ser integralmente compatível com o Ogre, a tecnologia Adobe Flash permite que interfaces gráficas sejam criadas de forma simples e fácil, contendo recursos para apresentar imagens e vídeos no formato FLV.

Já o Módulo de Interação contém os elementos necessários para que o usuário possa manipular e interagir com os objetos do cenário. Nesta versão, o usuário pode utilizar o mouse para selecionar os objetos que o mesmo deseja manipular. Este módulo também é responsável por tratar os eventos de controle da interface gráfica com o usuário.

A figura 5.5 apresenta a interface criada para reproduzir as alavancas de controle da cesta aérea do caminhão. Através destas alavancas o usuário pode rotacionar a cesta e alterar a sua altura, reproduzindo os controles encontrados no caminhão da AES Eletropaulo.

O Módulo de Controle do Treinamento é responsável por integrar a biblioteca

\footnotetext{
${ }^{1}$ Página do projeto Hikari: http://code.google.com/p/hikari-library/. Acessado em Agosto/2010.
} 


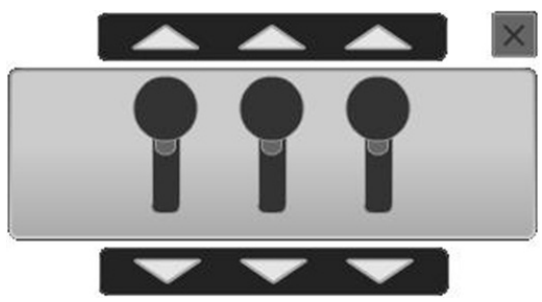

Figura 5.5: Interface de controle da cesta aérea.

de treinamento com os outros dois módulos da aplicação. Os eventos de interação do usuário são utilizados para identificar as ações que devem ser executadas. Estas ações são verificadas com o auxílio da biblioteca, de acordo com a descrição do procedimento, e os resultados são apresentados ao usuário através de alterações no modelo geométrico, ou utilizando outros recursos, como caixas de diálogo, por exemplo.

\subsubsection{Modelos Geométricos}

Para elaborar uma aplicação de treinamento em Realidade Virtual, foi necessário realizar a modelagem do cenário e de todos os objetos envolvidos no treinamento.

Para a atividade de troca de cruzeta simples em linha viva foi criado um ambiente virtual com características semelhantes ao encontrado durante a atividade, incluindo modelos para representar edifícios, casas, carros etc.

Além da criação do cenário, todos os objetos utilizados na atividade de treinamento também foram modelados, como condutores, ferramentas, coberturas de isolação, entre outros. Estes modelos virtuais foram elaborados seguindo criteriosamente todas as dimensões e proporções dos objetos reais.

A figura 5.6 ilustra o processo de criação da cruzeta, contendo os condutores da rede primária e o poste. Esta figura também apresenta o modelo da cela simples inferior, que sustenta o mastro do conjunto de elevação. Esta ilustração ressalta a importância de modelar os objetos seguindo criteriosamente as suas dimensões, caso contrário, não seria possível encaixá-los conforme demonstra a figura.

Além do processo de modelagem, diversas fotos foram utilizadas para a aplicação de texturas, que é um mecanismo que melhora a aparências das peças no ambiente virtual, aumentando o realismo e a sensação de imersão do usuário.

A tabela 5.3 apresenta uma lista dos principais modelos, com o número de polígonos (triângulos) utilizados para representá-los. Note que o nível de detalhe 

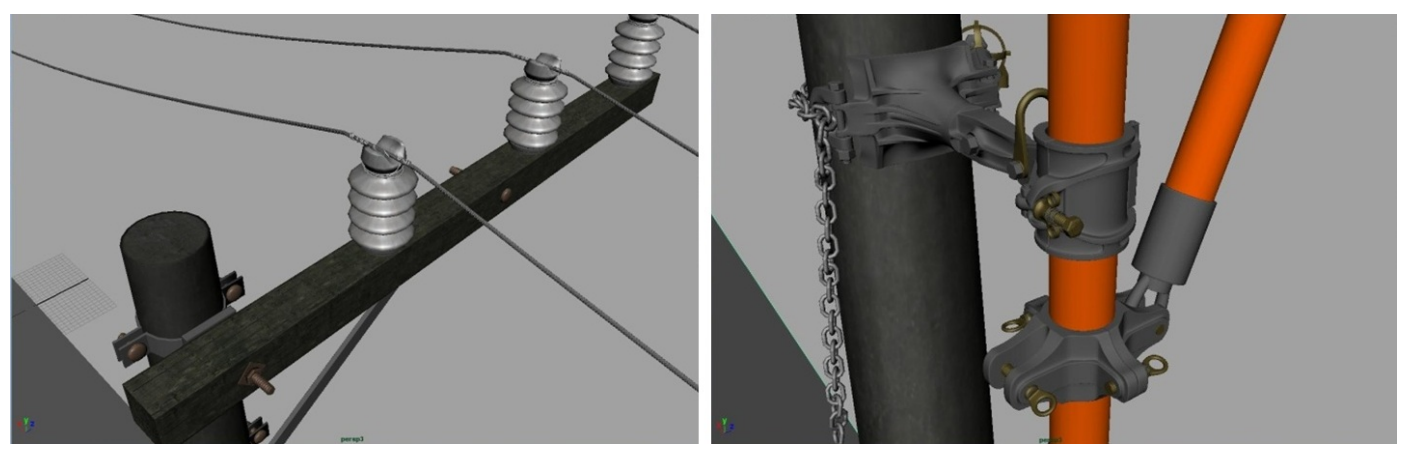

Figura 5.6: Modelos geométricos da cruzeta e do conjunto de elevação.

Tabela 5.3: Número aproximado de polígonos dos modelos geométricos.

\begin{tabular}{clr}
\hline Grupo & Descrição & $\begin{array}{r}\text { Número de } \\
\text { Triângulos }\end{array}$ \\
\hline Cenário & Edificações (diversos tipos) & 5.212 \\
& Carros (diversos tipos) & 27.700 \\
& Poste, fios e cruzeta & 22.680 \\
& Caminhão e cesta aérea & 68.550 \\
Coberturas & Cobertura para condutor (calha) & 1.192 \\
Isolantes & Cobertura para cruzeta & 6.072 \\
& Isolador de pino & 888 \\
& Cobertura circular (bombril) & 332 \\
& Manta isolante & 1.088 \\
Conjunto de & Bastão mastro & 77.060 \\
Elevação & Cruzeta auxiliar & 2.842 \\
& Bastão garra & 240 \\
& Cela simples de elevação & 188.922 \\
& Presilhas de suspensão & 45.558 \\
\hline
\end{tabular}

usado para representar cada objeto varia de acordo com a sua posição em relação ao observador.

Por exemplo, as edificações possuem modelos mais simples, pois estão distantes do usuário e, portanto, muitos dos seus detalhes podem ser representados de forma satisfatória através de texturas, reduzindo a complexidade do modelo geométrico.

\subsubsection{Vídeos}

Para auxiliar o processo de aprendizagem e enriquecer o conteúdo apresentado pela ferramenta de treinamento, foram realizadas filmagens de diversas etapas da atividade de troca de cruzeta em linha viva.

Os filmes foram capturados e inseridos na ferramenta de treinamento com os 
seguintes objetivos:

- Demonstrar a manipulação de ferramentas e outros equipamentos com os quais o usuário obtiver contato;

- Mostrar a posição da cesta e a postura dos operários mediante a realização de alguma atividade específica;

- Ilustrar o uso dos equipamentos de proteção individual, como luvas, capacetes e outros;

- Demonstrar a realização de procedimentos não simulados pela ferramenta, como isolamento do local de manutenção, seleção e verificação dos equipamentos, etc.

Nesta versão do software de treinamento, não está prevista a simulação da chegada do caminhão e a realização de preparos iniciais, como o isolamento da área e a seleção dos equipamentos a serem usados na atividade. Assim, estas etapas serão reproduzidas através de vídeos elaborados no local do treinamento tradicional.

Além disto, alguns vídeos foram elaborados para ilustrar a manipulação de determinadas peças ou ferramentas de maior complexidade. Em algumas etapas do procedimento, o paradigma de interação através de ações e o uso do mouse como principal periférico de interação pode limitar a experiência do usuário em relação à verdadeira complexidade da etapa.

Nestes casos, os vídeos foram introduzidos para enriquecer a compreensão do funcionário e amenizar as distorções existentes entre a complexidade observada no ambiente virtual e a complexidade da atividade real.

Estes vídeos podem ser acessados pelo usuário através da interface gráfica da própria aplicação, sem a necessidade de abrir outro aplicativo somente para esta finalidade. Além disto, a apresentação deste conteúdo é facultativa, ou seja, o vídeo será acionado apenas quando o usuário manifestar interesse, evitando a interrupção desnecessária do procedimento.

\subsubsection{Objetos interativos}

A criação dos objetos interativos para a realização da troca de cruzeta envolveu o desenvolvimento de uma extensão (plug-in) para ser inserido na biblioteca de 
treinamento. Esta extensão contém as Classes de Funcionamento dos objetos que serão manipulados durante o procedimento.

As Classes de Funcionamento determinam as regras de operação e as ações dos objetos, e são implementadas através da especialização da classe abstrata Object, disponível na biblioteca.

A figura 5.7 apresenta um diagrama resumido das principais Classes de Funcionamento implementadas para a realização do procedimento de troca de cruzeta. Neste diagrama, a classe abstrata Object contém o prefixo "prosim::", para enfatizar que esta pertence a biblioteca de simulação de procedimentos (procedure simulation). As classes com prefixo "aes ::" foram todas implementadas para o estudo de caso, e inseridas na extensão (plug-in) da AES Eletropaulo.

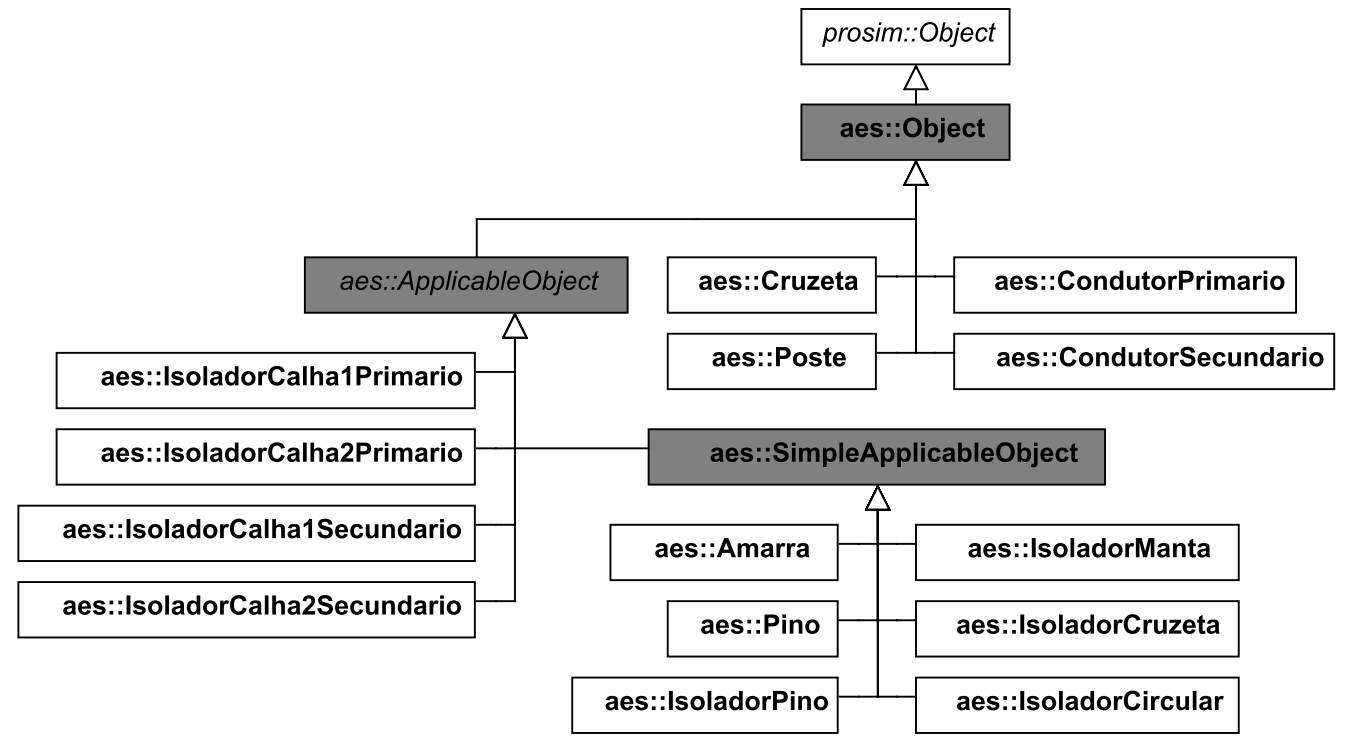

Figura 5.7: Diagrama das Classes de Funcionamento para troca de cruzeta.

Neste diagrama, a classe aes :: Object representa um objeto básico do procedimento de troca de cruzeta. Todos os objetos interativos deste procedimento devem herdar desta classe. No entanto, a sua implementação não contém nenhuma ação, apenas propriedades com informações básicas dos objetos.

Algumas propriedades registradas pela classe aes:: Object são: description, icon, selectable e apply. Estas propriedades devem ser preenchidas por todos os objetos e serão usadas, principalmente, pela interface gráfica da aplicação de treinamento. Por exemplo, quando se mostrar necessário utilizar um ícone para representar um determinado objeto, a aplicação consultará a imagem presente na propriedade icon deste objeto.

Uma das propriedades mais relevantes registradas pela classe aes :: Object é a propriedade apply. Esta propriedade contém uma lista de outros objetos que 
podem ser aplicados neste. Esta lista é usada pela aplicação para apresentar, mediante a requisição do usuário, uma lista das peças que podem ser aplicadas em um determinado objeto.

Por exemplo, de acordo com a figura 5.7, a classe aes :: Poste herda da classe aes :: Object. Embora o usuário não possa executar nenhuma ação para manipular o poste, o usuário poderá consultar quais o objetos que podem ser aplicados no poste, através da propriedade apply.

Listagem 5.1: Classe de Funcionamento ApplicableObject.

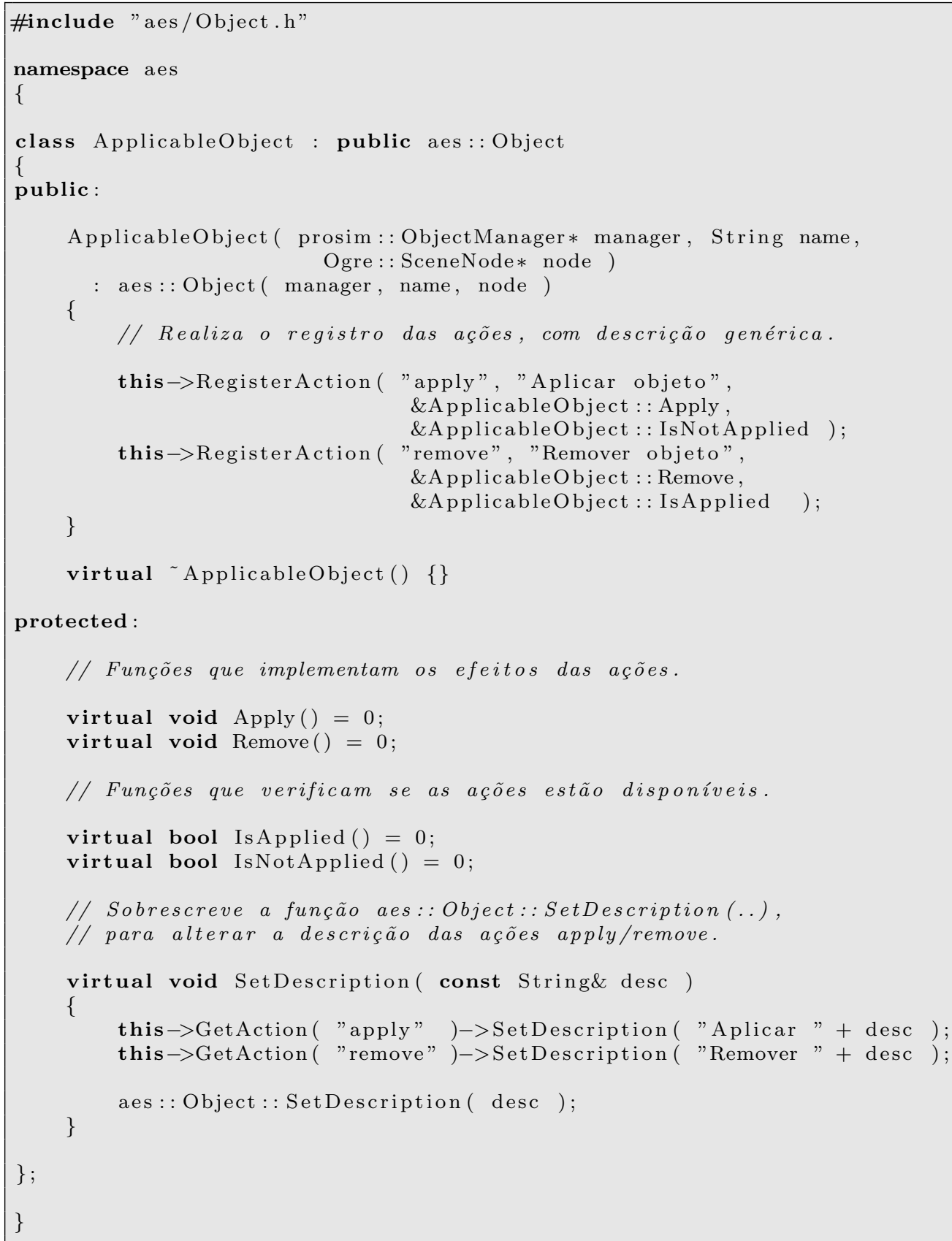

Todos os objetos presentes na lista da propriedade apply devem herdar da classe abstrata aes :: ApplicableObject. Esta classe contém, além das propriedades registradas por aes :: Object, duas ações para manipular os seus objetos: a ação 
apply e a ação remove.

Desta forma, quando o usuário aplicar uma peça em um determinado objeto, o mesmo escolherá esta peça a partir de uma lista disponível na propriedade apply deste objeto. Após a escolha do usuário, a aplicação identificará a peça escolhida e executara a sua ação apply. Por este motivo, é importante que todos os objetos presentes nesta lista sejam herdeiros da classe aes :: ApplicableObject, pois esta classe sempre terá uma ação com o nome apply.

A listagem 5.1 demonstra a implementação da Classe de Funcionamento abstrata aes :: ApplicableObject.

Nesta listagem, a Classe aes :: ApplicableObject registrou duas ações: apply e remove. Estas ações foram registradas utilizando a função Object::RegisterAction (..), que recebe como parâmetros o nome da ação, a descrição da ação, um ponteiro para a função que executa os efeitos da ação e, por último, um ponteiro para a função que verifica se esta ação está disponível.

Desta forma, os efeitos da ação remove serão efetuados pela função Remove(), e esta ação só estará disponível para o usuário quando a função IsApplied() retornar um valor booleano verdadeiro, ou seja, apenas quando o objeto já estiver aplicado.

No entanto, as funções que determinam os efeitos das ações, neste caso as funções Apply() e Remove(), são puramente virtuais, ou seja, a sua implementação não foi realizada nesta classe, fazendo com que todas as outras Classes que herdarem de aes :: ApplicableObject tenham que, de fato, implementar estas funções.

As Classes que herdarem de aes:: ApplicableObject, no entanto, poderão conter outras ações, outras propriedades e implementar um comportamento arbitrariamente complexo. Portanto, não há nenhuma restrição imposta pela Classe aes :: ApplicableObject, a não ser o fato de que suas herdeiras devem implementar as ações apply e remove.

Outra Classe de Funcionamento importante, da extensão AES Eletropaulo, é a classe aes :: SimpleApplicableObject. Esta classe é herdeira de aes :: ApplicableObject, no entanto, a mesma contém a implementação de todas as funções relevantes para o funcionamento da ações apply e remove.

A listagem 5.2 demonstra a implementação da Classe de Funcionamento aes :: SimpleApplicableObject. Observe que esta Classe herda de aes :: ApplicableObject e contém a implementação para todas as suas funções puramente virtuais, como Apply() e Remove(). 
Listagem 5.2: Classe de Funcionamento SimpleApplicableObject.

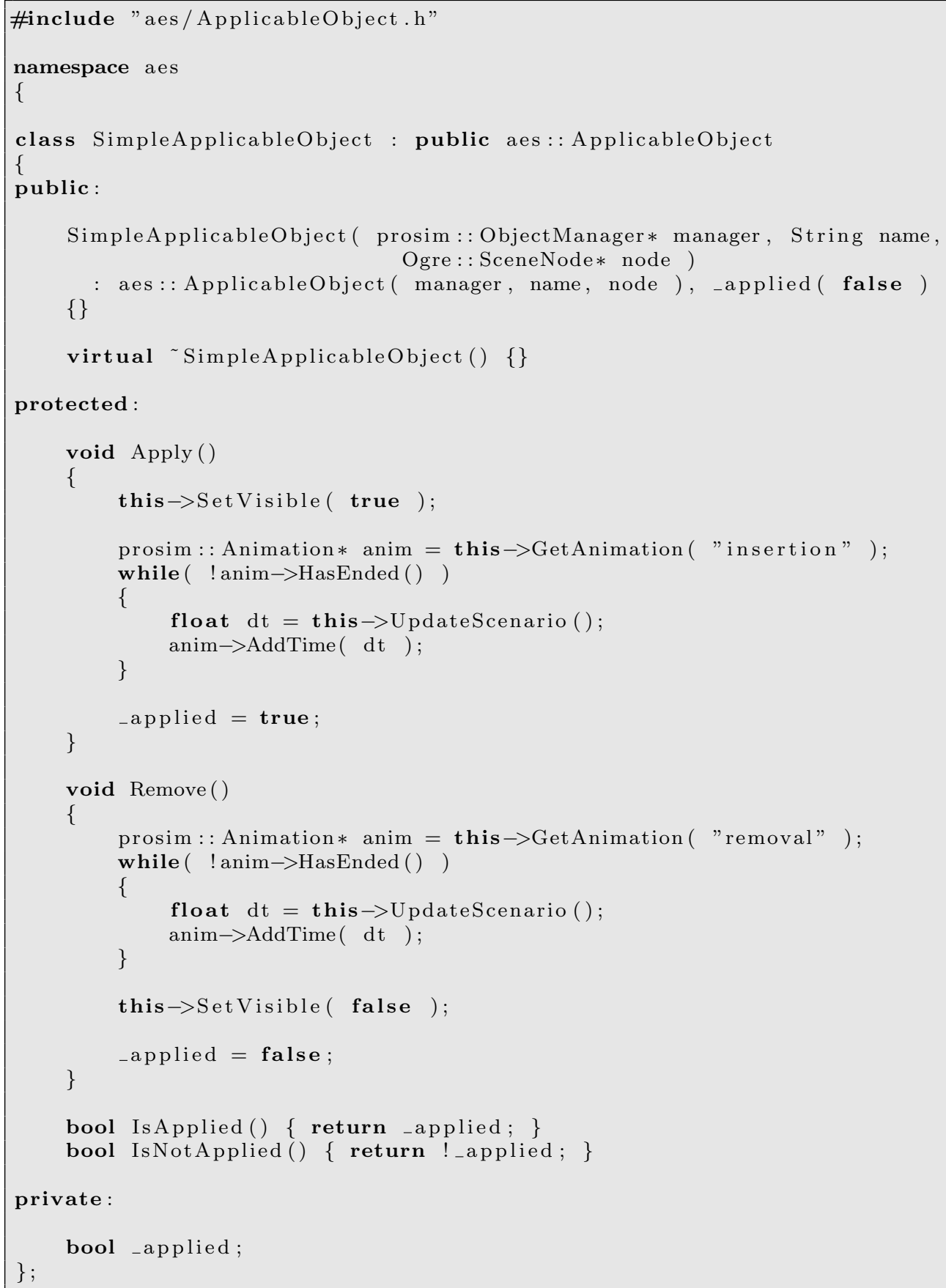

Ao contrário da classe básica aes :: ApplicableObject, a implementação da classe aes :: SimpleApplicableObject contém a definição de um funcionamento, que inclui os efeitos das ações apply e remove, e o controle de quando estas ações estarão disponíveis.

Esta Classe de Funcionamento é utilizada em diversos objetos do procedimento de troca de cruzeta que são manipulados apenas através destas duas ações, como os pinos de cerâmica, que fixam os condutores do primário na cruzeta, diversos tipos de isoladores, as peças do conjunto de elevação, entre outros. 
De acordo com esta listagem, os efeitos implementados na função Remove() consistem em apresentar a animação de nome removal, e em seguida, ocultar o objeto. A animação de nome removal reproduz o movimento de remoção da peça, e em seguida, a peça é ocultada para representar de forma simplificada a sua transferência para o homem de solo.

Durante a execução desta animação, a função Object::UpdateScenario() é chamada a cada interação do loop. Esta função é responsável por interromper momentaneamente a execução da animação, permitindo que as outras tarefas fundamentais da aplicação, como o processo de renderização, sejam realizadas periodicamente, evitando longos períodos de interrupção.

Ainda na listagem 5.2, observe que todos os métodos associados com as ações da Classe aes :: SimpleApplicableObject foram declarados como protegidos. Embora esta conduta não seja mandatória, esta declaração garante que as funções serão chamadas apenas mediante a execução de uma ação, ou seja, apenas através da classe prosim::MethodAction, que pertence ao gerenciamento de tarefas da biblioteca de treinamento.

Caso contrário, se uma destas funções for executada fora do contexto de uma ação, a mesma pode interromper o processo de renderização da aplicação, impedindo que o usuário observe os seus efeitos, como as animações.

A implementação das outras Classes de Funcionamento foi realizada de forma semelhante ao apresentado nesta seção, porém, com pequenas variações nas suas regras de funcionamento. Todas estas Classes foram registradas na extensão da AES Eletropaulo, para uso no procedimento de troca de cruzeta, e para outros procedimentos que serão desenvolvidos futuramente.

\subsubsection{Procedimento}

O modelo de Rede de Petri foi adotado como alternativa padrão para descrever os procedimentos na biblioteca de treinamento. Apesar de esta biblioteca permitir que novos modelos sejam introduzidos através do mecanismo de extensões ( $p l u g$ ins), isto não se mostrou necessário no caso da AES Eletropaulo.

Desta forma, a rede de Petri foi escolhida para descrever o procedimento de troca de cruzeta, pois além deste modelo apresentar todos os recursos necessários para definir esta atividade, já existem diversas aplicações distribuídas gratuitamente que auxiliam o processo de construção e validação destas redes.

Para elaborar o estudo de caso, o software Netlab foi escolhido por ser distri- 
buído gratuitamente, e permitir que as redes sejam salvas no formato de arquivo PNML (Petri Net Markup Language), que é o formato de arquivo adotado pela biblioteca de treinamento.

Ao descrever um procedimento utilizando redes de Petri, cada transição da rede está associada com uma ação de um determinado objeto interativo. Esta ação poderá ser executada pelo usuário apenas quando a sua transição estiver disponível para ser efetuada na rede de Petri.

Para associar uma transição com uma ação de um determinado objeto, o nome desta transição no arquivo PNML deve ter o seguinte formato "nome-daação@nome-do-objeto". Ao utilizar esta formatação, a biblioteca de treinamento consegue obter a partir do nome, o objeto e a ação ao qual a mesma se refere.

A figura 5.8 apresenta um trecho do início do procedimento de troca de cruzeta. Este trecho contém atividades puramente sequenciais, e envolve a aplicação de isoladores do tipo calha na fase $\mathrm{C}$ da rede secundária.

Cada fase da rede secundária precisa de dois isoladores. Na figura 5.8, os dois isoladores da fase $\mathrm{C}$ são identificados pelos nomes isolador_calha_fase_C_1 e isolador_calha_fase_C_2.

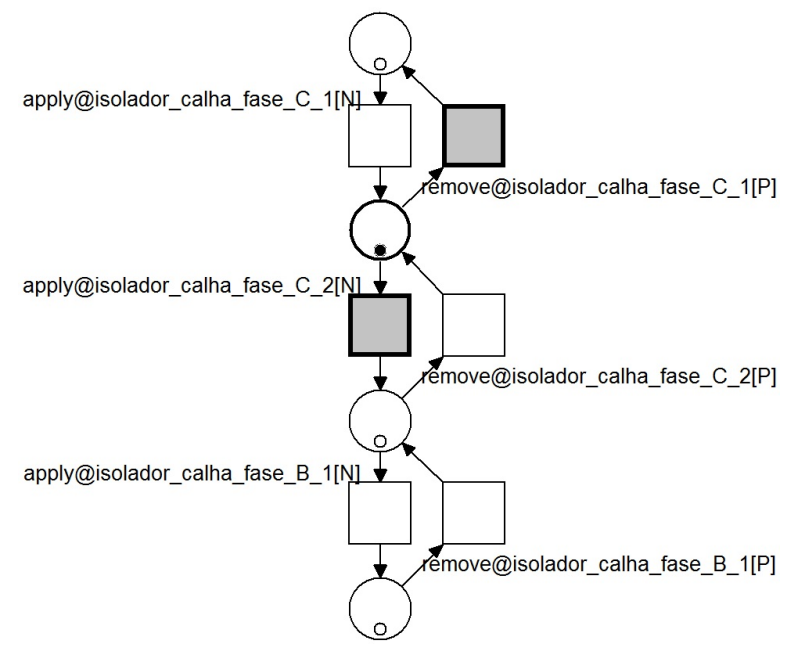

Figura 5.8: Trecho inicial do procedimento de troca de cruzeta.

Nesta figura, as transições disponíveis para execução foram destacadas com a cor cinza. O usuário pode, portanto, executar a ação apply do isolador 2 da fase $\mathrm{C}$, ou executar a ação remove do isolador 1 da mesma fase. Nesta situação, o usuário já aplicou o primeiro isolador e, agora, pode escolher entre removê-lo ou aplicar o segundo.

Estas situações ocorrem com frequência durante o treinamento da troca de cruzeta, pois todo o procedimento foi elaborado contendo caminhos de retorno, o 
que permite que o usuário possa escolher entre ações que irão avançar ou retroceder no procedimento.

Para diferenciar as transições da rede que avançam das que retrocedem, o nome destas transições possui o sufixo $[N]$ ou $[P]$. O sufixo $[N]$ é colocado nas transições que avançam no procedimento, enquanto que o sufixo $[P]$ é colocado no nome das transições que retrocedem no procedimento.

Embora grande parte da atividade de troca de cruzeta possa ser representada de forma sequencial, alguns trechos desta atividade oferecem alternativas ao usuário, onde este pode escolher qual a ordem em que as tarefas serão executadas. Nestes trechos, a representação sequencial não é adequada e outros recursos da rede de Petri precisam ser utilizados.

A figura 5.9 apresenta um trecho do procedimento que antecede a substituição da cruzeta. Neste momento, o usuário precisa remover os isoladores colocados na cruzeta antiga, antes de substituí-la pela cruzeta nova. Como os condutores da rede primária já foram transferidos para o conjunto de elevação, a cruzeta velha não está mais sendo usada e, portanto, não há mais risco de choque através da mesma.

Para melhorar a compreensão da figura, as transições que representam atividades semelhantes foram identificadas com a mesma cor. As transições que não foram coloridas representam o caminho de retorno.

A transição na cor amarela contém a última ação que envolve a transferência dos condutores, da cruzeta velha para o conjunto de elevação. Após esta ação, o usuário pode escolher em qual ordem os isoladores serão retirados da cruzeta velha.

As transições que contêm a remoção dos isoladores estão identificadas com a cor vermelha. Note que neste caso, há quatro trechos que o usuário precisa percorrer. Embora todos os trechos precisem ser executados pelo usuário, a ordem com que estes trechos serão executados é indiferente.

Após a retirada dos isoladores, o usuário precisa remover os pinos de cerâmica da cruzeta. A remoção destes pinos está identificada pelas transições na cor azul. De acordo com a rede, estas transições só ficarão disponíveis após a execução de todas as etapas em vermelho.

Ao final deste trecho, a ação que realiza a substituição da cruzeta está identificada pela cor verde. Esta ação só poderá ser executada após todos os pinos serem removidos. Conforme ilustrado através da rede de Petri, embora o usuário 


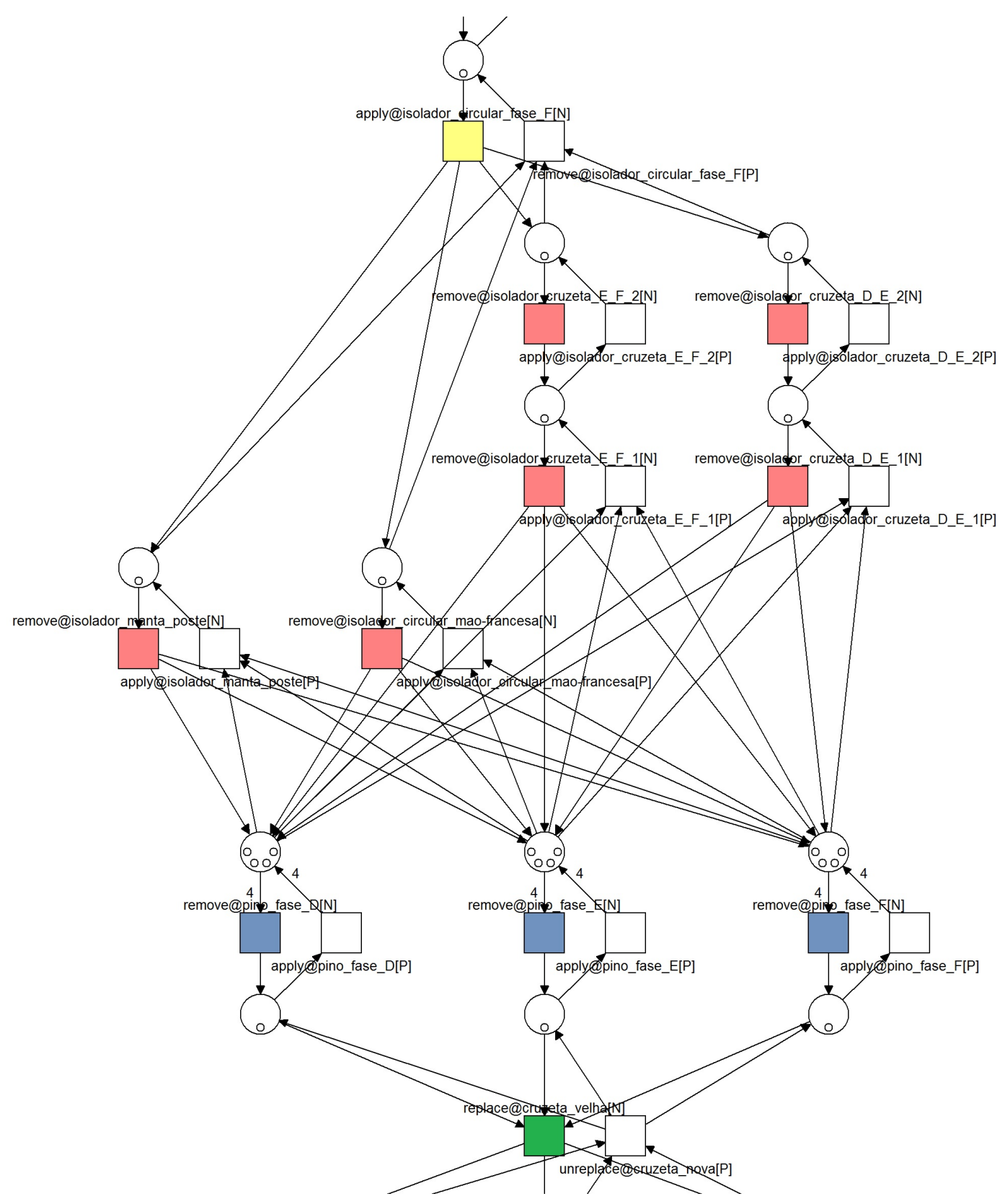

Figura 5.9: Trecho que antecede a substituição da cruzeta.

precise remover todos os pinos antes de trocar a cruzeta, a rede não determina a ordem em que estes pinos devem ser removidos.

Após a troca da cruzeta, a rede de Petri permanece de forma semelhante, permitindo que o usuário escolha a ordem em que os isoladores serão recolocados na cruzeta nova. Em seguida, o procedimento volta a ser sequencial, onde o usuário fará a transferência dos condutores, retornando os mesmos do conjunto de elevação para a cruzeta.

Para que o usuário possa concluir o procedimento adequadamente, uma transição com o nome Finish precisa estar disponível para ser executada no momento da conclusão. Caso esta transição não esteja disponível, a ferramenta de treina- 
mento informará o usuário de que ainda existem atividades pendentes para serem executadas. Ao contrário da conclusão, o cancelamento pode ser efetuado em qualquer momento, independente do estado da rede de Petri.

Para melhorar a compreensão das redes apresentadas nesta seção, o apêndice A apresenta alguns padrões de redes de Petri, utilizados com frequência ao declarar as relações de dependência existentes entre as ações dos objetos interativos. A rede Petri completa, utilizada no procedimento de troca de cruzeta em linha viva, pode ser consultada no apêndice B.

\subsubsection{Realização do treinamento}

A aplicação de treinamento foi elaborada com uma interface gráfica simples e de fácil compreensão, para permitir que mesmo os funcionários não familiarizados com aplicações complexas possam utilizá-la. Ao iniciar a ferramenta, o menu apresentado na figura 5.10 permite que o usuário escolha o modo de funcionamento da aplicação. Os modos disponíveis são: o modo Demonstração e o modo Avaliação.

No modo Demonstração, a ferramenta disponibilizará ao usuário mecanismos para avançar e retroceder no procedimento automaticamente. Neste modo, a intervenção do usuário é facultativa, o mesmo pode apenas observar a execução da atividade.

No modo Avaliação, o usuário precisa executar todo o procedimento, escolhendo manualmente as ações disponíveis em cada objeto. Neste modo, todas as ações executadas pelo usuário serão colocadas em um relatório, permitindo que o seu desempenho seja avaliado posteriormente.

Após a escolha do modo de funcionamento da ferramenta, o usuário já pode iniciar a execução do procedimento de troca de cruzeta. O procedimento começa com o funcionário virtual posicionado dentro da cesta aérea do caminhão, sendo que o poste ainda não contém nenhum isolador e o caminhão ainda não está aterrado.

O funcionário deve então controlar a posição da cesta, utilizando os controles disponíveis na interface gráfica, para se aproximar dos objetos que o mesmo deseja manipular. Ao se aproximar dos objetos, o usuário pode usar o cursor do mouse para selecionar as ações disponíveis.

Conforme ilustrado na figura 5.11, para descobrir quais elementos do cenário o usuário pode manipular, basta passar o mouse sobre estes elementos. Aqueles 


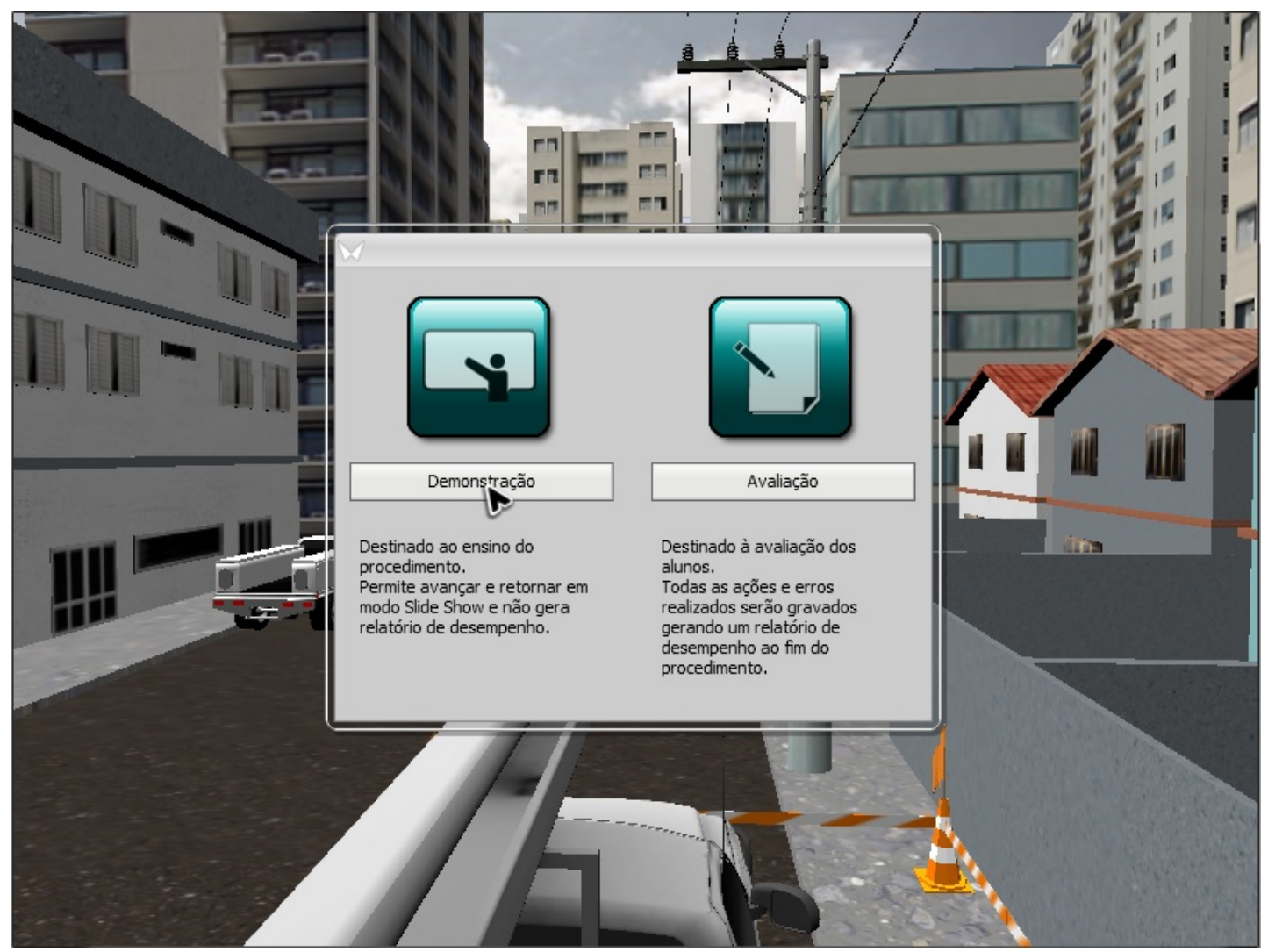

Figura 5.10: Tela de escolha do modo de funcionamento da aplicação.

que forem selecionados indicarão a presença de ações disponíveis.

A primeira ilustração da figura 5.11 (parte superior) mostra um condutor da rede secundária. Ao passar o mouse sobre este condutor, a sua cor é alterada para verde, indicando que existem ações disponíveis. Caso o usuário clique sobre o objeto, um menu de contexto será exibido mostrando as alternativas existentes para manipular o mesmo. Neste caso, as alternativas apresentadas são: Aplicar peças e Remover aterramento do caminhão.

Na parte inferior da mesma figura, o mesmo condutor é mostrado, porém com dois isoladores já aplicados. Neste caso, o usuário clicou sobre o próprio isolador, e o menu de contexto exibe a única opção disponível, que consiste em remover o isolador do condutor.

Durante o treinamento, o usuário deve proceder conforme ilustrado na figura 5.11 , alterando a posição da cesta para se aproximar dos objetos e utilizando o menu de contexto para selecionar as ações de acordo com a descrição do procedimento.

Caso o funcionário escolha a ação errada em um determinado momento, este será informado de seu erro através de uma caixa de diálogo. Após fechar a caixa de diálogo, o usuário pode realizar novas tentativas. Nesta versão, não há limite 


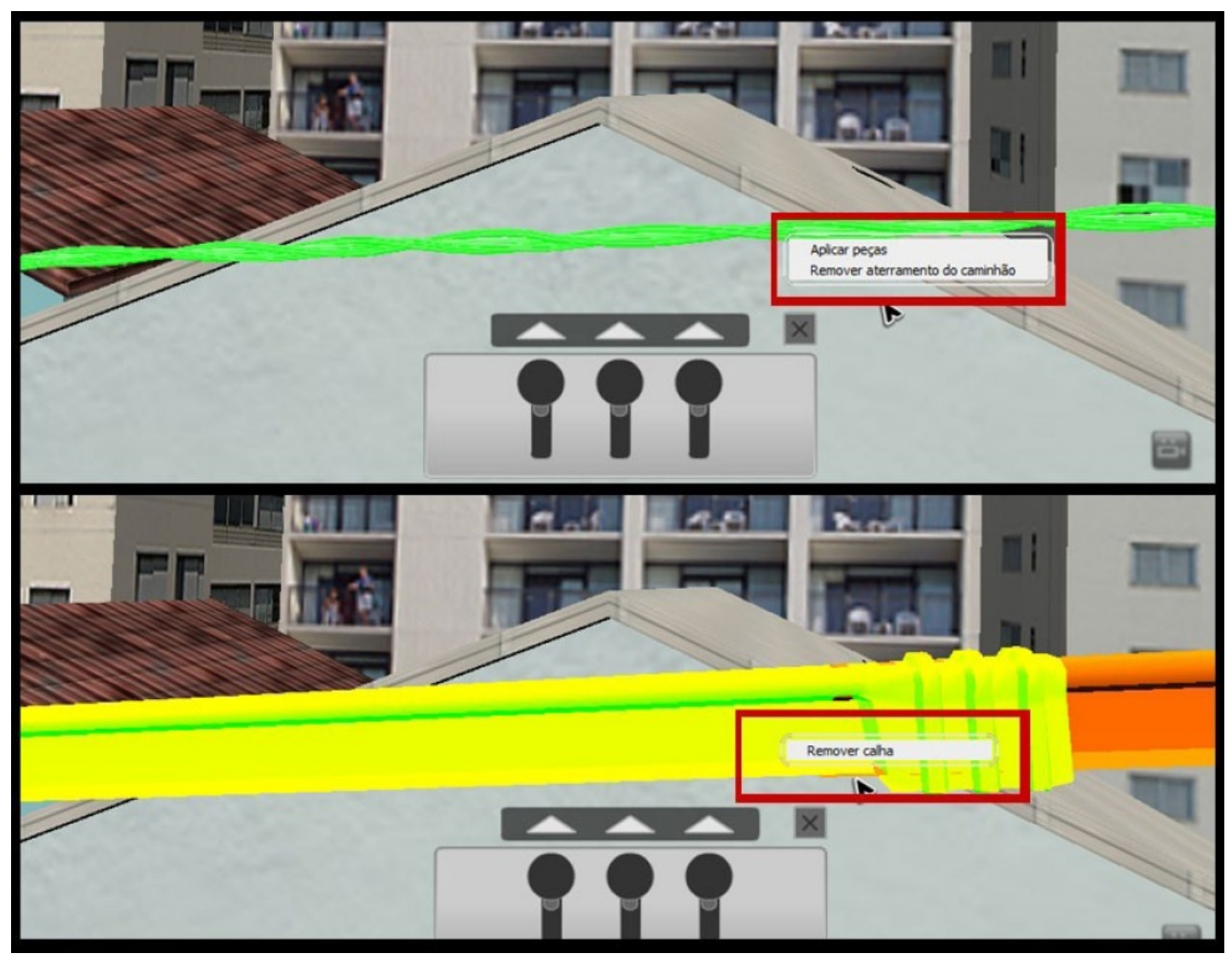

Figura 5.11: Seleção de objetos na aplicação.

de erros em nenhum modo de funcionamento da ferramenta. No entanto, no modo Avaliação, todos os erros são registrados no relatório.

A figura 5.12 apresenta os principais menus da interface gráfica da aplicação. Nesta figura, o usuário selecionou o primeiro condutor da rede primária (fase D), e após abrir o seu menu de contexto, o usuário escolheu a opção Aplicar peça.

Nesta opção, a ferramenta apresenta um menu contendo todas as peças que podem ser aplicadas neste condutor. O menu está à esquerda da figura 5.12 e contém dois itens: um isolador tipo calha e um isolador circular, ambos representados por seus respectivos ícones. Neste momento, o usuário pode escolher qual destes itens deve ser aplicado no condutor.

Ainda na figura 5.12, na parte inferior, nota-se a presença das alavancas de controle da cesta aérea, e na parte superior, um menu contendo as opções de controle do procedimento e o modo de funcionamento da aplicação. Neste exemplo, a aplicação está operando em modo Demonstração e, portanto, o menu contém opções para avançar e retroceder automaticamente no procedimento.

Esta versão da aplicação contém apenas a atividade que envolve a troca da cruzeta em linha viva. No entanto, novos procedimentos podem ser inseridos com 


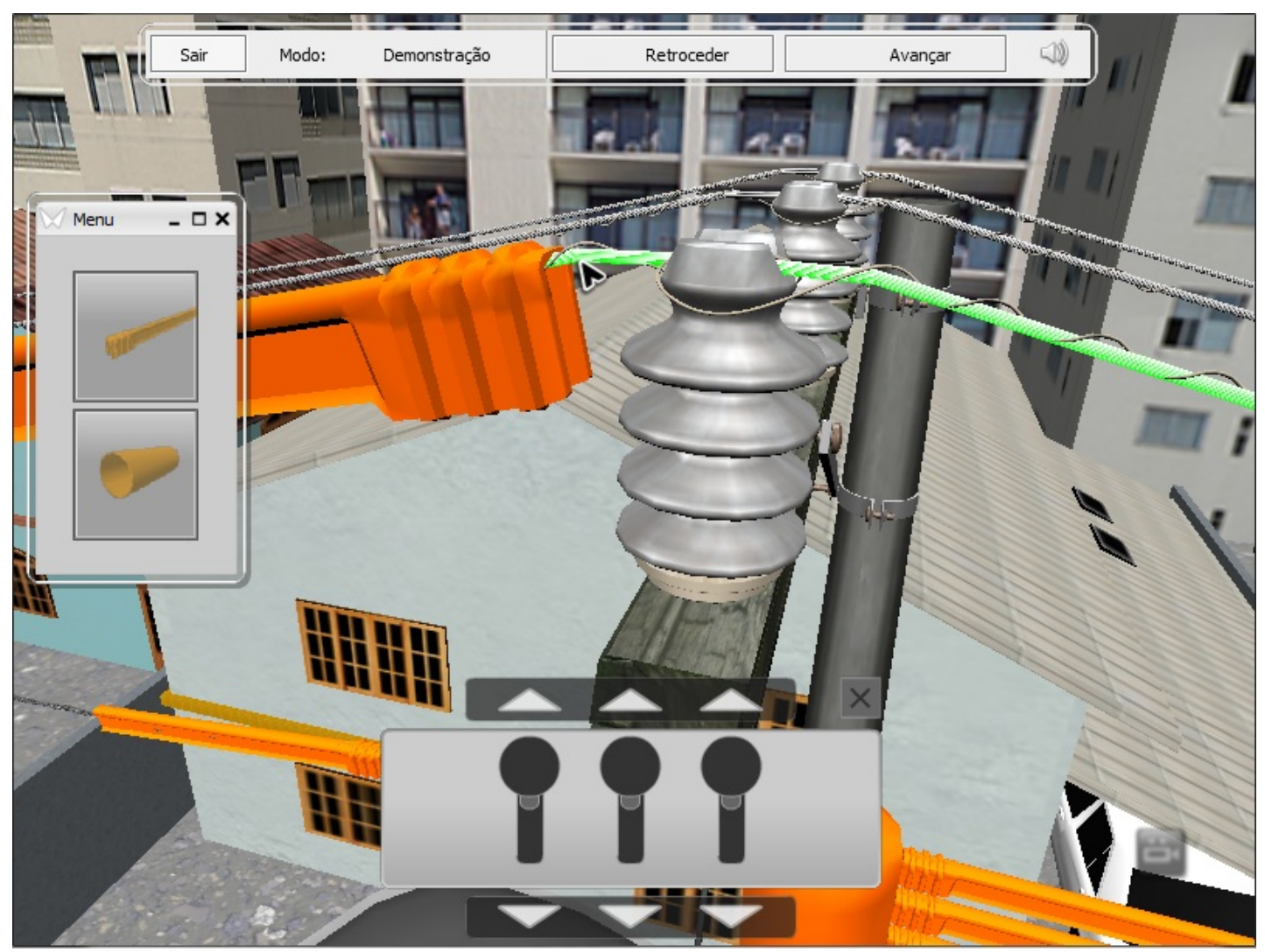

Figura 5.12: Menus principais da aplicação.

maior facilidade, uma vez que já existe um cenário modelado e grande parte dos objetos interativos já teve o seu comportamento definido.

\subsection{Estudo de caso Furnas Centrais Elétricas}

A aplicação de treinamento para Furnas Centrais Elétricas também foi desenvolvida no contexto de um projeto de P\&D financiado pela ANEEL (Agência Nacional de Energia Elétrica), através do convênio de número 0394-034/2006. O projeto tem como objetivo enriquecer o material utilizado na capacitação das equipes de manutenção, através do desenvolvimento de aplicações em Realidade Virtual.

O uso de aplicações de treinamento na área de manutenção de Unidades Geradoras é importante, pois os equipamentos e peças manipulados durante estas atividades são extremamente grandes e complexas. Além disto, o custo de aquisição e instalação destes equipamentos é muito elevado, o que torna inviável a aquisição de máquinas apenas para realização de treinamento.

Outro aspecto deste tipo de aplicação, é que o custo associado à interrupção no funcionamento de uma destas máquinas é muito elevado. Embora as mesmas 
apresentem um índice de falha extremamente baixo, quando estas falhas ocorrem, o reparo deve ser realizado urgentemente.

Este cenário favorece o uso de tecnologias de Realidade Virtual. Ao contrário do primeiro estudo de caso, este tipo de capacitação não tem enfoque no treinamento de atividades de risco, mas na familiarização e na capacitação do trabalho com máquinas e peças que não estão disponíveis para treinamento no dia-a-dia dos funcionários.

\subsubsection{Aplicação de Treinamento}

Neste estudo de caso, os procedimentos praticados pelo usuário envolvem a montagem e a desmontagem de uma Unidade Geradora, através da execução de atividades meramente ilustrativas, envolvendo apenas a manipulação das principais peças da UG. No entanto, quando executado realmente, este procedimento envolve uma equipe com um grande número de funcionários, podendo levar semanas até a sua conclusão.

Desta forma, o principal objetivo desta aplicação é permitir com que o funcionário se familiarize com os componentes de uma Unidade Geradora, e com as etapas fundamentais do seu processo de montagem e desmontagem para manutenção.

Para enriquecer o conteúdo apresentado ao usuário, a ferramenta de treinamento desenvolvida para este estudo de caso permite que diversas informações técnicas sejam anexadas a cada peça da UG, estas informações podem conter inclusive outros arquivos, como figuras, cortes 2D, planilhas, entre outros.

Ao elaborar o cenário virtual, todos os modelos geométricos da Unidade Geradora foram obtidos a partir da conversão de arquivos de CAD. Os modelos em CAD foram construídos no software Autodesk Inventor, e foram convertidos para malhas poligonais usando o mecanismo de importação disponível na ferramenta de modelagem 3D Studio Max, também da Autodesk.

Após o procedimento de conversão, uma extensão (plug-in) da biblioteca foi desenvolvida para acomodar as Classes de Funcionamento dos objetos interativos desta ferramenta. Estes objetos interativos foram desenvolvidos de forma semelhante ao apresentado no estudo de caso anterior, porém com um número reduzido de Classes.

O diagrama da figura 5.13 apresenta as principais Classes de Funcionamento desta extensão. Neste diagrama, a classe furnas:: Object representa um objeto 


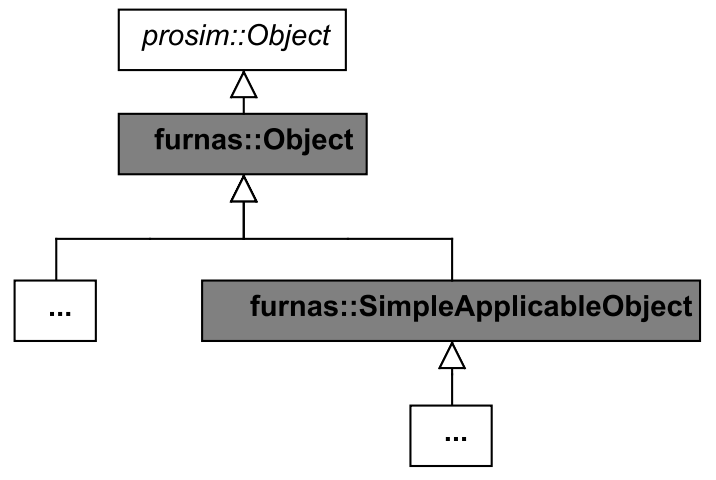

Figura 5.13: Diagrama das Classes de Funcionamento para a Unidade Geradora.

básico dos procedimentos de montagem e desmontagem e, da mesma forma como no caso AES Eletropaulo, contém propriedades como: description, icon, selectable e apply.

No entanto, para permitir que informações técnicas sejam anexadas a qualquer objeto do procedimento, a classe furnas :: Object ainda contém a propriedade information. Esta propriedade aponta para um arquivo XML, que armazena todas as informações técnicas da peça, contendo inclusive apontamentos para outros documentos, se necessário.

Nos procedimento de montagem e desmontagem, o usuário pode apenas inserir e retirar peças da UG. Desta forma, todos os objetos interativos do procedimento podem ser representados através de uma única Classe de Funcionamento, ilustrada no diagrama pela classe furnas :: SimpleApplicableObject, e implementada de forma muito semelhante com o apresentado no estudo de caso anterior.

Embora as atividades deste estudo de caso tenham sido simplificadas, os procedimentos de montagem e desmontagem devem ser realizados de acordo com as instruções de manutenção. Estas instruções foram representadas através de uma rede de Petri contendo apenas etapas sequenciais.

A figura 5.14 apresenta um trecho do início do procedimento de desmontagem da Unidade Geradora. Neste trecho, assim como em todo o restante da atividade, o usuário dispõe de caminhos de retorno, representados por transições com sufixo $[P]$, que retrocedem nas etapas do procedimento.

\subsubsection{Realização do treinamento}

Ao contrário do simulador de troca de cruzeta, a aplicação de treinamento para o estudo de caso de Furnas não possui modos de funcionamento. Desta forma, esta 


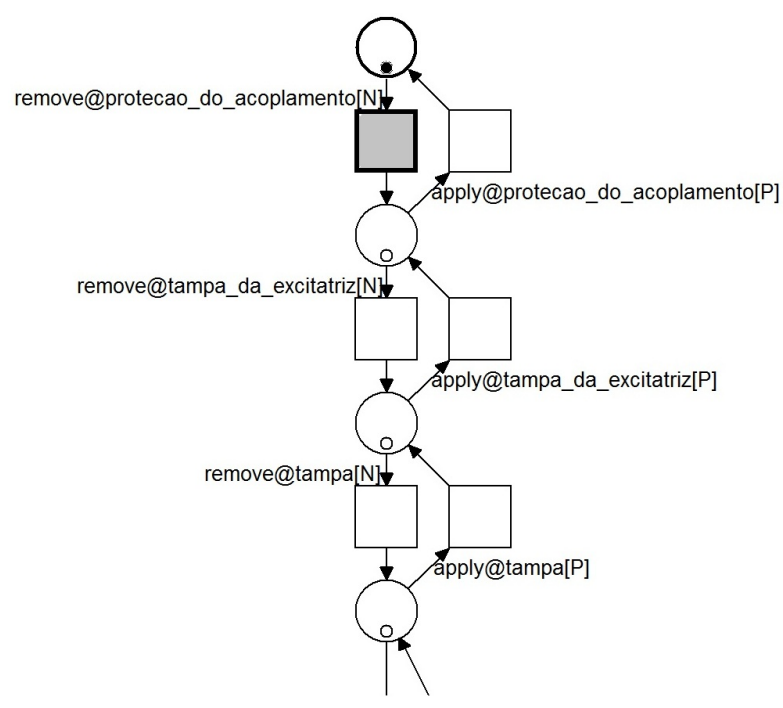

Figura 5.14: Trecho inicial do procedimento de desmontagem da Unidade Geradora.

aplicação não dispõe de nenhum recurso para avaliar o usuário, sendo que este sempre pode contar com o auxílio da aplicação para completar o procedimento.

Para este estudo de caso, foram desenvolvidos procedimentos para quatro atividades, que consistem na montagem e desmontagem da Unidade Geradora, e também na montagem e desmontagem do Mancal Guia e Escora do Gerador, que é um componente complexo e importante da UG.

A figura 5.15 demonstra a execução do processo de desmontagem da UG. Note que o mecanismo de interação é semelhante ao apresentado no estudo de caso anterior, onde as peças que possuem ações disponíveis são selecionadas, com a cor verde, quando o usuário passa o cursor do mouse sobre elas.

Esta figura apresenta ainda o menu de contexto, que aparece quando o objeto selecionado é clicado pelo usuário, e uma outra janela à esquerda, que contém a árvore de todas as peças relevantes para o procedimento em execução. Nesta última janela, o usuário dispõe de recursos para obter informações sobre cada peça da Unidade Geradora.

Ainda na figura 5.15, na margem superior, nota-se o menu principal de controle da ferramenta. Através deste menu o usuário pode alterar o procedimento corrente, ocultar a árvore de peças, avançar e retroceder no procedimento automaticamente, entre outras opções.

A figura 5.16 demonstra o procedimento de desmontagem do Mancal Guia e Escora do Gerador. Nesta imagem, o usuário exibe a janela de informações do objeto Mancal. As informações do Mancal contêm instruções detalhadas para as 


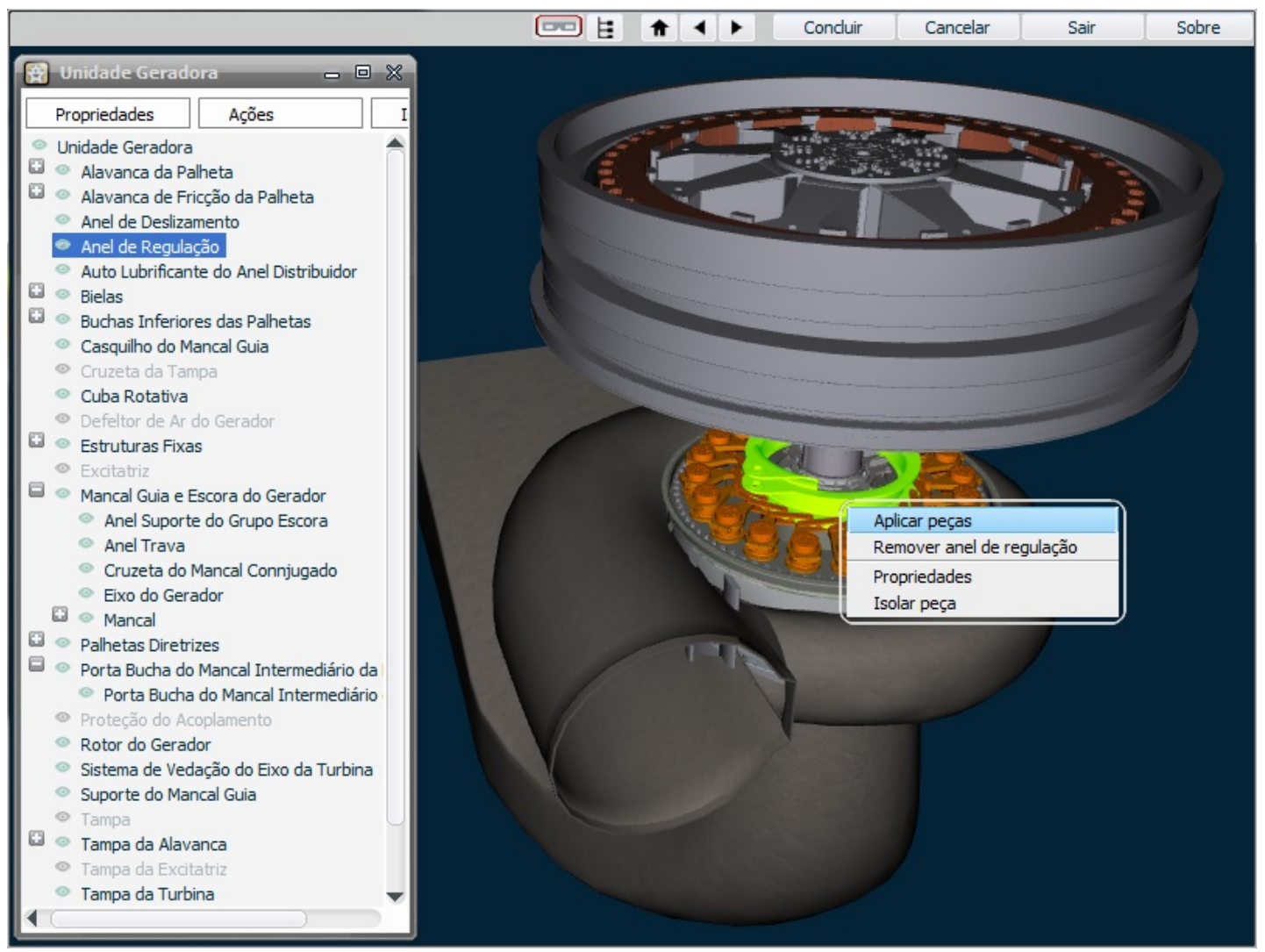

Figura 5.15: Procedimento de desmontagem da UG.

suas atividades de manutenção. Esta janela pode conter ainda links para páginas na Internet, e para outros arquivos, como vídeos, imagens e documentos.

Embora, atualmente, esta ferramenta disponha apenas de procedimentos resumidos, trabalhos futuros podem expandir o número de objetos interativos e segmentar os atuais procedimentos de montagem em diversas etapas mais complexas e com maior riqueza de detalhes.

\subsection{Avaliação da biblioteca}

A biblioteca de software para aplicações de treinamento, implementada com base na arquitetura apresentada no capítulo 3, tem o propósito de facilitar a criação de simuladores de procedimentos, reduzindo o tempo e o custo necessário para o desenvolvimento destas soluções.

Além disto, a biblioteca foi planejada para interpretar cenários de treinamento cuja estrutura de dados possui camadas com diferentes níveis de abstração e complexidade, facilitando a sua manutenção e o seu aperfeiçoamento.

As aplicações desenvolvidas para as empresas AES Eletropaulo e Furnas Centrais Elétricas foram fundamentais para investigar estas características. Os pro- 


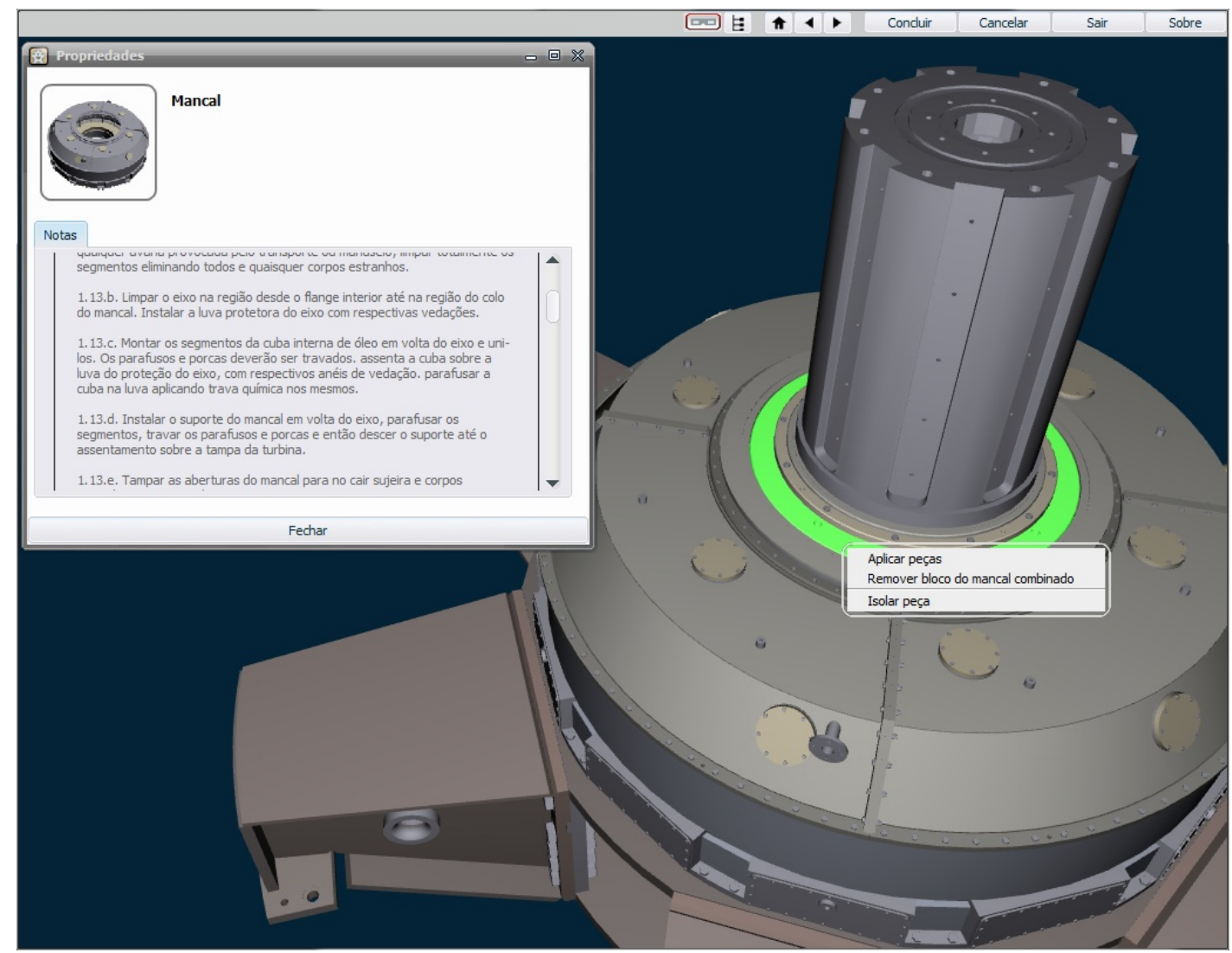

Figura 5.16: Procedimento de desmontagem do Mancal Guia e Escora do Gerador.

jetos de P\&D, financiados pela ANEEL, foram conduzidos no mesmo período deste trabalho, e viabilizaram a abordagem de problemas que realmente serão beneficiados pelo treinamento em RV.

Estas aplicações foram apresentadas como resultado dos seus respectivos projetos de P\&D. Apesar de estes projetos terem como compromisso a criação de protótipos de treinamento, os resultados obtidos através destes protótipos atenderam aos requisitos estabelecidos por engenheiros e profissionais da área de treinamento destas empresas.

Embora esta avaliação seja qualitativa, os elementos apresentados neste capítulo visam enfatizar os recursos fundamentais da biblioteca, e demonstrar como estes recursos podem ser usados para definir procedimentos de forma elegante, e facilitar a implementação de objetos interativos.

No caso de uso AES Eletropaulo, a implementação de alguns objetos foi demonstrada através do código de suas Classes de Funcionamento. Embora a linguagem de programação utilizada seja $\mathrm{C}++$ e a complexidade da Classe variar em função das regras de operação do objeto, ao registrar esta Classe em uma determinada extensão, a mesma pode ser reutilizada inúmeras vezes, facilitando 
a criação de cenários futuros.

Este fato é demonstrado no caso de Furnas, onde algumas poucas Classes de Funcionamento foram suficientes para definir um pequeno conjunto de procedimentos, com diversos objetos interativos.

No caso da Eletropaulo, entretanto, foi necessário criar um número maior de Classes de Funcionamento. Isto ocorre ao considerar a prática de uma atividade de risco, onde o procedimento virtual precisa reproduzir fielmente as atividades conduzidas em campo.

No entanto, embora não explorado neste trabalho, o custo na elaboração de novos procedimentos será beneficiado por este esforço inicial, uma vez que grande parte das peças e ferramentas já foram desenvolvidas, e poderão ser reutilizadas nas próximas atividades.

Outra característica importante da biblioteca, observada na elaboração destes casos de uso, foi a facilidade de criar e validar os procedimentos utilizando redes de Petri. Além da flexibilidade deste modelo, a interpretação de redes no formato PNML permite que o usuário utilize aplicações disponíveis gratuitamente, contendo recursos gráficos que facilitam a montagem, o teste e a manutenção dos procedimentos.

Desta forma, os recursos apresentados na arquitetura e implementados na biblioteca de treinamento disponibilizam os insumos básicos para a estruturação e o desenvolvimento de simuladores de procedimentos. Estes recursos facilitam e aceleram a criação de ferramentas de treinamento, reduzindo o esforço necessário para a consolidação destas soluções.

\subsubsection{Outras considerações}

Atualmente, a biblioteca utiliza um paradigma de interação que envolve a manipulação de objetos através das suas respectivas ações. Este mecanismo precisa ser considerado em aplicações de RV que utilizam outros periféricos de interação, como luvas, sensores de posição, entre outros.

A evolução e a popularização destas tecnologias permitirão que objetos virtuais sejam manipulados diretamente pelo usuário, de forma mais intuitiva e natural. Este caso de uso precisa ser considerado em maior detalhe na elaboração de trabalhos futuros, para identificar possíveis alterações na arquitetura, e aperfeiçoar os mecanismos existentes na biblioteca para manipular os objetos interativos. 
Outro fator importante, é aprimorar a biblioteca para facilitar a manutenção dos cenários de treinamento existentes e acelerar o processo de criação de novas atividades. Neste sentido, um dos principais requisitos exigidos para o desenvolvimento de objetos interativos, é o conhecimento da linguagem de programação $\mathrm{C}++$.

Apesar das facilidades apresentadas pela biblioteca, esta linguagem de programação impõe barreiras difíceis de serem superadas, principalmente para profissionais pouco familiarizados com o desenvolvimento de software de baixo nível.

Para superar estas dificuldades, trabalhos futuros podem considerar o uso de linguagens de programação em script, principalmente para elaborar as extensões (plug-ins). A investigação desta alternativa pode trazer resultados que irão facilitar ainda mais a criação e a manutenção dos procedimentos.

\subsection{Síntese}

Este capítulo apresentou dois casos de uso, ambos envolvendo a utilização dos principais recursos da biblioteca de treinamento. Estes casos de uso foram elaborados com a participação de parceiros do Setor de Energia Elétrica, como a AES Eletropaulo e Furnas Centrais Elétricas, e foram desenvolvidos no contexto de projetos de P\&D, financiados pela Agência Nacional de Energia Elétrica (ANEEL).

O capítulo iniciou com a apresentação detalhada do desenvolvimento de um simulador de troca de cruzeta em linha viva, procedimento utilizado com frequência na manutenção das redes de distribuição. Este procedimento compreende a execução de uma atividade de risco, pois envolve a manipulação de condutores energizados para evitar a interrupção no fornecimento de energia elétrica.

Em seguida, a aplicação de Furnas foi apresentada de forma resumida. Esta aplicação contém atividades para realizar a montagem e a desmontagem de uma Unidade Geradora Hidrelétrica.

O capítulo conclui com uma avaliação dos recursos fundamentais da biblioteca, e como estes recursos auxiliaram o desenvolvimento dos casos de uso. Esta avaliação também apresenta considerações sobre aspectos da arquitetura e da biblioteca que podem ser aperfeiçoados em revisões futuras.

O próximo capítulo apresenta a conclusão final, mencionando as contribuições realizadas durante a execução deste trabalho, e as considerações a serem feitas na realização de trabalhos futuros. 


\section{Conclusões}

O aumento da procura por aplicações de treinamento de procedimentos em RV promoveu o desenvolvimento de arcabouços e ferramentas em diversas instituições relevantes de pesquisa, como no Fraunhofer IFF da Alemanha e no INRIA da França.

As ferramentas desenvolvidas por estes laboratórios têm como objetivo facilitar e reduzir os custos no desenvolvimento e na implantação de soluções de treinamento em Realidade Virtual.

No entanto, no cenário nacional, poucos trabalhos foram desenvolvidos nesta área de pesquisa. Sendo que a grande maioria apresenta resultados obtidos ao utilizar as tecnologias de RV em segmentos específicos da indústria, com abordagens limitadas ao processo de capacitação de uma classe específica de operários.

Desta forma, há poucas iniciativas no cenário nacional para abordar este problema de forma mais ampla, promovendo soluções que possam ser usadas em diversos segmentos da indústria, para treinar um número arbitrário de atividades.

A pesquisa apresentada neste documento identifica diversas técnicas e modelos usados em outros trabalhos acadêmicos de treinamento. Estas técnicas apresentam mecanismos para descrever as regras de operação dos objetos do treinamento, e também mecanismos para definir as etapas de uma determinada atividade.

Estas técnicas foram utilizadas na elaboração de um arcabouço para facilitar o desenvolvimento de aplicações de treinamento. Este arcabouço foi baseado em diversas características discutidas no estado da arte, e possui recursos para reduzir o trabalho na criação de novos cenários interativos e facilitar a introdução de novos procedimentos.

Além disto, a arquitetura deste arcabouço foi usada como referência para o desenvolvimento de uma biblioteca de software. Esta biblioteca de treinamento possui diversos recursos para facilitar e acelerar a elaboração de aplicações que simulam a execução de procedimentos. 
As características fundamentais da arquitetura, concretizadas através da implementação desta biblioteca, foram validadas no desenvolvimento de dois casos de uso. Estes casos de uso, elaborados através de parcerias estabelecidas com duas empresas do Setor Elétrico, AES Eletropaulo e Furnas Centrais Elétricas, foram fundamentais neste processo de validação.

Ambos os casos de uso foram desenvolvidos no contexto de projetos de P\&D, financiados pela Agência Nacional de Energia Elétrica (ANEEL), o que viabilizou a abordagem de problemas práticos, que realmente serão beneficiados pelo treinamento em RV.

Estas aplicações, desenvolvidas no mesmo período em que este trabalho foi conduzido, foram apresentadas como resultados destes projetos de $\mathrm{P} \& \mathrm{D}$, e atenderam aos requisitos destes, estabelecidos por engenheiros e profissionais da área de treinamento.

Baseado nestes resultados e nas discussões realizadas, temos evidências de que este trabalho atingiu os objetivos propostos.

\subsection{Contribuições}

As principais contribuições realizadas neste trabalho foram classificadas como científicas e tecnológicas. As contribuições identificadas como científicas são apresentadas a seguir:

- Uma revisão da literatura, contendo uma análise das técnicas e arquiteturas usadas no desenvolvimento de simuladores de procedimentos;

- A proposta de uma arquitetura para acelerar o desenvolvimento de aplicações de treinamento e facilitar a introdução de novos procedimentos;

As contribuições identificadas como tecnológicas estão apresentadas abaixo:

- A implementação de referência da arquitetura, através de uma biblioteca de software;

- Uma ferramenta de treinamento para a atividade de troca de cruzeta em linha viva, a ser usada na AES Eletropaulo;

- Uma aplicação de treinamento para auxiliar a compreensão dos principais componentes de uma Unidade Geradora Hidrelétrica, a ser utilizada em Furnas Centrais Elétricas; 


\subsection{Trabalhos Futuros}

A realização de trabalhos futuros deve considerar alguns aspectos que podem ser aperfeiçoados na arquitetura e na biblioteca de software. A lista apresentada abaixo sugere alguns tópicos a serem considerados:

- Introduzir recursos para o treinamento distribuído e em grupo, com a presença virtual de diversos participantes;

- Adequar o arcabouço para dispositivos móveis, visando assistir o funcionário na execução da própria atividade;

- Investigar o uso de periféricos de interação mais sofisticados, como luvas, rastreadores de posição, entre outros;

- Inserir suporte a linguagem de programação em script, para facilitar a criação de objetos interativos;

Esta lista contém recursos para aprimorar as aplicações de treinamento já existentes, e ampliar os casos de uso que podem ser beneficiados pelo treinamento em RV. 


\section{Referências}

ADAMS, R. J.; KLOWDEN, D.; HANNAFORD, B. Virtual training for a manual assembly task. Haptics-e: The Electronic Journal of Haptics Research, v. 2, 2001.

AHMAD, O. et al. Hierarchical, concurrent state machines for behavior modeling and scenario control. In: . [S.l.: s.n.], 1994. p. $36-42$.

ANGELOV, A.; STYCZYNSKI, Z. Computer-aided 3d virtual training in power system education. In: Power Engineering Society General Meeting, 200\%. IEEE. [S.l.: s.n.], 2007. p. 1-4. ISSN 1932-5517.

ARENDARSKI, B.; TERMATH, W.; MECKING, P. Maintenance of complex machines in electric power systems using virtual reality techniques. In: . [S.l.: s.n.], 2008. p. $483-487$. ISSN 1089-084X.

BADLER, N. I.; ERIGNAC, C. A.; LIU, Y. Virtual humans for validating maintenance procedures. Commun. ACM, ACM, New York, NY, USA, v. 45, n. 7, p. 56-63, 2002. ISSN 0001-0782.

BARATA, P. N. A. et al. Virtual technical instructions of maintenance and operation of a hydraulic generating unit. In: Proceedings of the XI Symposium on Virtual and Augmented Reality. Porto Alegre, RS, Brazil: [s.n.], 2009.

BEHR, J.; DäHNE, P.; ROTH, M. Utilizing X3D for immersive environments. In: Web3D '04: Proceedings of the ninth international conference on $3 \mathrm{D} \mathrm{Web}$ technology. New York, NY, USA: ACM, 2004. p. 71-78. ISBN 1-58113-845-8.

BLÜMEL, E. et al. Perspectives on simulation in education and training: virtual environments for the training of maintenance and service tasks. In: WSC '03: Proceedings of the 35th conference on Winter simulation. [S.1.]: Winter Simulation Conference, 2003. p. 2001-2007. ISBN 0-7803-8132-7.

BLÜMEL, E. et al. Technology enhanced training at workplace: A virtual reality based training system for the technical domain. In: Proceedings of the 1st International Conference on E-Business and E-Learning, EBEL. Amman, Jordan: [s.n.], 2005. p. 57-62.

BLÜMEL, E. et al. Pragmatic approach to apply virtual reality technology in accelerating a product life cycle. In: Proceedings of the International Conference INNOVATIONS. Slany, Czech Republic: [s.n.], 2004. p. 199-207.

BRAITENBERG, V. Vehicles: Experiments in Synthetic Psychology. The MIT Press, 1986. Disponível em: <http://www.worldcat.org/isbn/0262521121>.

CAREY, R.; BELL, G. The annotated VRML 2.0 reference manual. Essex, UK, UK: Addison-Wesley Longman Ltd., 1997. ISBN 0-201-41974-2. 
CHEN, G. et al. Equipment simulation training system based on virtual reality. In: ICCEE '08: Proceedings of the 2008 International Conference on Computer and Electrical Engineering. Washington, DC, USA: IEEE Computer Society, 2008. p. 563-567. ISBN 978-0-7695-3504-3.

CREMER, J.; KEARNEY, J.; PAPELIS, Y. HCSM: A framework for behavior and scenario control in virtual environments. ACM Transactions on Modeling and Computer Simulation, v. 5, p. 242-267, 1995.

CRONIN, P. Report on the application of virtual reality to education. Report, HCRC, University of Edinburgh, 1997.

CRUZ-NEIRA, C. et al. The cave: audio visual experience automatic virtual environment. Commun. ACM, ACM, New York, NY, USA, v. 35, n. 6, p. 64-72, 1992. ISSN 0001-0782.

DALY, L.; BRUTZMAN, D. X3D: Extensible 3d graphics standard [standards in a nutshell]. Signal Processing Magazine, IEEE, v. 24, n. 6, p. $130-135$, Nov. 2007. ISSN 1053-5888.

DEV, P. et al. Virtual worlds and team training. Anesthesiology Clinics, Elsevier Saunders, v. 25, p. 321-336, 2007.

DEVILLERS, F. et al. A programming environment for behavioural animation. Journal of Visualization and Computer Animation, v. 13, p. 200-2, 2002.

DONIKIAN, S. HPTS: a behaviour modelling language for autonomous agents. In: AGENTS '01: Proceedings of the fifth international conference on Autonomous agents. New York, NY, USA: ACM, 2001. p. 401-408. ISBN 1-58113-326-X.

DONIKIAN, S.; RUTTEN, E. Reactivity, concurrency, data-flow and hierarchical preemption for behavioural animation. In: Eurographics Workshop on Programming Paradigms in Graphics. [S.l.: s.n.], 1995. p. 137-153.

DOUGLASS, B. P. State machines and statecharts. In: Proceedings of Embedded Systems Conference. SÃ £o Francisco, USA: [s.n.], 2001.

ELETROPAUlO, A. Estado da Arte das Atividades de manutenção em Linha Viva: Características das Redes Aéreas de Distribuição, Principais Atividades Executadas e Equipamentos Utilizados. Novembro 2007. Nota técnica 1 - Projeto ANEEL 0390-0001/2006.

ELETROPAUlO, A. Manual de Procedimentos de Linha Viva. Abril 2007. Manuais Técnicos de Operação - AES Eletropaulo.

GALLAGHER, A. G. et al. Virtual reality simulation for the operating room proficiency-based training as a paradigm shift in surgical skills training. Annals of Surgery, v. 241(2), p. 364-372, February 2005.

GAMMA, E. et al. Design Patterns: Elements of Reusable Object-Oriented Software. 1. ed. [S.l.]: Addison-Wesley Professional, 1994.

GERBAUD, S. et al. GVT: a platform to create virtual environments for procedural training. In: IEEE Virtual Reality Conference. [S.l.: s.n.], 2008. p. $225-232$. 
HAREL, D. Statecharts: A visual formalism for complex systems. In: Science of Computer Programming. [S.l.: s.n.], 1987. v. 8, p. 231-274.

HILL, R. W. et al. Virtual humans in the mission rehearsal exercise system. In KI Embodied Conversational Agents, v. 17, p. 32-38, 2003.

JOHNSON, W. L.; RICKEL, J. Steve: an animated pedagogical agent for procedural training in virtual environments. SIGART Bulletin, ACM, New York, NY, USA, v. 8, n. 1-4, p. 16-21, 1997. ISSN 0163-5719.

JUNKER, G. Pro OGRE 3D Programming. 1. ed. [S.1.]: Apress, 2006.

KALLMANN, M.; THALMANN, D. Modeling objects for interaction tasks. In: Proc. Eurographics Workshop on Animation and Simulation. [S.l.: s.n.], 1998. p. 73-86.

KUHL, J. et al. The iowa driving simulator: An immersive research environment. Computer, IEEE Computer Society Press, Los Alamitos, CA, USA, v. 28, n. 7, p. 35-41, 1995. ISSN 0018-9162.

LIN, F. The development of intelligent virtual reality-based industrial training systems. Tese (Doutorado) - Hong Kong University of Science and Technology, 1998. Adviser-Su, Chuan-Jun.

LIN, F.; HON, C. L.; SU, C.-J. A virtual reality-based training system for cnc milling machine operations. Annual journal of IIE(HK), p. 13-16, 1996.

LIN, F. et al. Developing virtual environments for industrial training. Inf. Sci. Inf. Comput. Sci., Elsevier Science Inc., New York, NY, USA, v. 140, n. 1, p. 153-170, 2002. ISSN 0020-0255.

LOFTIN, R. B.; KENNEY, P. J. Training the hubble space telescope flight team. IEEE Comput. Graph. Appl., IEEE Computer Society Press, Los Alamitos, CA, USA, v. 15, n. 5, p. 31-37, 1995. ISSN 0272-1716.

MARTZ, P. OpenSceneGraph Quick Start Guide. [S.l.]: Skew Matrix Software LLC, 2007.

MOLLET, N.; ARNALDI, B. Storytelling in virtual reality for training. In: First International Conference on Technologies for E-Learning and Digital Entertainment, Edutainment. [S.1.: s.n.], 2006. p. 334-347.

MOLLET, N.; GERBAUD, S.; ARNALDI, B. STORM: a generic interaction and behavioral model for 3d objects and humanoids in a virtual environment. In: IPT-EGVE the 13th Eurographics Symposium on Virtual Environments. [S.l.: s.n.], 2007. p. 95-100.

OLIVEIRA, D. et al. Virtual reality system for industrial training. In: Industrial Electronics, 200\%. ISIE 200\%. IEEE International Symposium on. [S.l.: s.n.], 2007. p. $1715-1720$.

OMG, O. M. G. UML v2.3 Superstructure Specification. 2010. Online. Acessado em Agosto/2010. Disponível em: <http://www.omg.org/spec/UML/2.3/>. 
PANNE, M. van de; FIUME, E. Sensor-actuator networks. In: SIGGRAPH '93: Proceedings of the 20th annual conference on Computer graphics and interactive techniques. New York, NY, USA: ACM, 1993. p. 335-342. ISBN 0-89791-601-8.

PLAUGER, P. J. et al. The $C++$ Standard Template Library. 1. ed. [S.l.]: Prentice Hall, 2000.

PONDER, M. et al. Immersive vr decision training: telling interactive stories featuring advanced virtual human simulation technologies. In: EGVE '03: Proceedings of the workshop on Virtual environments 2003. New York, NY, USA: ACM, 2003. p. 97-106. ISBN 1-58113-686-2.

QUERREC, R.; CHEVAILLIER, P. Virtual storytelling for training: An application to fire fighting in industrial environment. In: ICVS '01: Proceedings of the International Conference on Virtual Storytelling: Using Virtual Reality Technologies for Storytelling. London, UK: Springer-Verlag, 2001. p. 201-204. ISBN 3-540-42611-6.

REINERS, D.; VOSS, G.; BEHR, J. Opensg: Basic concepts. In: OpenSG Forum. [S.l.: s.n.], 2002.

REYNOLDS, C. W. Flocks, herds and schools: A distributed behavioral model. In: SIGGRAPH '8\%: Proceedings of the 14th annual conference on Computer graphics and interactive techniques. New York, NY, USA: ACM, 1987. p. 25-34. ISBN 0-89791-227-6.

RICKEL, J.; JOHNSON, W. L. Animated agents for procedural training in virtual reality: Perception, cognition, and motor control. Applied Artificial Intelligence, v. 13, p. 343-382, 1998.

RICKEL, J. et al. Toward a new generation of virtual humans for interactive experiences. IEEE Intelligent Systems, v. 17, p. 32-38, 2002.

RUSSELL, S.; NORVIG, P. Artificial Intelligence: A Modern Approach (3rd Edition). [S.l.]: Prentice Hall, 2009.

SCHENK, M. et al. Vr-platform for developing and training on casting installations. In: Short version of Conference Lectures: 10. Internationale Giesserei-Fachmesse. Düsseldorf: [s.n.], 2003.

SCONS. An open source software construction tool. 2010. Online. Acessado em Agosto/2010. Disponível em: <http://www.scons.org >.

SIMS, K. Evolving virtual creatures. In: SIGGRAPH '94: Proceedings of the 21st annual conference on Computer graphics and interactive techniques. New York, NY, USA: ACM, 1994. p. 15-22. ISBN 0-89791-667-0.

SOUZA, M. P. A. de et al. Maintenance and assembly training in a hydroelectric unit of energy using virtual reality desktop. Latin America Transactions, IEEE (Revista IEEE America Latina), v. 6, n. 5, p. 484-491, Sept. 2008. ISSN 1548-0992.

TEUBL, F. et al. Passeio digital: Um sistema de multiprojeção de baixo custo voltado às aplicações educacionais. In: Proceedings of the XI Symposium on Virtual and Augmented Reality. Porto Alegre, RS, Brazil: [s.n.], 2009. 
TU, X.; TERZOPOULOS, D. Artificial fishes: physics, locomotion, perception, behavior. In: SIGGRAPH '94: Proceedings of the 21st annual conference on Computer graphics and interactive techniques. New York, NY, USA: ACM, 1994. p. 43-50. ISBN 0-89791-667-0.

WASFY, A.; WASFY, T.; NOOR, A. Intelligent virtual environment for process training. Adv. Eng. Softw., Elsevier Science Ltd., Oxford, UK, UK, v. 35, n. 6, p. 337-355, 2004. ISSN 0965-9978.

WAVEFRONT. OBJ Specification. 2010. Online. Acessado em Agosto/2010.

Disponível em: <http://www .martinreddy.net/gfx/3d/OBJ.spec>.

WEB3D CONSORTIUM. Extensible 3D (X3D) Specifications. 2008. Online. Acessado em Agosto/2010. Disponível em: <http://www.web3d.org/x3d/ specifications $>$.

WEXELBLAT, A. (Ed.). Virtual reality applications and explorations. San Diego, CA, USA: Academic Press Professional, Inc., 1993. ISBN 0-12-745045-9. 


\section{Apêndice A - Padrões de redes de Petri}

Este apêndice apresenta alguns padrões de rede de Petri, para representar as relações de dependência mais comuns existentes entre as tarefas de um determinado procedimento.

A primeira ilustração (esquerda) da figura A.1 apresenta uma rede onde a transição identificada pela letra $A$ ficará disponível para ser efetuada apenas após a transição $B$ ou $C$ ser executada. Neste caso, as transições $B$ e $C$ não podem ambas serem executadas, apenas uma delas. Isto porque a posição (place) que as antecede contém apenas um marcador (token).

A segunda ilustração (direita) da mesma figura, mostra a mesma relação de dependência entre as transições $A, B$ e $C$, porém contendo um caminho de retorno. As transições identificadas pelos nomes $r A, r B$ e $r C$ oferecem um mecanismo para que o usuário possa desfazer as ações conduzidas pelas transições $A, B$ e $C$, respectivamente.
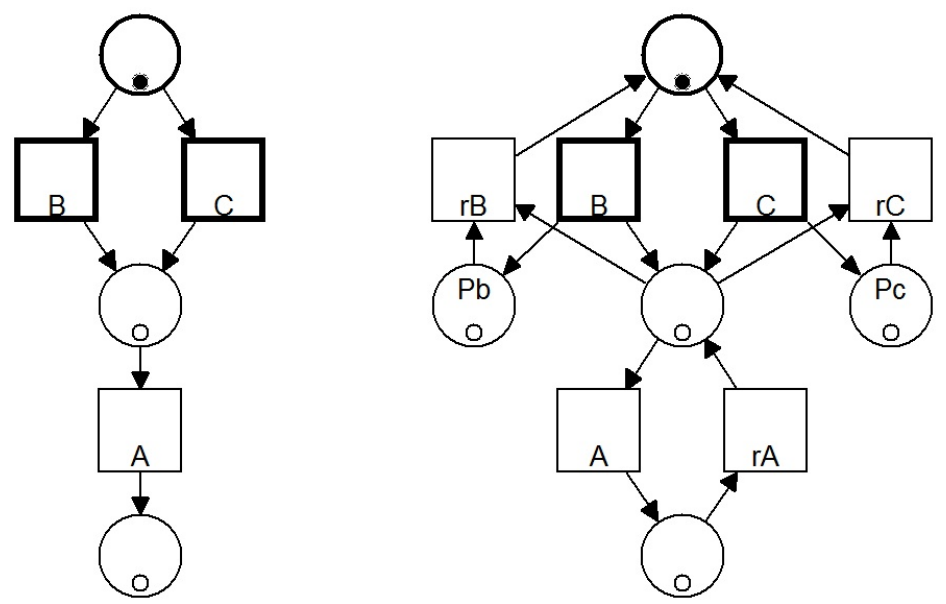

Figura A.1: Rede de Petri onde $A$ depende de $B$ ou $C$.

Ainda na figura A.1, as posições identificadas pelos nomes $P b$ e $P c$ servem apenas para marcar qual transição foi executada pelo usuário ao passar por este trecho, se foi a transição $B$ ou a transição $C$. Desta forma, ao executar o ca- 
minho de retorno, o usuário terá de desfazer exatamente as ações conduzidas anteriormente.

A figura A.2 apresenta uma rede onde a transição $A$ ficará disponível apenas após a execução de ambas as transições $B$ e $C$. Neste caso, note que a ordem de execução das transições $B$ e $C$ é indiferente. A segunda ilustração desta figura demonstra a aplicação do caminho de retorno.
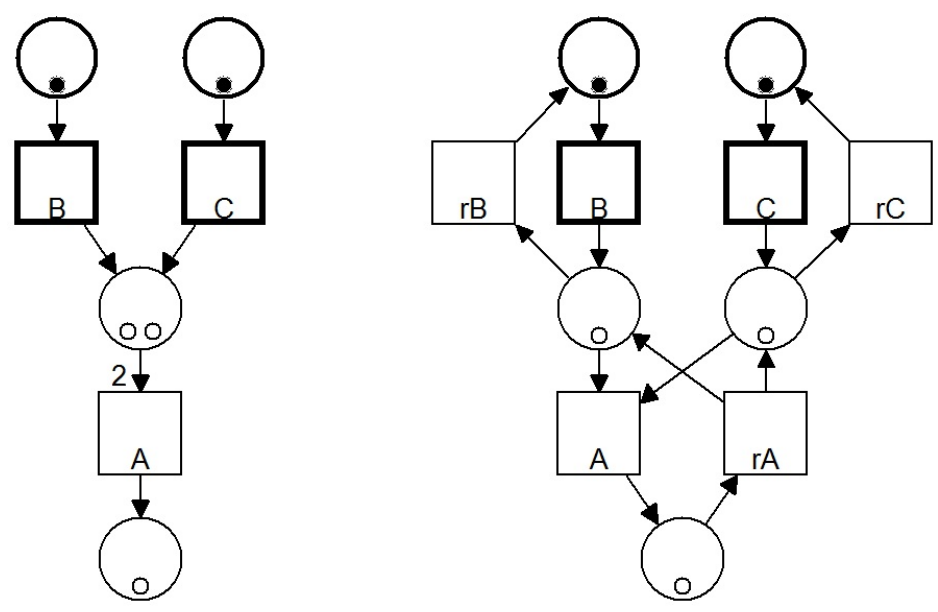

Figura A.2: Rede de Petri onde $A$ depende de $B$ e $C$.

A figura A.3 apresenta um exemplo com trechos mutuamente exclusivos. Neste exemplo, a transição $A$ só poderá ser executada após a conclusão de ambos os trechos $\mathrm{Bi}$ e $\mathrm{Ci}$. Embora ambos os trechos precisem ser executados, a sua execução não pode ser efetuada de forma concorrente.

Desta forma, a posição identificada por $M$ garante que apenas um destes trechos será executado de cada vez. Esta posição contém apenas um marcador, que é consumido na primeira transição, e é devolvido apenas na última transição, impedindo que o usuário inicie a execução do segundo trecho antes de concluir o primeiro.

A segunda ilustração da mesma figura funciona de forma semelhante, porém com caminho de retorno. Neste caso, ao efetuar o retorno, o usuário não precisa fazê-lo na ordem inversa em que o mesmo foi concluído. Os trechos de retorno podem ser efetuados em qualquer ordem novamente, porém, ainda de forma mutuamente exclusiva, ou seja, apenas um dos trechos de cada vez. 

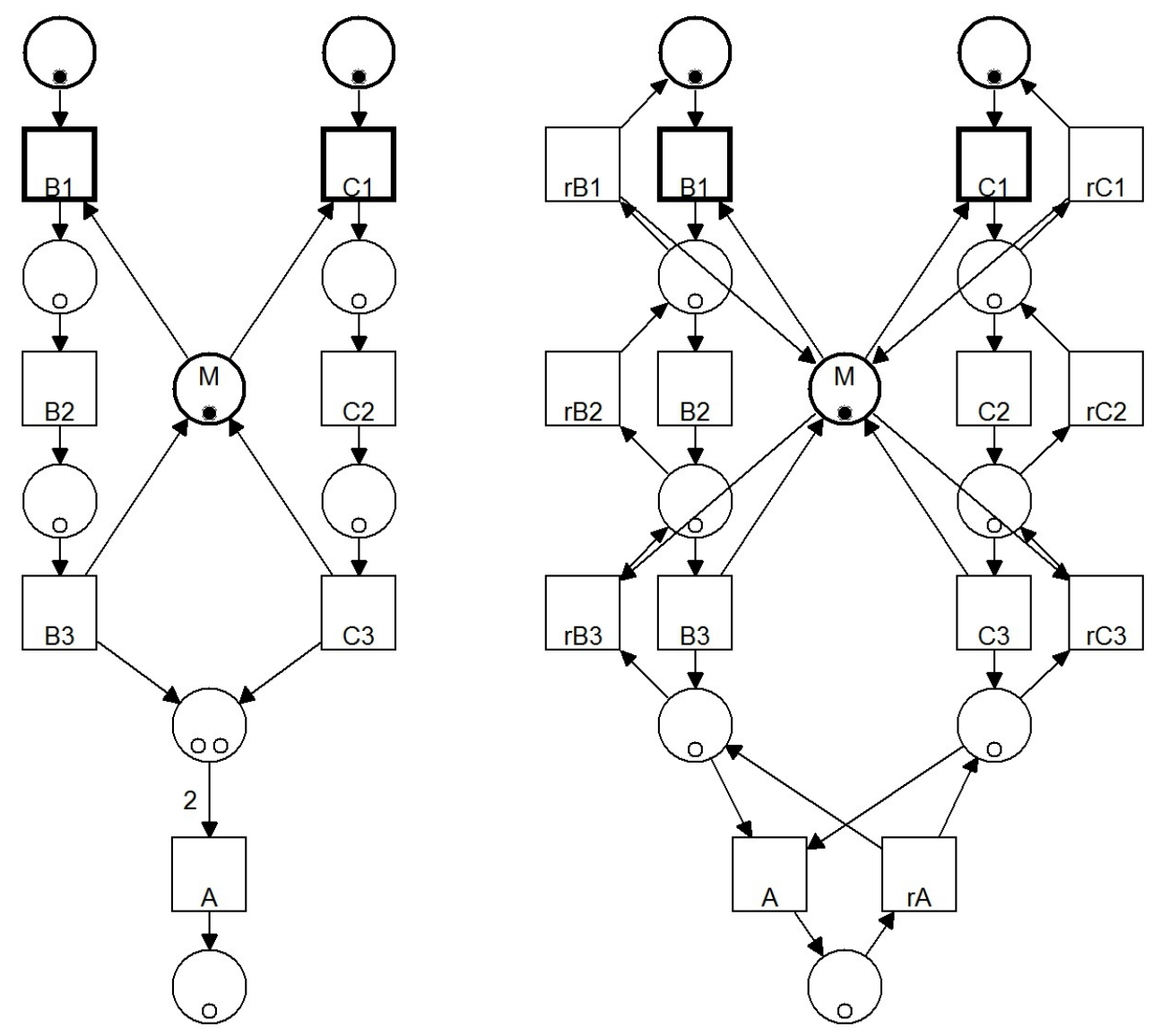

Figura A.3: Rede de Petri onde $A$ depende de trechos mutuamente exclusivos. 


\section{Apêndice B - Rede de Petri do procedimento de troca de cruzeta}

Este apêndice contém a rede de Petri do procedimento completo de troca de cruzeta em linha viva, utilizada no estudo de caso da AES Eletropaulo. Os nomes das transições seguem o formato "nome-da-ação@nome-do-objeto[N/P]", onde o sufixo $[N]$ é utilizado nas transições que avançam no procedimento, e o sufixo $[P]$ é usado nas transições que retrocedem.

O procedimento inicia com a transição de nome Start disponível, e termina somente quando a transição de nome Finish estiver disponível. Na apresentação da rede de Petri, as páginas com duas colunas correspondem a trechos sequenciais iniciando pela coluna da esquerda, ao invés de trechos paralelos.

Neste caso, todo o procedimento possui caminho de retorno, de tal forma que, em qualquer situação, o usuário pode executar ações para desfazer tarefas já concluídas. 

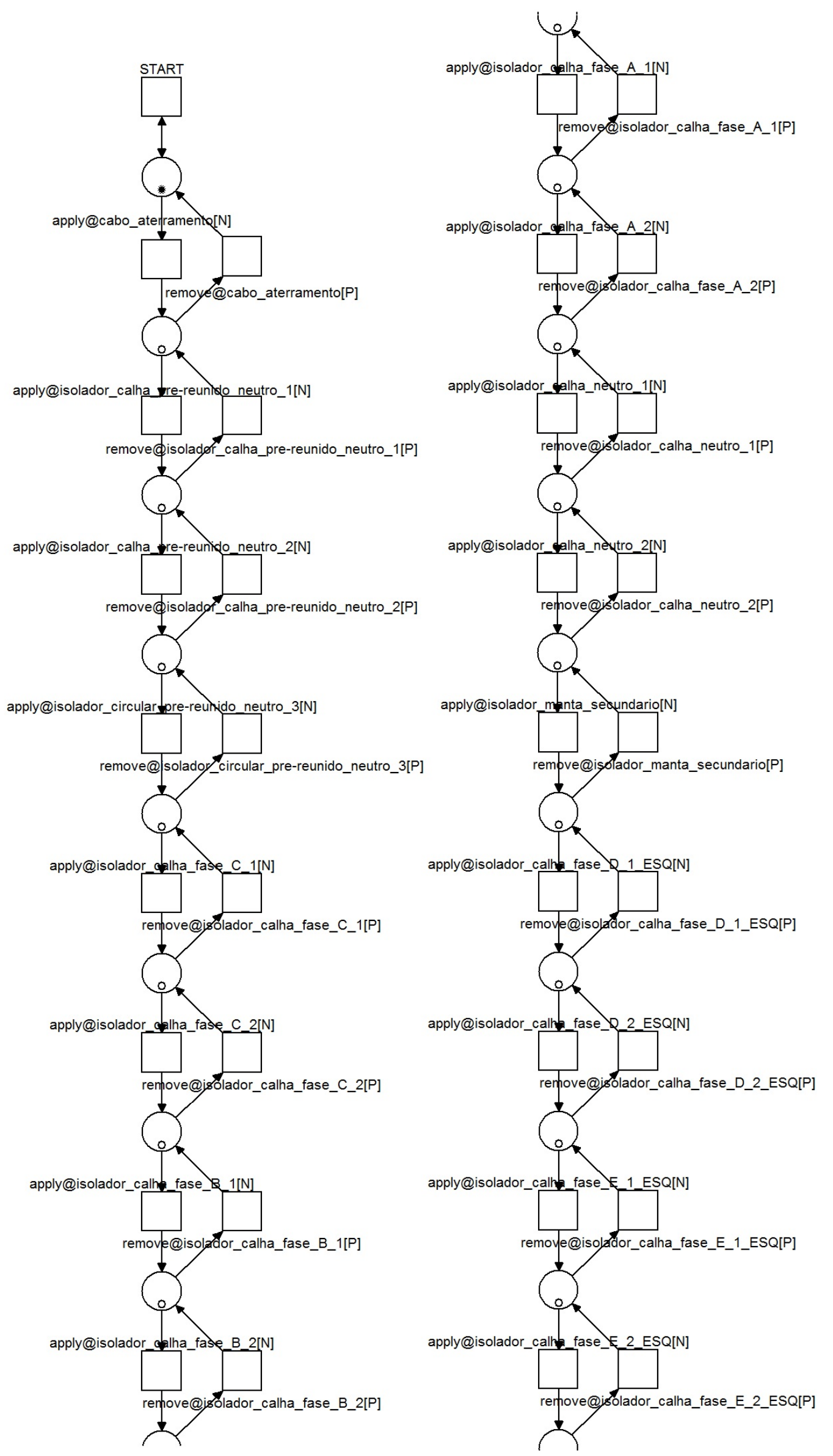

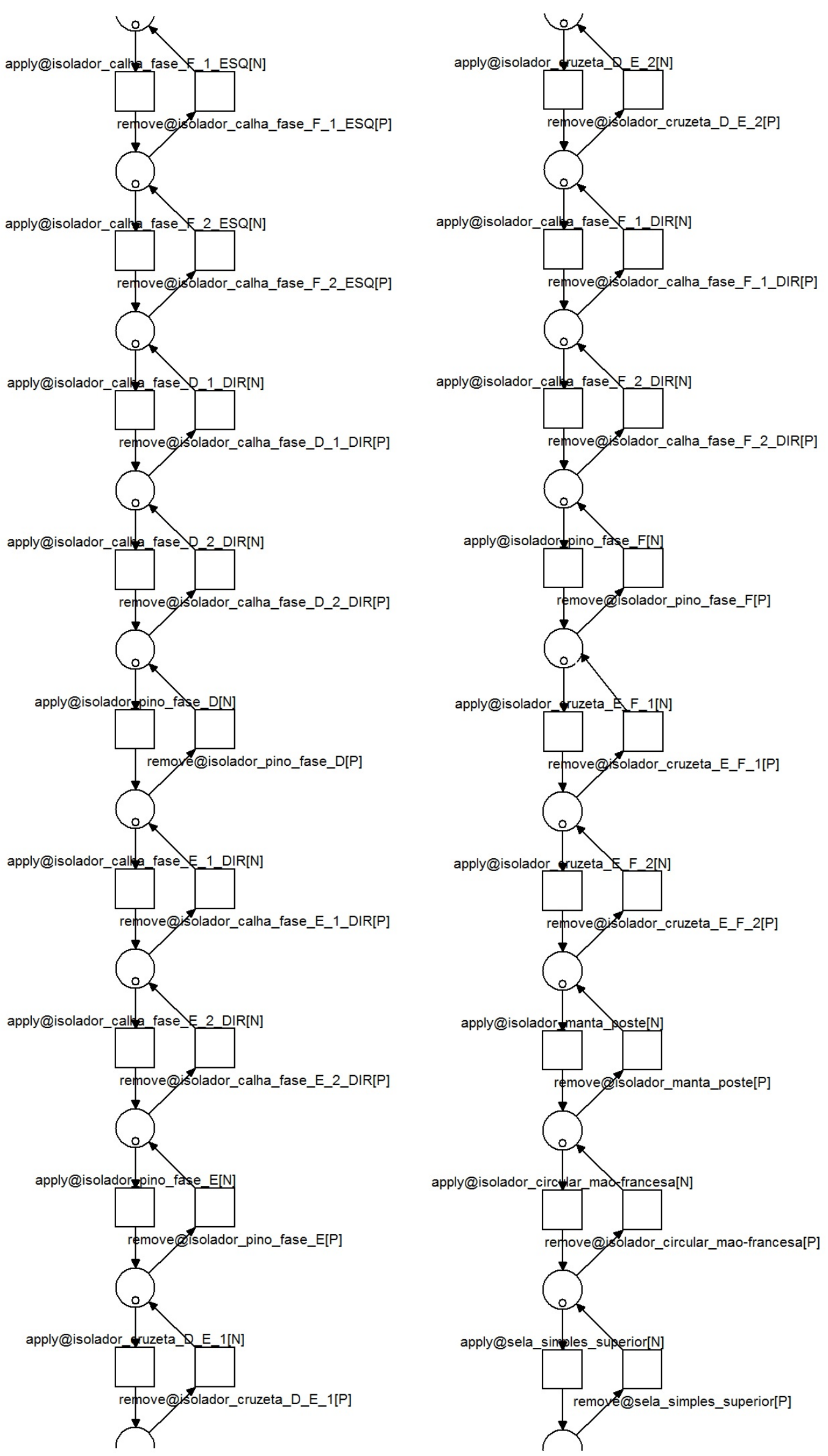

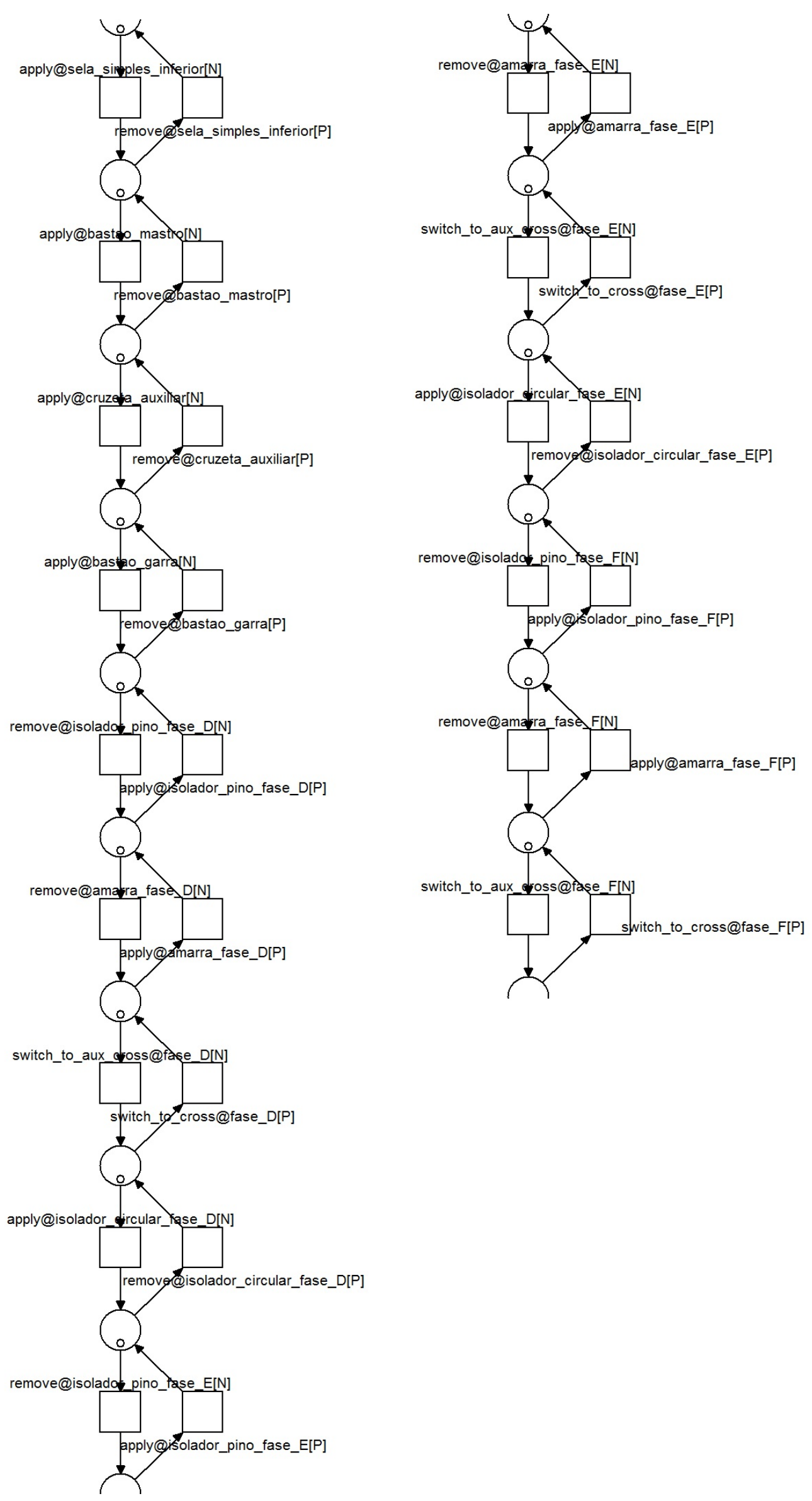


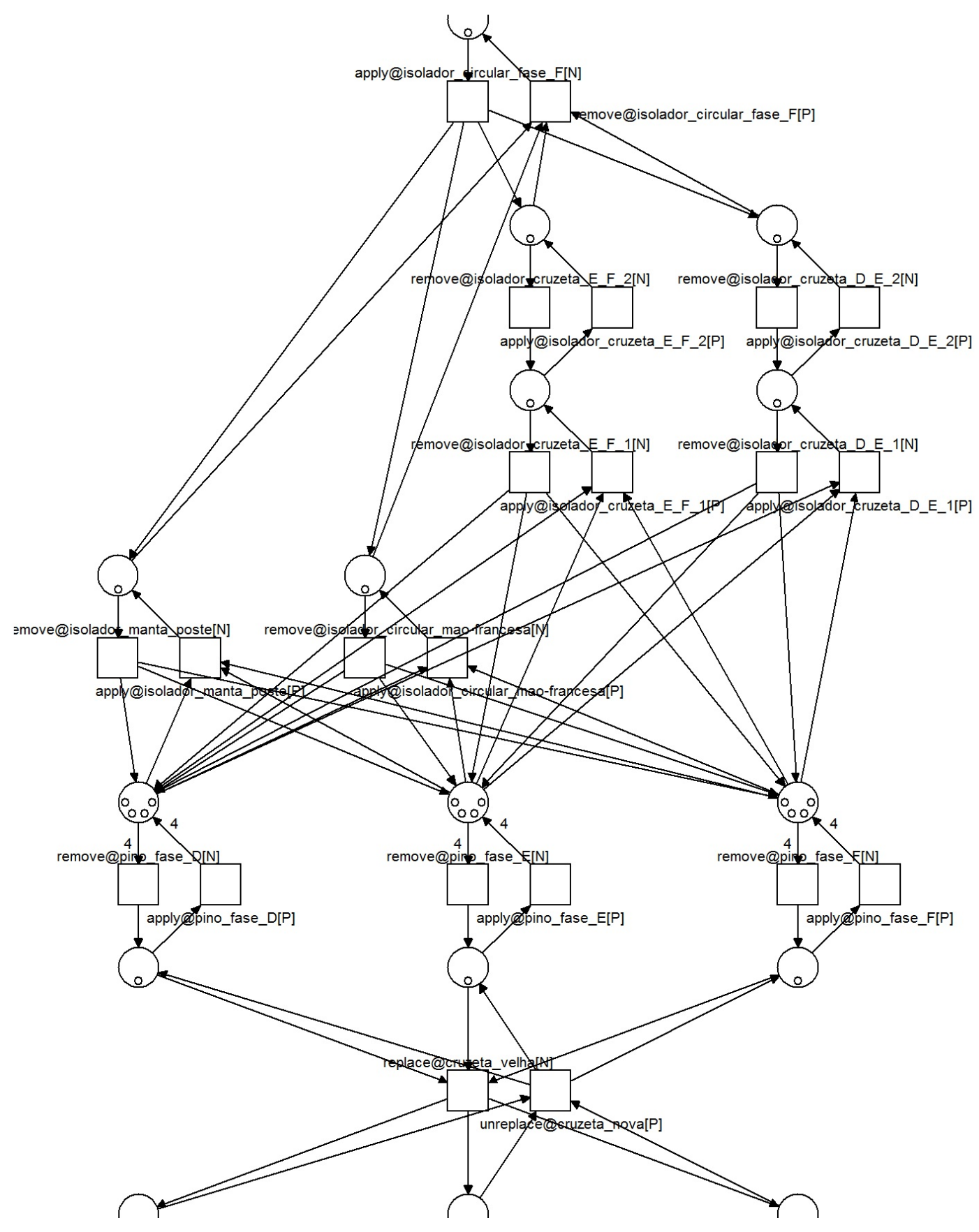




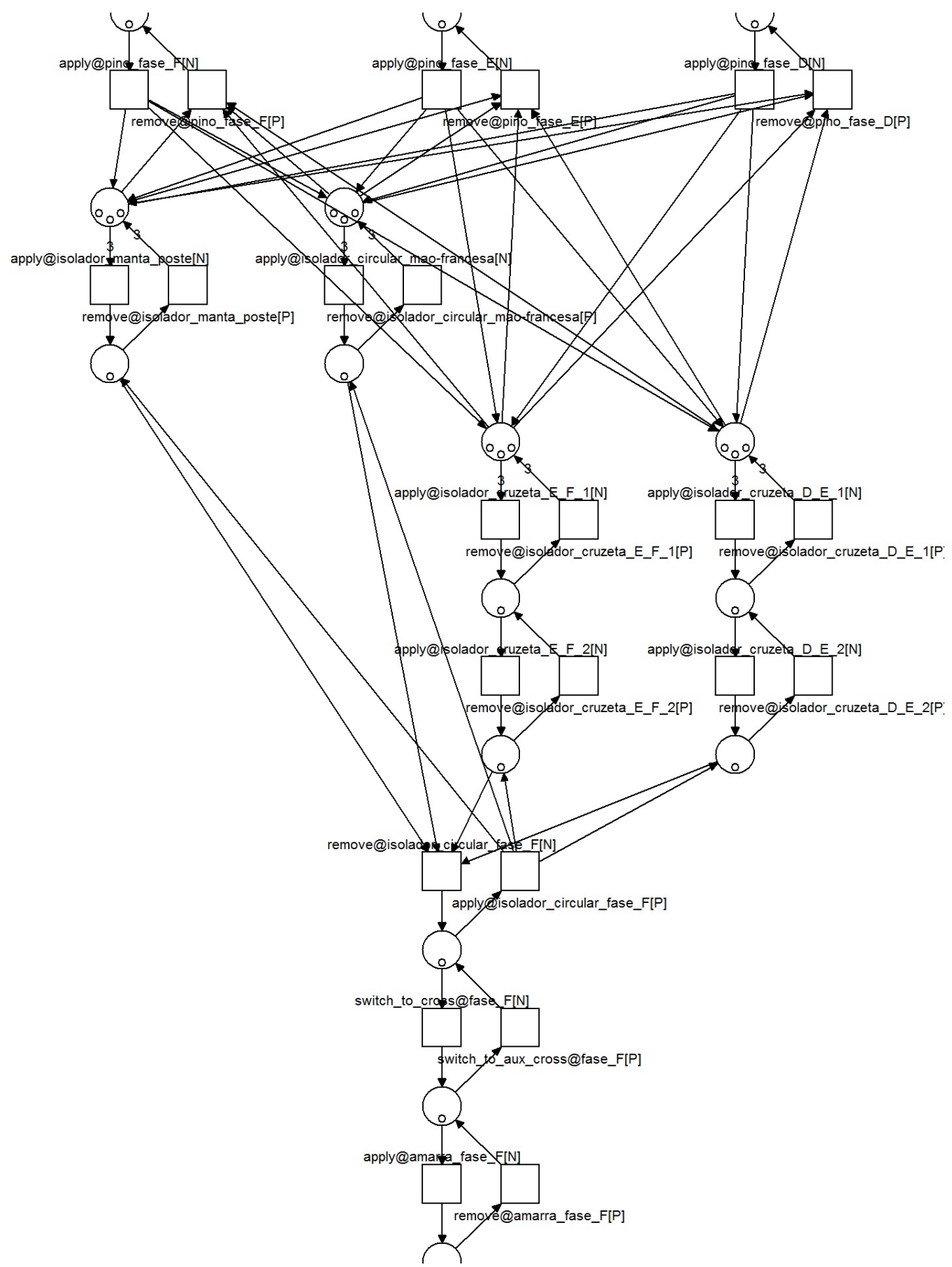



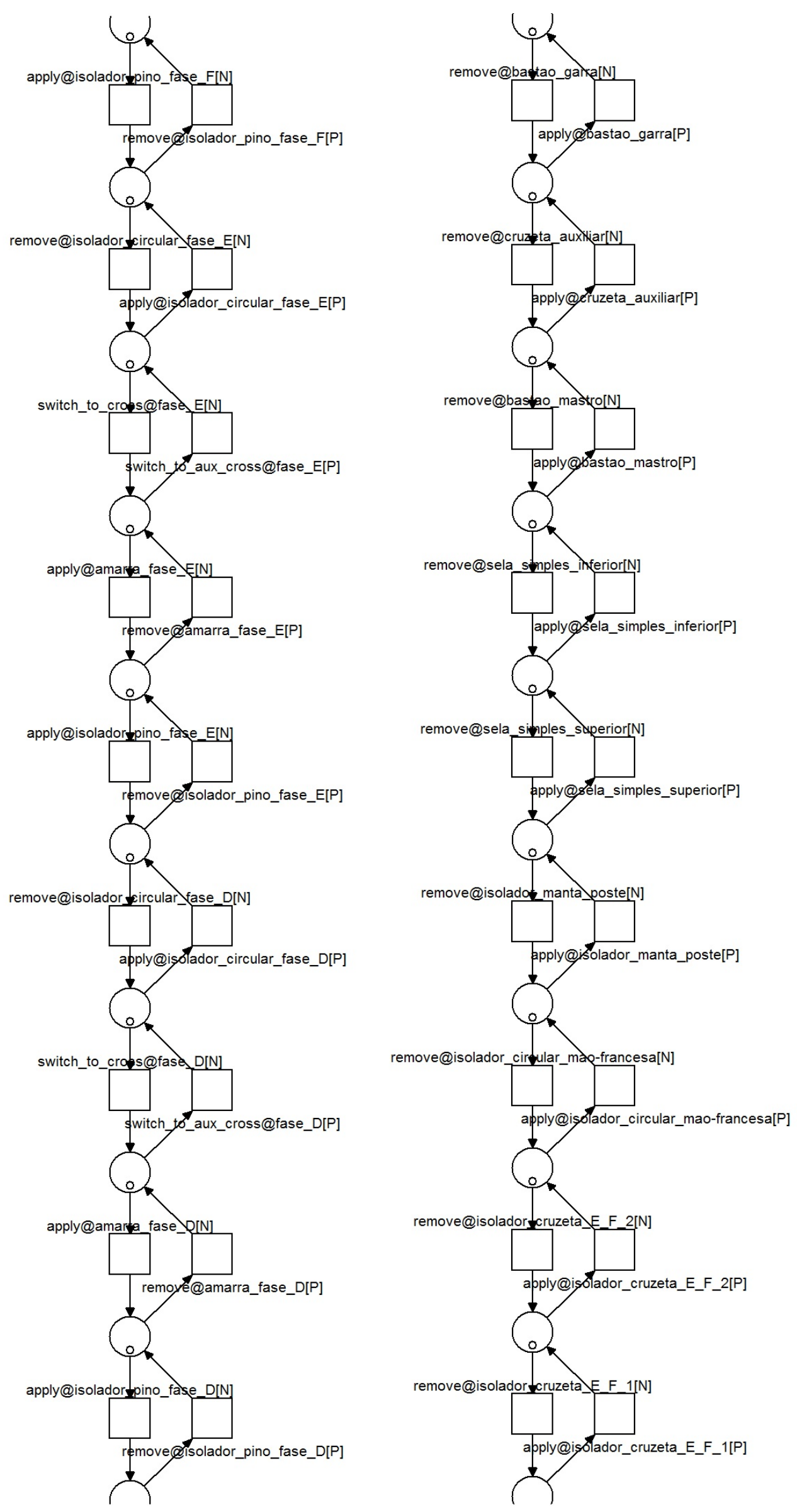


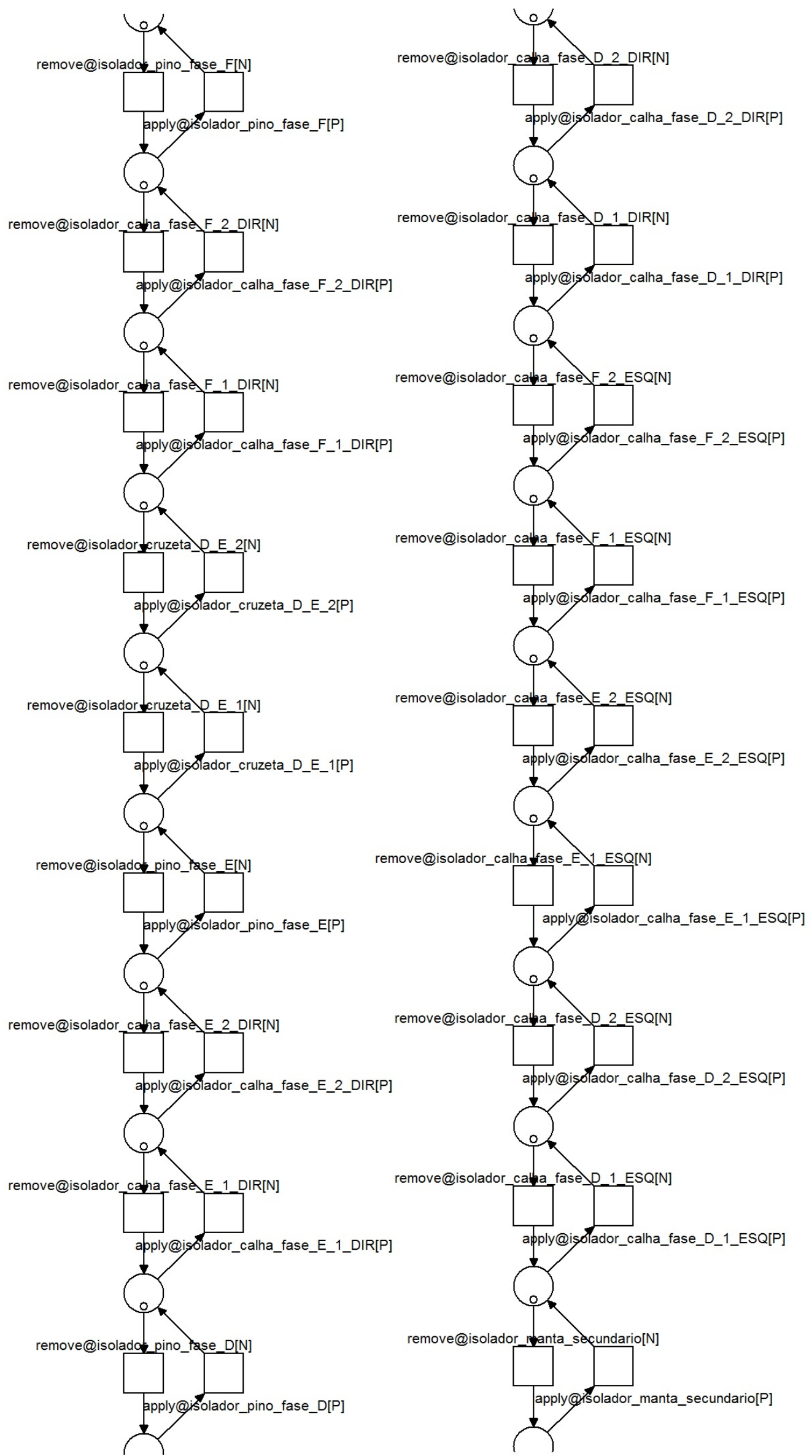




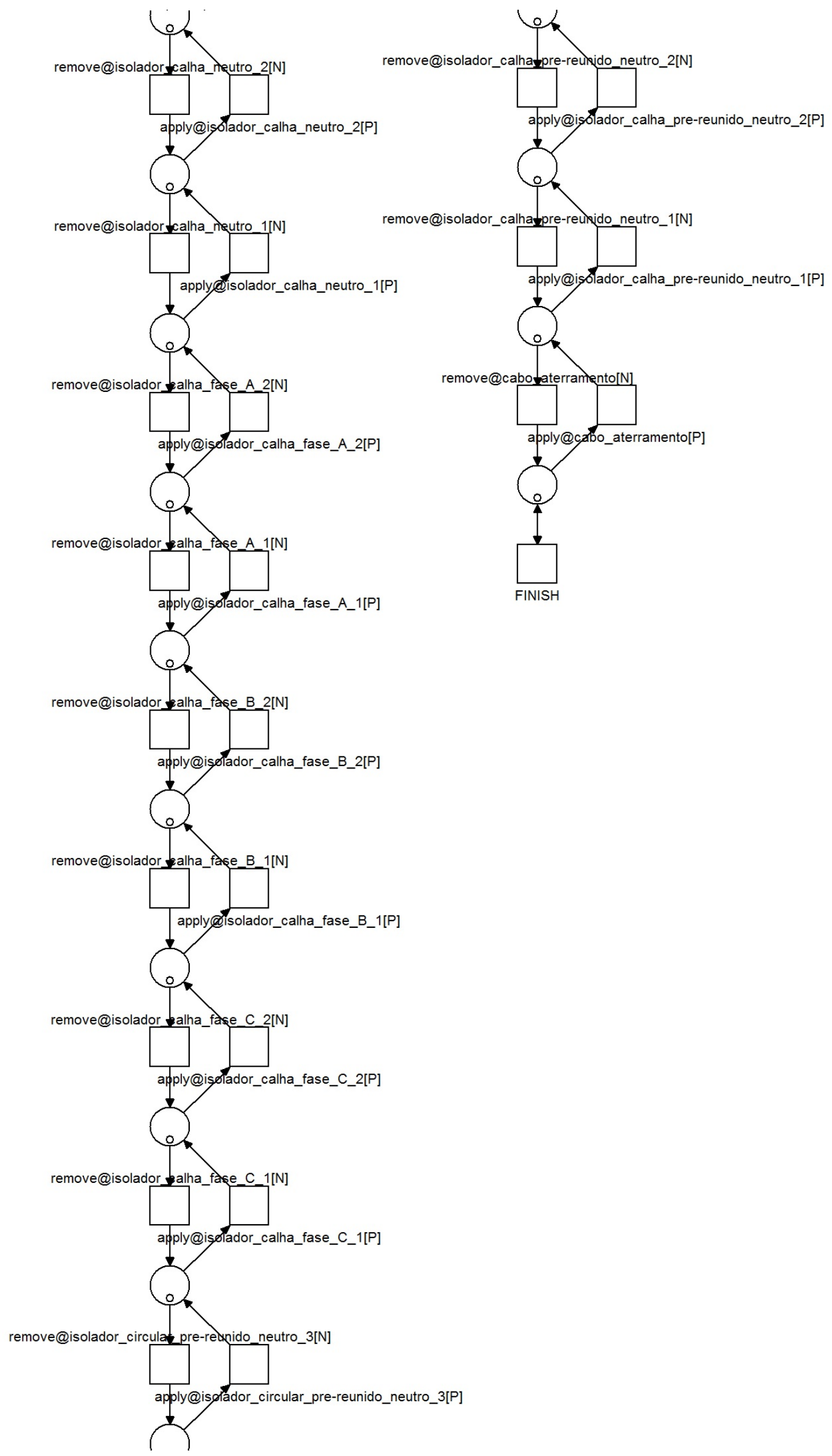

